Portland State University

PDXScholar

Spring 6-4-2019

\title{
"It's All Because I Like the Person That's Teaching Me": Masculinities, Engagement, and Caring Relationships in Secondary Schools
}

Cristy Lauren Weggelaar

Portland State University

Follow this and additional works at: https://pdxscholar.library.pdx.edu/open_access_etds

Part of the Educational Leadership Commons

Let us know how access to this document benefits you.

\section{Recommended Citation}

Weggelaar, Cristy Lauren, "'It's All Because I Like the Person That's Teaching Me": Masculinities, Engagement, and Caring Relationships in Secondary Schools" (2019). Dissertations and Theses. Paper 5007.

https://doi.org/10.15760/etd.6883

This Dissertation is brought to you for free and open access. It has been accepted for inclusion in Dissertations and Theses by an authorized administrator of PDXScholar. Please contact us if we can make this document more accessible: pdxscholar@pdx.edu. 
"It's All Because I Like the Person That's Teaching Me": Masculinities, Engagement, and Caring Relationships in Secondary Schools

\author{
by \\ Cristy Lauren Weggelaar
}

A dissertation submitted in partial fulfillment of the requirements for the degree of

\author{
Doctor of Education \\ in \\ Education Leadership: Curriculum and Instruction
}

Dissertation Committee:

Anita Bright, Chair

Susan Lenski

Jason Ranker

Eric Mankowski

Portland State University

2019 
(C) 2019 Cristy Lauren Weggelaar 


\begin{abstract}
U.S. schools face a well-documented gender gap within some important educational and social indicators. In the United States, boys and young men are significantly more likely than girls and young women to be diagnosed with a learning disability, leave high school without a diploma, receive failing grades in core classes, and be suspended or expelled from school. This study uses an interpretive research framework to investigate the relationship between this gender gap in education and constructions of masculinity, social and cultural capital, agency, caring and resistance in secondary schools. Data collected through interviews with young men who engaged in acts of resistance against schooling yielded three major findings. First, some acts of resistance provided the participants with a means to ease the tedium and stress of academic work and enhance social capital among their male peers. Second, some acts of resistance provided participants with a means to regain personal agency when they felt either marginalized by an oppressive system or generally rejected, ignored, or alienated from the formal schooling environment. Finally, participants expressed an appreciation for authentic relationships with their teachers and stated that they were less likely to engage in acts of resistance with teachers who nurtured authentic caring relationships in the classroom.
\end{abstract}




\section{Acknowledgements}

The past four and a half years have been unbelievably challenging. I owe a debt of gratitude to many people for their support and guidance along the way:

To my committee, for allowing me to stand on your shoulders so I could see a bit farther.

To mom and dad, for allowing me to believe I could.

To Steve, for having more faith in me than I sometimes have in myself.

To Anita Bright, whose name is so fitting, for shining your light as I wandered in the shadows of uncertainty and crippling self-doubt. I couldn't have done this without your guidance.

And to my students, who have always been my why. 


\section{Table of Contents}

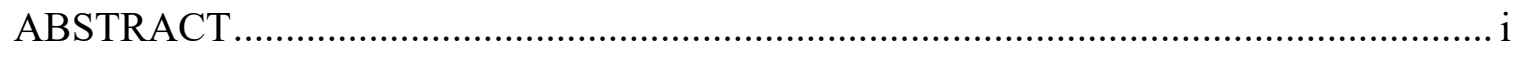

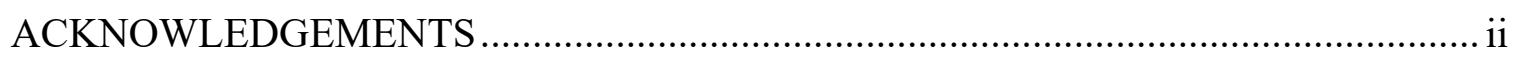

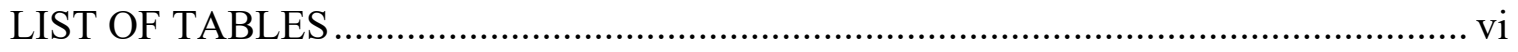

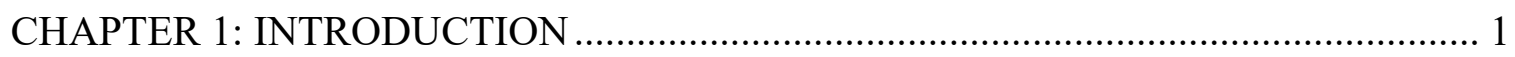

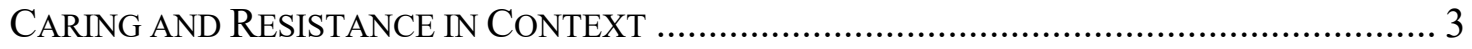

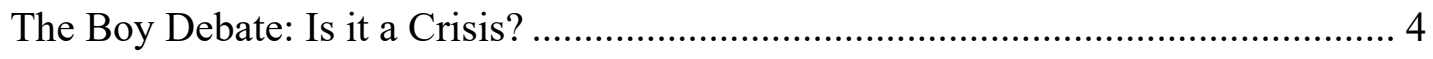

The Boy Debate: A Historical Perspective …........................................................ 7

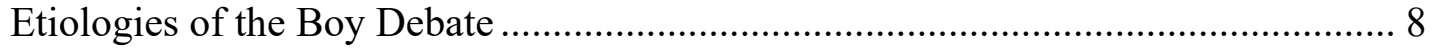

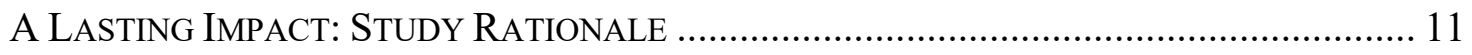

CONCEPTUAL FRAMEWORK AND DEFINITIONS ....................................................... 13

Gender and Social Constructionism................................................................. 13

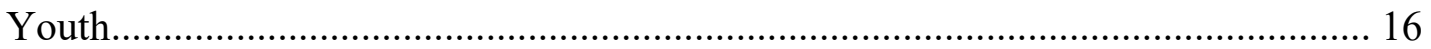

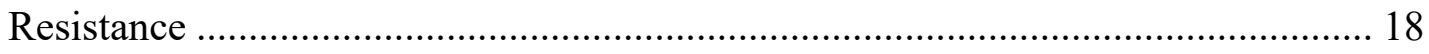

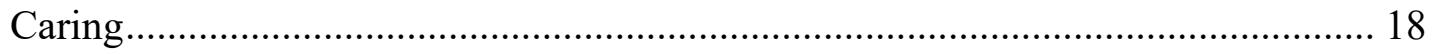

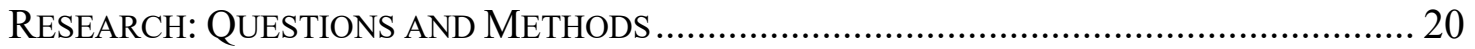

FILLING A VOID IN THE LITERATURE .................................................................... 22

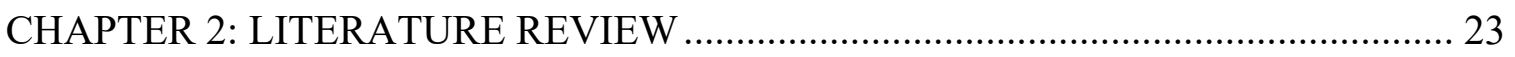

CONCEPTUAL FRAMEWORK: GENDER THEORY ...................................................... 23

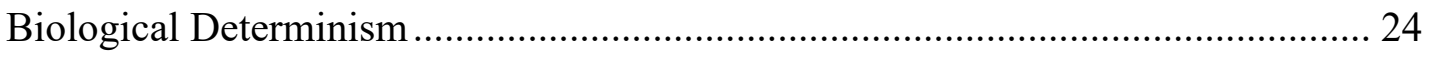

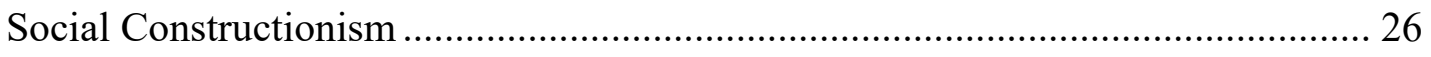

Social Learning Perspectives and Social Constructionist Perspectives .................. 27

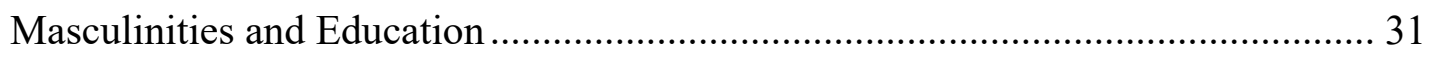

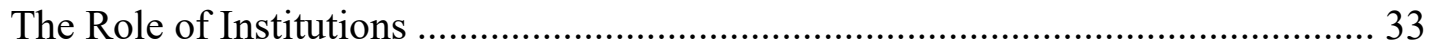

Youth, Cultural Dominance, Hegemony, And Resistance ................................ 35

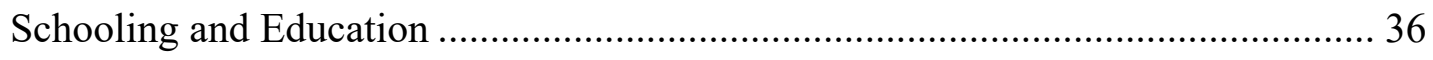

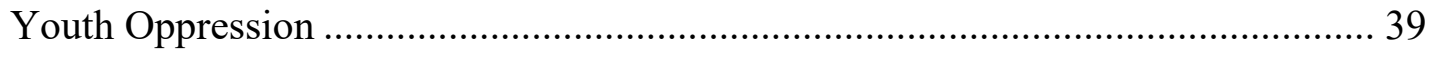

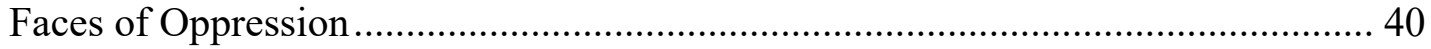


IT'S ALL BECAUSE I LIKE THE PERSON THAT'S TEACHING ME iv

The Hidden Curriculum ........................................................................................... 42

Differentiation and Resistance ...................................................................... 43

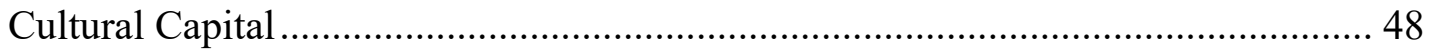

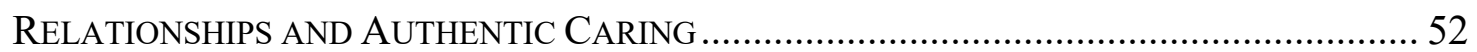

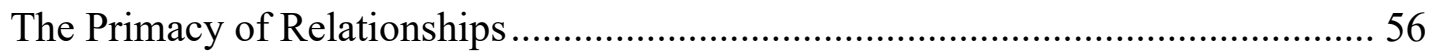

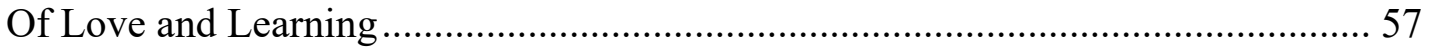

RESEARCH FramEWORK: A QUALITATIVE APPROACH .............................................. 58

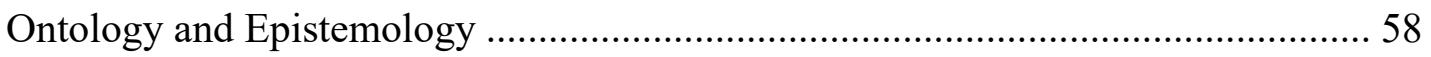

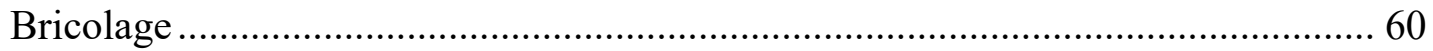

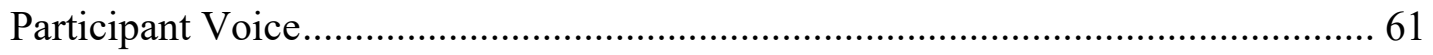

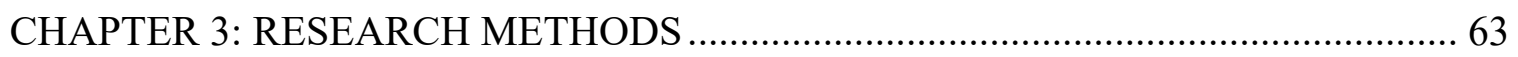

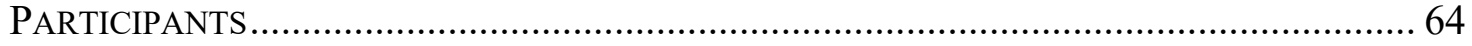

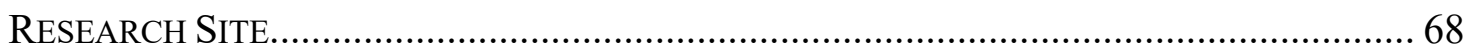

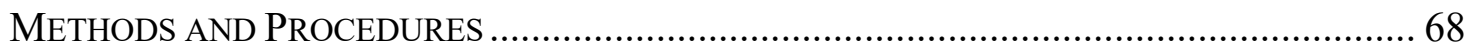

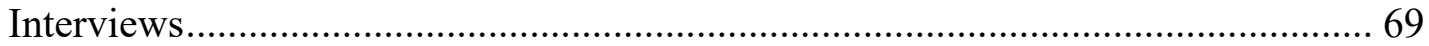

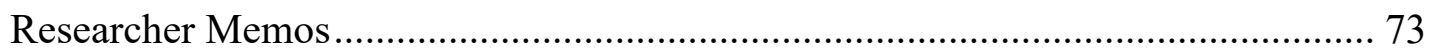

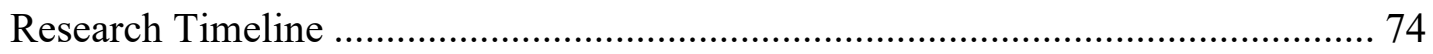

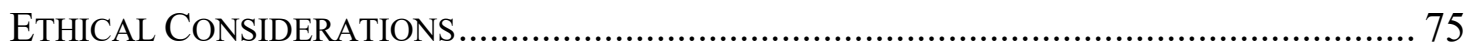

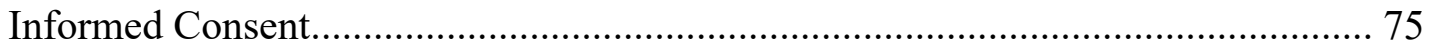

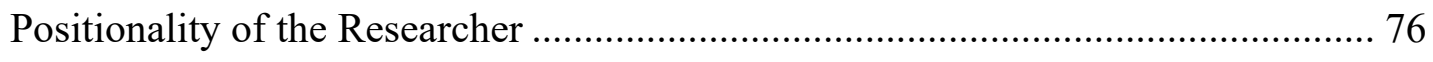

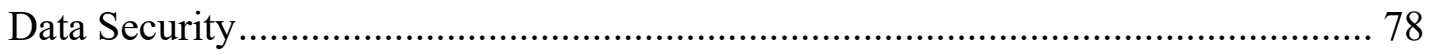

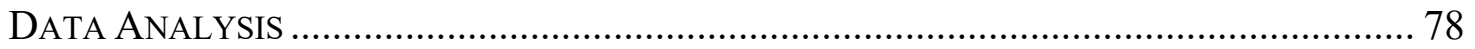

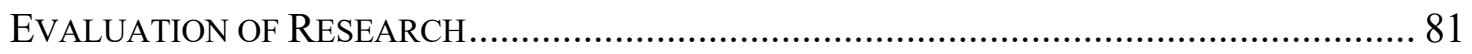

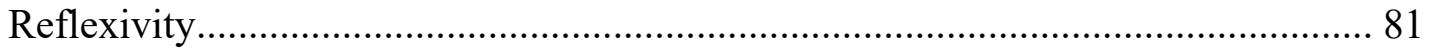

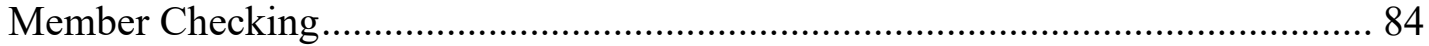

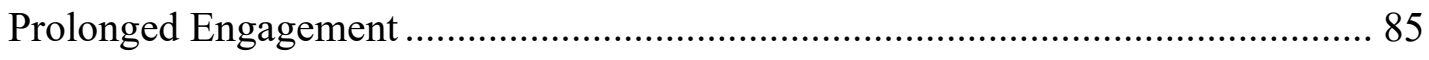

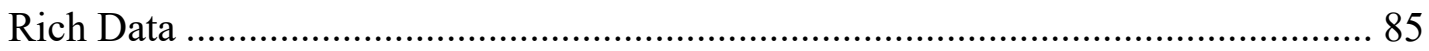

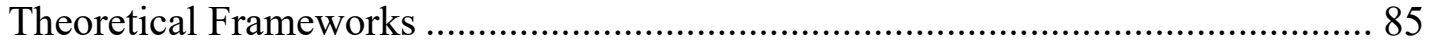

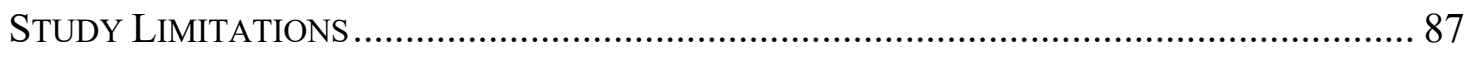

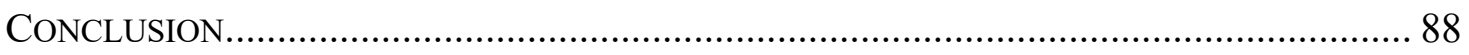


IT'S ALL BECAUSE I LIKE THE PERSON THAT'S TEACHING ME V

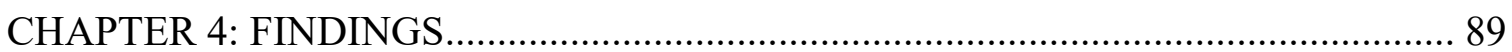

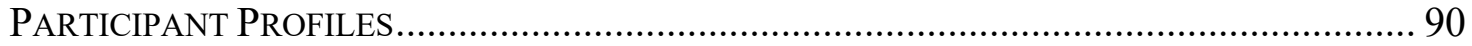

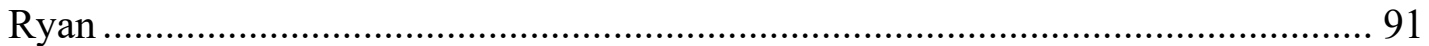

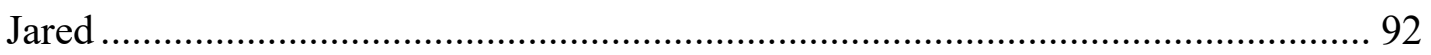

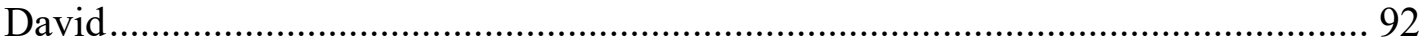

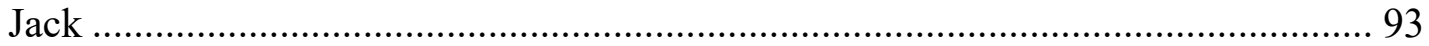

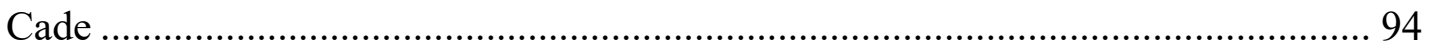

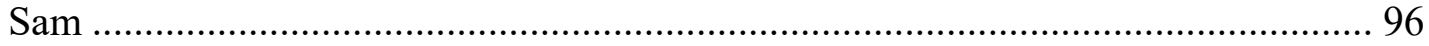

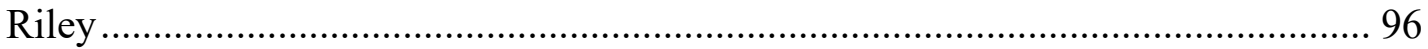

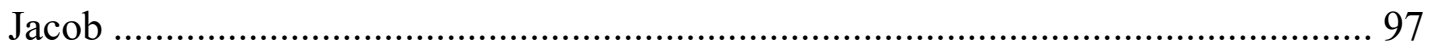

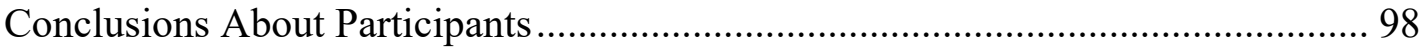

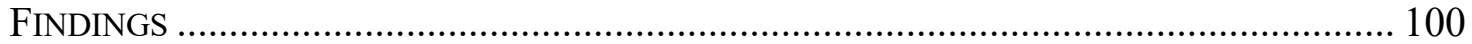

Resistance in High School ........................................................................... 100

The Role of Caring Relationships in Acts of Resistance ...................................... 132

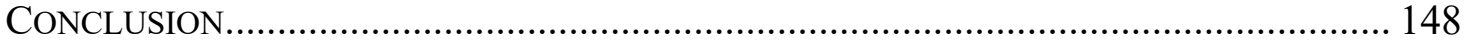

CHAPTER 5: CONCLUSIONS AND IMPLICATIONS …..................................... 151

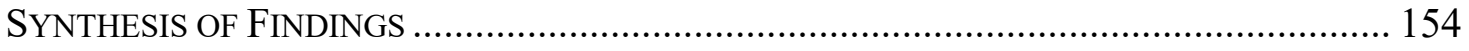

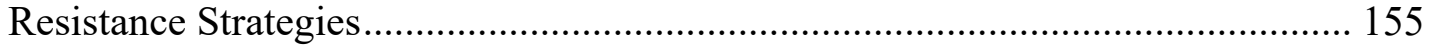

Caring Relationships and Acts of Resistance .................................................... 162

BUILDING BRIDGES: RECOMMENDATIONS FOR CHANGE......................................... 165

Male-Friendly Curriculum and Instructional Practices...................................... 167

Gender-based Pedagogy and Programs ............................................................ 171

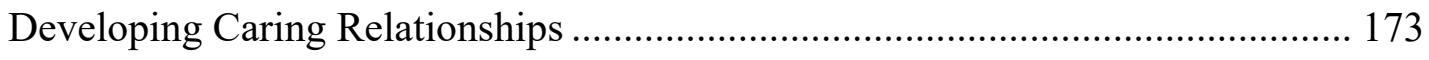

TOWARD GREATER EQUITY: IMPLICATIONS FOR FUTURE RESEARCH ........................ 180

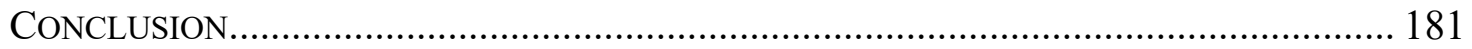

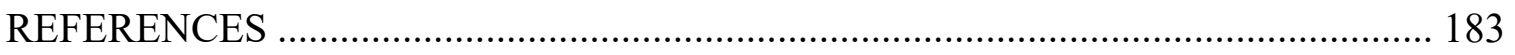

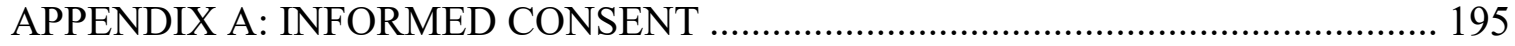

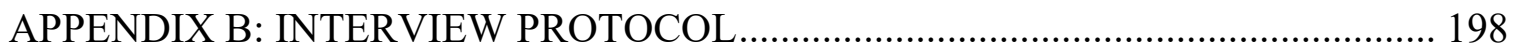




\section{List of Tables}

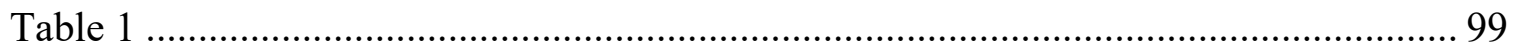




\section{CHAPTER 1: INTRODUCTION}

Most teachers enter the profession because they want to make a difference; implicitly, they value the lives of the youth they work with. And yet I have worked with many young men like Dan. In 2015, Dan was a senior at the large suburban high school where I teach language arts. A little older and physically much bigger and louder than many of his peers, his presence could be intimidating. Dan had transferred to my high school during his sophomore year, but was later expelled, diagnosed with oppositional defiant disorder, and sent to a residential program for "difficult" and "troubled" young men. As a student, he regularly cursed at teachers, stormed out of classes, and skipped school for weeks at a time. He particularly enjoyed snoring loudly during lectures and reveled in his teachers' angry reactions to his behavior. If you asked Dan about this, he would proudly admit that most teachers and administrators considered him to be a "pain in the ass." Proudly, because that is the student persona he has been constructing since his father completed suicide when Dan was in middle school.

Eventually, Dan was allowed to return from his expulsion to finish his education and I was somehow successful in establishing a positive working relationship with him from our first few days of learning together; he often proudly threw open my door in the morning (when I was invariably mid-sentence in front of my class), exclaiming with a wide smile, "Hey, Wegg! I came to school today!" and walking out as abruptly as he had entered. On other days, he would affirm his appreciation for me as a caring teacher by 
contrasting me with other adults in his life: "Wegg, thank you for not being as dumb as old-what's-her-name in first period."

On an average day late in the academic year, Dan was working in my classroom during my prep period. He had chosen to skip his second period class to catch up on a pile of late work for another class and had just finished a lengthy diatribe about what he felt was lacking in the personality of his 2 nd period teacher. Then, head bowed in frustration, he went back to his assignment, scratching words on his paper, engaging in the work he had just emphatically told me was a monumental waste of his time. I was concerned about his negativity, but all I found to mutter in response was, "I know you feel that way. I'm really sorry."

I went back to my own work. Ten minutes passed, each of us enmeshed in a cocoon of solitude. Suddenly, Dan's head snapped up and he sat back, flinging his pencil to the muddy-colored carpet. He looked at me: "Ms. Wegg, sometimes I feel like nobody gives a shit about me!" and slammed his textbook closed to emphasize the brutal, emotional power of his statement. At the time, there was only one response in my mind, so that was what escaped with my breath: "Hey! I give a shit about you!"

Dan, through aggressive, individual acts of resistance, had publicly constructed the persona of a student who did not care about school, about the rules, or about most of his teachers. At the same time, he perceived that his relationships with his teachers were reciprocal; that is, he felt that his teachers cared very little about him. Taken together, my interactions with Dan reveal a complex irony: he was deeply wounded by his teachers' perceived apathy towards him, despite how loudly his words and acts of resistance 
seemed to proclaim that he did not care. And although I could not name what I had done or said to change this pattern of perceived apathy, we both understood implicitly that my classroom was a safe and caring place to be in a school where Dan generally felt disregarded.

\section{Caring and Resistance in Context}

I first met Dan in a course designed to guide high school seniors through a process that would help them meet the Oregon writing essential skills requirement for graduation. Most of my students took this course because they had not met the benchmark on the state-mandated writing test. Perhaps the most remarkable characteristic of this course was its demographics: of 24 students in Dan's class, 20 of them were young men. This does not surprise me, as every section of this course I had taught over the previous four years had a similar disproportionality of male to female students, as have all of my other academic support classes. Even in the more traditional grade-level courses I teach, my phone calls home about failing grades are most often to parents of young men and the most worried parents at conferences are generally not the parents of young women, but rather the parents of young men. Furthermore, this pattern is not only recognizable within my classes and throughout my school, but in schools across the United States. It has been the subject of recent public policy debates because, although many boys and young men do thrive in public schools in the United States, there is a measurable discrepancy in indicators of academic performance (including grades, 
graduation rates, and test scores) between male and female students - a pattern the media have been calling the "boy crisis" since the early 2000's (Kleinfeld, 2009).

\section{The Boy Debate: Is it a Crisis?}

A compilation of troubling statistics brings this phenomenon into stunning clarity. For example, in 2006, for every 100 girls who repeated kindergarten, 196 boys repeated kindergarten (Malone, West, Denton \& Park, 2006). And in 2014, for every 100 girls and young women who had been diagnosed with a learning disability at some point in their academic career, 276 boys and young men had also been diagnosed with a learning disability (Cortiella, 2011). There are many other such observable patterns that suggest a problem in the ways communities and schools educate and acculturate boys and young men. For example, male students constitute over two-thirds of the special education population in the United States, which means they are more likely than female students to be labeled, tracked, and placed in academic intervention classes (Cortiella, 2011).

Likewise, male students are twice as likely as female students to be diagnosed with a conduct or behavioral disorder (Perou et al., 2013) and two and a half times more likely than female students to be diagnosed with Attention Deficit Disorder or Attention Deficit Hyperactivity Disorder (Visser et al., 2014). Fox, Connelly, and Snyder (2005) found that boys and young men are more likely than girls and young women to be held back a grade, suspended, expelled, or otherwise excluded from school.

Furthermore, results from the National Assessment of Educational Progress (NAEP) revealed that female students have consistently outscored their male counterparts in both reading and writing since the test debuted in 1971 (Mead, 2006). Although 
standardized test scores are most often cited as performance indicators in studies that analyze academic achievement, they offer only part of the picture. On average, female students receive higher grades in all subject areas, including math and science, and graduate from high school with higher overall GPAs (Downey \& Vogt Yuan, 2005; Martino \& Ingrey, 2016). Conversely, males are more likely than females to receive failing grades and males report spending less time on homework; they are also involved in fewer school-related clubs and activities (Xu, 2006).

The "boy crisis" has only been in the public consciousness in the United States for about two decades, but the concerns around some boys' behavior and academic underperformance have existed for as long as schooling has been compulsory (Vasudevan \& Campano, 2009). Since similar patterns can be found across racial and socioeconomic lines, Mead (2006) cautioned that "when racial and economic gaps combine with gender achievement gaps in reading, the result is disturbingly low achievement for poor, black and Hispanic boys" (p. 9). Mead criticized rhetoric claiming a crisis in boys' education and instead claimed that gender is not the most important factor affecting school achievement. For example, achievement gaps between privileged White children, minority children, and children living in poverty are generally wider than achievement gaps based on gender. Lingard, Martino, and Mills (2009) agreed with Mead and noted that this intersectionality of social class, race and gender has been the primary focus of U.S. research on achievement gaps.

While the gender gap in academic achievement is undeniably impacted by complex intersections of race, socioeconomic status, and culture, I argue that constructs 
of dominant masculinity shape the academic engagement of most boys and young men. Therefore, to construct a clear understanding of how social and cultural forces place boys and young men within, outside of, and on the borders of a gender hierarchy, one must consider the agency of every community actor, including those who are privileged (Martino \& Pallotta-Chiarolli, 2003). Connell (2005) agreed that "the overall gender relation between women and men is a powerful basis of consciousness and practice too" (p. 249). For this reason, in choosing participants for my study, I did not intentionally seek out young men who have been marginalized by any particular characteristics such as race, ethnicity, sexuality, ability, or social class. If the participant constructed himself as a person who had been marginalized based on any of these characteristics, I included a discussion of the impact of that intersectionality on his experiences.

Unfortunately, the media and some researchers and public commentators have been using the term "boy crisis" to frame boys and young men within a deficit model, suggesting boys and young men are in need of saving due to an inherent weakness in their biology or character. Others have used the term to suggest that school systems have become predatory, engaging in a hostile "war" against boys (Sommers, 2013). I am uncomfortable with deficit frameworks and firmly believe that we should refrain from arguing over the perceived shortcomings of boys and young men. Rather, educators, parents and community members should be rewriting the conversation around gender and education, focusing on institutional and social factors that impact the success of boys and young men in school. Therefore, I reject the term "boy crisis" and will refer to this 
phenomenon as the "boy debate"-a more neutral term suggested by Lingard, Martino, and Mills (2009).

\section{The Boy Debate: A Historical Perspective}

Lingard, Martino, and Mills (2009) argued that the boy debate is reactionary, emerging from second-wave feminism in the 1970's and 1980's in English-speaking countries such as Australia and England. In the United States, however, the boy debate is more recent, originating from third-wave feminism in the 1990's, when organizations such the National Women's Law Center and the American Association of University Women (AAUW) began focusing their policy work on adolescent girls (Kleinfeld, 2009).

In 1992, the American Association of University Women (AAUW) published How Schools Shortchange Girls to bring their concerns about the academic achievement of adolescent girls to the forefront of policy discussions amongst legislators, psychologists, administrators, parents, teachers, and other stakeholders. The report explained that, at the time of writing, there was a small, yet persistent achievement gap in math and science outcomes between boys and girls, and that girls generally scored lower than boys on standardized achievement tests. The authors also argued that teachers accorded more classroom attention to boys over girls, calling on them more frequently, asking them more challenging questions, and allowing them to call out answers more regularly without raising their hands. The report recommended using Title IX resources and funding, training teachers in gender equitable classroom practices, and revisiting curriculum to include the presence of influential women's voices in literature, history, 
and science. This work has led to a successful nationwide campaign for policy change that supports gender equity (Kleinfeld, 2009).

Somewhat ironically, such well-publicized reports by the AAUW and subsequent bestselling books about girls' unique emotional and educational needs (Gilligan, 1993; Pipher, 1994; Shandler, 1999) sparked a backlash amongst the popular media and conservative researchers, who presented evidence of an emerging "boy crisis." This discourse entered the mainstream in the late 1990's, with the publication of bestselling books such as Gurian's Boys and Girls Learn Differently! (2002) and Kindlon and Thompson's Raising Cain: Protecting the Emotional Lives of Boys (1999). As the movement accelerated, newspapers and magazines published articles weighing in on the boy debate, often with dramatic and inflammatory titles such as "Boys at the Back" (Sommers, 2013, February 2) and "The Problem with Boys...Is Actually a Problem with Men" (Chiarella, 2006). New books were published, loudly proclaiming that boys were lost or even under siege (Sax, 2009; Sommers, 2013; Whitmire, 2010). The stage was set for a debate in which the media and popular trade books cast boys and young men as victims in crisis.

\section{Etiologies of the Boy Debate}

Weaver-Hightower (2003) used the term "boy turn" to define how the discourse on gender and education has shifted away from an advocacy approach focused solely on girls, to a more inclusive approach that also considers the unique needs of boys. To better analyze the discourse, he identified several key divisions within literature, which he called "etiologies" on the boy debate. Because I believe these etiologies are an important 
indicator of the current climate of discussion on this boy debate, I will synthesize several of them here.

Popular-rhetorical literature. Best-selling literature (which Weaver-Hightower calls "popular-rhetorical literature") commenting on the boy turn generally focuses on biological differences between the sexes, claiming biology has a greater impact than culture on the way children learn, process information, express emotion, and relate to others. Scholars in this genre often argue that because schools require students to sit quietly for most of the day, engaging in hours of reading, writing, and discussion, boys are at a distinct disadvantage to girls, who (they claim) are naturally better at sitting still for longer periods of time and whose verbal skills develop at an earlier age (Gurian, 2005).

Other commentators within the popular-rhetorical genre, such as Pollack (1999), and Kindlon and Thompson (1999) postulated that the boy debate must consider behavioral and emotional elements in addition to academic ones. For example, in addition to high dropout and $\mathrm{ADD} / \mathrm{ADHD}$ diagnosis rates, males commit 95 percent of all homicides and represent more than 80 percent of all reported adolescent suicides (Suicide prevention: Youth suicide, 2015). These commentators contended that society approaches boys from a rigid version of masculinity that unwittingly steers them away from an emotionally rich life. And since social expectations of masculinity can be rigid, boys are often taught (and thus learn) to mask their discomfort with silence, anger, or violence. Such feelings can manifest themselves in a myriad of ways at school, including: bullying, violence, and a reluctance to participate in activities deemed nerdy or feminine, such as 
reading and writing (Kindlon \& Thompson, 1999). While Kindlon and Thompson (1999) and Gurian (2005) made their observations based on years of experience working directly with adolescents and their families, Weaver-Hightower (2003) warned that their work lacked academic references and the rigor of the peer review process, relying instead on case studies and anecdotal evidence and employing essentialist viewpoints of gender, which ignore elements of gender that are socially constructed, and treat boys as one homogenous, static group.

Sociologists and feminist scholars. A second group of scholars-primarily sociologists - used a range of perspectives and critical lenses from qualitative research to examine how schools and society construct masculinity. Connell (2005), for example, attempted to refine contemporary understandings of masculinity to include a discussion of masculinities as a diverse set of social constructs. And Kimmel (2010) added that “what lies beneath boys' problems (apparent or real) is an outdated ideology of masculinity to which boys are struggling desperately to adhere, and which is applied ruthlessly and coercively by other boys" (p. 94). While the commentary within this genre is nuanced and built on a legacy of feminism and critical theory, it does not often provide practical solutions to the problem, especially in regard to the academic side of schooling, which is the one area of great concern to the public (Weaver-Hightower, 2003). Because of its critical focus, the work of these sociologists constitutes the bulk of my literature review on the social construction of gender.

Practical application. Finally, a third major group of scholars is educators who are responding to teacher and parent concerns about gender in education by developing 
and evaluating school- and classroom-based instruction. For example, educatorresearchers such as Smith and Wilhelm (2002) advocated for "boy-friendly" curriculum and instructional techniques that incorporate hands-on activities, active learning, expanded choice on assignments and readings (including allowing boys to write on violent or "gross" topics), and the implementation of single-gender courses or programs. Weaver-Hightower (2003) warned that scholars using this framework often lack the theoretical foundation found in the work of sociologists and critical scholars, relying instead on anecdotal evidence and "quick fixes" that fail to address the underlying complexities of gender as a social construction. He argued that more work needs to be done to bridge the current gap between sociological theory, psychology, and practical interventions.

\section{A Lasting Impact: Study Rationale}

Many researchers have suggested that the impact of the perceived patterns of underachievement of some boys and young men extends into adulthood and has wide social and economic implications. For example, Owens (2016) compiled data from a longitudinal study, which suggested that students who engage in behavior that teachers

label "problematic" in kindergarten are less likely than their peers to graduate high school and complete college. She claimed, "Boys' behaviors on school entrance initiate cumulative cascades that shape educational attainment and ultimately help account for the gender gap in college completion in the United States" (p. 240). Kleinfeld (2009) added that academic underperformance in secondary schools may result in many young 
men entering the workforce unprepared to participate in a "knowledge-based economy" (p. 28), and are therefore more vulnerable to declines in wages, economic downturns, and changes in the global economy. In fact, while overall employment in the goods-producing sector, a sector previously dominated by men, has declined significantly due to outsourcing, employment in service-providing industries, a sector increasingly occupied by women, has risen. Vespa (2017) found that the loss of jobs in the goods-producing sector has had particularly strong economic implications for working-class men in the United States. The unemployment rate of men aged 25-36 was lower in 2016 than it was in 1975; however, in 1975 just 25 percent of men between the ages of 25 and 34 had incomes of less than $\$ 30,000$ a year, but by 2016 more than 40 percent of men had incomes of similar levels. When adjusted for inflation, the average salary of men in this age cohort fell from $\$ 45,000$ in 1975 to $\$ 40,000$ in 2016 . By comparison, the average wages of women of the same age cohort rose from $\$ 22,000$ in 1975 to $\$ 29,000$ in 2016 . Of course, the growing service sector typically requires post-secondary training, but male participation in and graduation from bachelor's programs has been steadily declining since 1976 (Mortenson, 2011). In the end, male underperformance in school intersects with the increased educational demands in middle class and upper middle class professional positions (including rapidly expanding service-sector jobs), the increased cost of post-secondary training, and the disappearance of manufacturing jobs and highskilled labor positions; these competing factors have prevented many men from gaining middle and upper middle class jobs in high-paying sectors such as finance, business, technology, and communications. 


\section{Conceptual Framework and Definitions}

Throughout this paper, I will integrate several theoretical frameworks to support my argument. Chief among them are social constructionism, caring theory, and resistance theory.

\section{Gender and Social Constructionism}

According to Connell (2005), gender refers to the range of socially constructed characteristics and behaviors attributed to being male or female; it is different from biological sex in that it is culturally constructed. Because discussions of gender are prone to essentialism, I will attempt to describe gender in terms of observable and quantifiable patterns without postulating that all boys and young men necessarily fit into those patterns. In a related press against this risk of essentialism, I draw from Connell (2005), who argued that “"masculinity' does not exist except in contrast with 'femininity"” (p. 68) and indeed, a conversation about the experiences of boys and young men also invokes comparisons with the experiences of girls and young women. The intent of such comparisons is not to invoke a "competing victims" mentality (Cox, 1995) in which the rights of males are pitted against the rights of females, but to find ways to construct a more mutually beneficial and equitable system of education for all genders.

When I use the gendered terms boys and young men, I draw from the binary model of gender to mean children and young adults who identify as male, present as male to others, and are perceived by others to be male, and by girls and young women, I mean children and young adults who identify as female, present as female to others, and are perceived by others to be female. 
Social constructionism. In describing gender roles, I draw primarily from social constructionism, which conceptualizes gender roles as socially constructed and postulates that it is impossible to separate an individual's biological characteristics from those characteristics molded by social circumstances (Howard \& Hollander, 1997). Because gender is socially constructed, there can be no single definition of masculinity or of femininity. Instead, there is a wide range of masculinities and femininities that vary by culture, community, race, age, and class, and change over time (Connell, 2005).

Social constructionism maintains that society imposes gender expectations on individuals through dominant social actors such as the media, educational institutions, parents, and peers. However, individuals also play a key role in constructing their own gender identity, choosing certain gendered behavior options over others within the bounds that society determines as appropriate within a given context (Howard \& Hollander, 1997). Kimmel (2013) pointed out the tension between the individual and society in the performance of gender: "Our gendered identities are both voluntary-we choose to become who we are — and coerced - we are pressured, forced, sanctioned, and often physically beaten into submission to some rules" (p. 114). In other words, males and females are expected to perform or "do" gender in a way that is considered socially appropriate. When individuals transgress socially constructed gender rules, they are policed by other individuals or by institutions; thus, there is considerable pressure for all members of society to conform to gender expectations. The fact that gender is socially constructed through cultural institutions is particularly relevant to this study because school systems are key sites for the production and reinforcement of gender roles. As 
students grow up, they use public spaces in schools to construct and maintain their gender identities and school culture in turn supports and reinforces socially accepted gender roles.

The differences between socially constructed definitions of masculinity and femininity, and the regularity with which women and men "do gender" in socially acceptable ways, reinforces and legitimizes dominant versions of masculinity and femininity, making traditional gender roles appear to be natural and fundamental (Howard \& Hollander, 1997). Connell's (2005) concept of hegemonic masculinity builds on this concept. Hegemonic masculinity refers to a set of masculine characteristics that are considered to be ideal and reinforced as such through dominant social actors such as film and television, athletic programs, parents, and peers. It includes personality traits that are considered to be particularly masculine, including a propensity for risk-taking, adventure, athleticism, aggression, emotional stoicism, and competition. Such traits are constructed in opposition to feminine traits and thus dominant masculinity is often positioned as both anti-feminine and anti-gay (Pascoe, 2012). Other traits, such as perceived levels of success, personal wealth, and appearance also play a role in the social construction of dominant masculinity. It is through the cultivation of these traits that boys and young men assert their social domination over others (Connell, 2005). In Chapter 2, I posit that dominant constructions of masculinity play a key role in academic achievement for many young men. 


\section{Youth}

Because my research focused on youth, age is a foundational concept in this study. The most commonly accepted term for the age group I studied (high school students between the ages of 14 and 18) is adolescence-a term coined in 1882 by sociologist G. Stanley Hall. Hall (1882) initially defined adolescence as the time coinciding with sexual maturation and described it as a period of "storm and stress" characterized by a "lack of emotional steadiness, violent impulses, unreasonable conduct, [and a] lack of enthusiasm and sympathy" (p. 26). Although Hall conceptualized adolescence as a period of chaotic behavior, he also viewed it as a transitional time that holds great promise, when young people attempt to find their way through a wide range of contradictory impulses, such as happiness and depression and sensitivity and cruelty (Demos \& Demos, 1969). Hall's generation was particularly interested in the role of youth in the family, with an intense focus on nurturing children of the middle class and responding to the developing "boy problem"- - a phenomenon characterized by growing street gangs and rising "juvenile delinquency” of working-class youth urban areas (Grant, 2014; Keniston, 1962). This focus on youth translated to new public-school programs intended to form youth into socially and economically productive individuals. High school graduation rates began to rise, the adolescent years lengthened, and a new term entered the public consciousness: "teenager" (Kimmel, 2008).

A half century after G. Stanley Hall, psychologist Erik Erikson’s (1988) work conceptualized human development in eight evolutionary stages, identifying adolescence as a transitional period of identity-building, during which youth bridge the gap between 
childhood and adulthood. For adults who have always been wary of this transition, Erikson's ideas were reassuring: it is natural, he said, for young people to spend the formative years of their youth building their personal identity, realizing their personal agency, and testing the boundaries set for them (Kimmel, 2008). Today researchers have settled on a more comprehensive and clinical definition of adolescence: a period of a person's life stretching from puberty to the age of 18, when the body physically matures, the brain develops executive functioning skills (including decision-making, organization, and planning), and the social environment intensifies as adolescents negotiate their roles in their families, in their communities, and in an adult world of work and romantic relationships. It is a time of potential vulnerability, growing responsibility, and rapid change (Mann, Harmoni, \& Power, 1989). Frosh, Phoenix, and Pattman (2002) fused this contemporary definition of adolescence with a sociological framework to build a definition of adolescent masculinity:

A period mainly in the teenage years in which boys are becoming acculturated (or acculturating themselves) into increasingly salient masculinities. Much of the social concern hinges around the control of young men's masculinities in the interest of maintaining social order. (p. 1)

It is this definition of adolescent masculinity—a time of acculturating boys into salient masculinities - that drives my understanding of the youth in my study. Because I analyze the role of social constructionism in the lives of adolescents who persist with one foot in childhood and one foot in adulthood, I choose to honor their agency and that of their peers by using the terms young men and young women to identify them; these terms refer 
to people of high school age and into their early twenties. The alternative terms, boys and girls, are reserved for references to youth of elementary and middle school age.

\section{Resistance}

I use the term resistance throughout this paper in reference to young men who engage in resistance strategies against schooling, in either verbal or non-verbal ways. Such strategies may be intended as a critique or a challenge to the traditional education system, or to particular rules, teachers, or administrators (McLaren, 2003). However, resistance strategies may also be less intentional_evidence of students who are disengaged from a school life that does not meet their needs, or an expression of masculine posturing. Whether consciously intentional or not, such resistance strategies may include tardiness, truancy, breaking school rules, or not completing class assignments (Toshalis, 2015). In discussing resistance, I draw heavily from resistance theory and masculinities theory, both of which are grounded heavily in Marxism, feminism and post-structuralism. I present a thorough discussion of resistance and related frameworks in Chapter 2.

\section{Caring}

Dan, who was introduced at the beginning of this chapter, and the many young men like him who regularly engage in resistance strategies against schooling, illustrate an important but often overlooked concept in secondary education: many youths in U.S. classrooms need to feel cared for in order to learn. Noddings (2013) theorized that a student's academic engagement should be secondary to authentic caring - the creation of meaningful, personal relationships between the teacher and their students. She described 
a gap between what teachers think they are accomplishing in the classroom and what students perceive: "In many of our schools today, we find teachers who are trying to care and students who want to be cared for, and yet many of those students claim, 'Nobody cares!'” (p. XV). If Noddings is correct that much of the process of teaching and learning is predicated on the politics of caring (teachers must care about their students and students must care about learning), then it follows that any significant disruptions in the caring of students or their teachers can stymie the learning process (Toshalis, 2012). As illustrated through Dan's story, students whom teachers and administrators perceive to be disengaged or even actively resistant to education are often most in need of a caring relationship at school. Unfortunately, students like Dan who are perceived to be disengaged, or even hostile at times, may be written off as unreachable (Valenzuela, 1999). This is in part because teachers, who are often overwhelmed with heavy workloads and large class sizes, may be tempted to use one overarching personality trait to make a judgment on the whole child. Thus, a child who works hard in class and does all of their homework might be embraced as a "good kid" and a child who does the opposite might be framed as "naughty" or "lazy" and then abandoned (Noddings, 2005). Robinson (2011) referred to this phenomenon using the literature device of synecdoche, which describes when the writer uses a part of something to symbolically represent the whole. To illustrate this phenomenon, Robinson invoked the example of Shakespeare, who might use a mast in his literature to represent an entire ship; students, Robinson explained, are likewise often branded by a single, significant personality trait. Thus, the student dutifully raising a hand to answer questions every day might be considered 
"bright" and "hard-working" while the student slouching at a desk just two rows back might be labeled "lazy." Busy teachers may have neither the time nor the inclination to look beneath the surface.

To further delineate the concept of caring, Noddings (2005) differentiated between authentic caring, which is based on Dewey's (1922) ethos of nurturing students as individuals, and aesthetical caring, which is a prioritization of curriculum, standards, and assessments. Noddings argued that secondary teachers tend to focus more on aesthetical caring, delivering a standardized curriculum and focusing on student growth as measured by standardized assessments; that is, many teachers require students to care about the curriculum before any relationships have been established. However, Noddings suggested that many students need to experience authentic caring before they can access the content of the course. It is precisely this disconnect between how teachers and students each define and perceive of caring that drives the purpose of this research: to describe how authentic caring relationships are of value to young men at the secondary level who engage in acts of resistance against schooling.

\section{Research: Questions and Methods}

Having worked in the context of a large comprehensive high school of more than 1700 students over the span of a decade, I have observed a pattern that strongly resembles those described in the extant literature: boys and young men are disproportionately resisting school, sometimes receiving failing grades in classes or leaving without a diploma as a result. I have experienced many interactions with students like Dan, who 
regularly engaged in resistance strategies, yet craved caring relationships with his teachers. Such interactions, combined with a personal need to understand the perspectives of my students and faithfully record their voices, gave rise to the four research questions guiding this study:

1. How do young men engaging in resistance strategies at Sherwood High School describe the methods and purpose of their resistance?

2. How do young men engaging in resistance strategies at Sherwood High School describe their relationships with their teachers?

3. According to young men who engage in resistance strategies at Sherwood High School, what are the characteristics of teachers who are skilled at fostering authentic caring relationships?

4. According to young men who engage in resistance strategies at Sherwood High School, what distinguishes caring teachers from uncaring teachers?

Since social constructionism is a central framework in my understanding of gender, it follows that I engaged in qualitative research deriving from a post-positivist paradigm based on the foundational understanding that reality is constructed differently by each person who experiences it, and that social constructions interact with individual constructions to create a unique interpretation of reality (Denzin \& Lincoln, 2005). Therefore, in qualitative research, one interpretation of reality is not considered more correct than any other interpretation of reality. As such, there $i$ s no objective reality; the goal of the researcher is to capture the perceived reality of an individual, and to 
understand how that reality is constructed in part by the social environment of that individual (Guba \& Lincoln, 2005).

In this study, I attempted to understand how young men perceived and expressed their own resistance and I used theoretical frameworks related to caring, masculinities, and resistance to help me further interpret their statements. To address my four main research questions, I relied primarily on individual interviews of young men whom I have observed disengaging from formal educational environments. I have provided a more detailed description of my research rationale and approach in Chapter 2 and Chapter 3 of this paper.

\section{Filling a Void in the Literature}

Although much scholarship exists on the conceptual frameworks of caring, engagement and resistance, there is a lack of qualitative research (especially ethnographic studies) connecting the impact of caring responses on students who typically disengage from formal educational environments. This lack of qualitative research means that the voices of the stakeholders in this system are missing, especially the voices of students. I attempted to address this void in the literature by carefully listening to eight young men and faithfully conveying their stories in Chapter 4. 


\section{CHAPTER 2: LITERATURE REVIEW}

The boy debate reached the public consciousness in the United States in the late 1990's and individuals interested in this phenomenon have since produced a wide range of research studies, newspaper articles, and books exploring the differences in academic behaviors and achievement between male and female students. I have directly witnessed this phenomenon through my own work as a high school educator and it was through my lived experiences that I identified the purpose of this study: to describe how authentic caring relationships are of value to young men at the secondary level who engage in acts of resistance against schooling. I used several theoretical frameworks in support of my inquiry: the role of gender constructions in the educational experiences of young men, the relationship of gender and age to cultural dominance and hegemony, and the connection of these frameworks to theories of resistance and caring.

\section{Conceptual Framework: Gender Theory}

Gender is a central consideration in any discussion of male engagement and achievement in school. The discourse on sex and gender is complex and is divided among a range of academic disciplines including biology, psychology, social psychology, and sociology. However, paradigms concerning the role of gender in the boy debate can be divided into two separate categories: biological determinism, which stipulates that behaviors and outcomes are largely a matter of biology, and social theories of gender, which stipulate that behaviors and outcomes are largely a result of learned or social 
constructed gender roles (Addis, Reigeluth \& Schwab, 2016). It is important to note that the academic disciplines of psychology, social psychology, and sociology use different terminology to describe these paradigms; although I draw from research from multiple disciplines throughout this paper, I favor terminology used by sociologists, reflecting my academic background.

\section{Biological Determinism}

We have been told that men are from Mars and women are from Venus (Gray, 1992), and it is clear that males and females can be quite different when it comes to physical characteristics. Such physiological differences include their anatomies, hormone levels, and chemical compositions (Kimmel, 2013) and many such differences are readily observable to a casual audience: on average, males are taller than females, with broader shoulders and hands, and more dense muscular structures. They also grow thicker hair over a larger portion of their body than women do. According to biological determinism, it is primarily these "innate, stable differences between the sexes [that] shape divergent social behaviors" (Howard \& Hollander, 1997, p. 26). Therefore, an individual's biological sex should provide a valid and sufficient explanation for human behavior. Within the boy debate, supporters of biological determinism often refer to studies that demonstrate how young boys tend to develop differently from young girls in measurable ways. For example, young boys develop stronger gross motor skills early on, while girls tend to develop stronger fine motor skills early on; Gurian (2002) purports that this difference in motor skill development may account for differences in handwriting 
between boys and girls, and may explain why boys are more likely than girls to engage in sports and physical activity at an earlier age.

Limitations of biological determinism. While biological determinism holds that differences between males and females are largely attributable to biology, this framework has the tendency to ignore the great diversity that exists among members of the same sex. For example, some males are aggressive and enjoy participating in team sports with high levels of physical contact, while others are quieter and have no interest in organized sports. Some love reading while others love skateboarding. There are males who excel in written expression and those who excel in real-world applications of physics. And although strength is a characteristic typically associated with men, it is important to remember that there are actually plenty of females who have greater physical strength than plenty of males. In fact, while differences between men and women, whether innate or taught, are substantial, the differences among men and women are even more varied and significant (Kimmel, 2013). To illustrate this concept, Hyde (2005) conducted a review of 46 meta-analyses in support of the gender similarities hypothesis in psychology, which holds that there are more differences among men and among women, than between men and women. The study found that $78 \%$ of traits analyzed by the study (including cognitive ability, communication styles, and personality traits) revealed a gender difference of small or close to zero, including traits or skills commonly associated with one particular gender, such as mathematical ability, aggressive behaviors, and nurturing behaviors. Several key exceptions where large differences in gender were noted included physical aggression, motor performance and some aspects of sexuality, such as 
frequency of masturbation and attitudes about casual sex. Finally, Hyde found that gender differences are not stable, but tend to fluctuate according to age and context. The finding that gender differences change according to the social environment of the individual actors suggests that gender essentialism provides an insufficient explanation for the causes of gender traits and behaviors. Furthermore, I caution that relying too heavily on essentialist viewpoints can position gender differences as natural and inevitable, suggesting that gendered roles and behaviors cannot be changed (Blazina \& Bartone, 2016). Doing so threatens to justify inequalities, trap people in rigid gender roles, uphold current patriarchal power structures, and dissuade community actors from effectuating change that could support both males and females in living healthier and more authentic lives (Smiler \& Gelman, 2008). Instead, it is important to recognize gender as the result of the complex interplay between biology and social constructions. Social constructionist theories of gender challenge the view that gender is biologically determined by suggesting that gender is more heavily influenced by social factors than by biological ones.

\section{Social Constructionism}

While biological determinism maintains that fundamental differences between males and females are biologically innate, social constructionism of gender maintains that masculinity is "socially situated and well-coordinated repertoires of activity that create meanings of gender" (Addis, Reigeluth \& Schwab, 2016, p. 82). While I recognize that women and men are physiologically different and that biology strongly impacts the lives of men and women, it is clear that socially constructed gender roles have a more 
meaningful impact on our identities and social interactions. Regarding both paradigms (biological determinism and social constructionism), Newkirk (2002) cautioned that any “generalizations about gender at best can only describe tendencies and patterns — not deterministic limitations" (p. 22); therefore, it is important to be cognizant of the limitations of either paradigm to fully convey the complexities of gender.

\section{Social Learning Perspectives and Social Constructionist Perspectives}

Although it is common to differentiate sociocultural views of gender (such as sex role socialization, gender socialization, and social construction of gender) from essentialist views (biological determinism), it is also important to note that sociocultural views of gender represent a diverse range of theoretical constructs, which can be divided into two clear subcategories: social learning theories and social constructionist paradigms (Brooks \& Elder, 2016).

Behaviorism and social learning. Classical behaviorists theorize that all people operate according to the same basic principles, regardless of gender, social class, or race. In fact, behaviorists are concerned only with observable behavior (rather than internal processes of learning such as the role of memory, motivation, and internal reflection) and attempt to explain learning through stimulus-response causality. Because classical behaviorism does not account for cognitive processes, it has mostly fallen out of favor in the fields of education and sociology (Freiberg \& Brophy, 1999; Howard \& Hollander, 1997). However, several theoretical frameworks in sociology do borrow heavily from behaviorist traditions, arguing that gender is a result of an individual's response to rewards and punishments for particular behaviors. For example, social learning theory 
stipulates that children learn gender roles both through direct reinforcement and by observing others' behavior and the consequences of that behavior. Social actors typically reward children for engaging in behaviors considered acceptable for their gender and punish them for engaging in behaviors that are not considered acceptable for their gender (Bandura, 1971; Howard \& Hollander, 1997). According to Bandura (1971), "man is neither driven by hidden forces, nor buffeted helplessly by environmental influences. Rather, psychological functioning is best understood in terms of a continuous reciprocal interaction between behavior and its controlling conditions" (p. 2). Social learning theories are currently popular within the academic discipline of social psychology because they emphasize the importance of observation, replication, reinforcement and punishment in the learning of gender roles; however, social learning theories fail to account for the impact of elements such as social context, personal agency, or biology on the construction of gendered identities (Brooks \& Elder, 2016; Howard \& Hollander, 1997). By contrast, the role of social context and personal agency are central components in social constructionism, which is a key theoretical construct supporting this study and will be discussed in greater detail throughout this chapter.

Social exchange theory. Social exchange theory also stems from classical behaviorism and-like social learning theory_-assumes that children learn gender roles through a system of rewards and punishments. In particular, social exchange theory draws from Skinnerian operant psychology in that it conceptualizes social interactions as rational exchanges between individuals (Emerson, 1976). Borrowing from capitalist economic principles, Homans (1958) suggested that when people interact, they do so in 
the interest of exchanging "materials" for mutual benefits, including time, money, friendship, or assistance with a task. Likewise, each individual weighs the costs and benefits of specific interactions in an attempt to maximize benefits and minimize costs; individuals may choose to discontinue social relationships if the reciprocal nature of the relationship is violated or if the perceived costs begin to outweigh the benefits (Cook \& Rice, 2006).

One major limitation of social exchange theory is the way it reduces complex human behavior to rule-bound economic principles. Central to this critique is the theory's assumption that although all individuals may not have equal resources, and some people may in fact leverage resources to coerce or retaliate against other parties, all individuals do have equal power to procure resources or abandon unfavorable exchanges (Zafirovski, 2005). Considering this assumption of equality, social exchange theory fails to fully account for the impact of power imbalances based on gender, race, sexuality, or class (Chibucos, Leite \& Weis, 2004). By contrast social constructionism, which is inextricably linked to feminism and critical perspectives, emphasizes the centrality of these power imbalances in gender relations. Both social constructionism and feminism will be explored later in this chapter.

Despite its limitations, social exchange theory remains helpful in the examination of social relationships. In particular, Bourdieu (1986) borrowed from the language of economic exchange to explain the dynamics of cultural reproduction in schools, including the power of various social and cultural assets, which he termed social and cultural 
capital, to promote social mobility and confer social status. I will explore Bourdieu's theory of capital in greater depth later in this chapter.

Social constructionism. Social constructionism is the dominant learning theory sociologists use to describe gendered relationships. In contrast to social learning frameworks, social constructionism conceptualizes gender roles as socially constructed, meaning that while society imposes gender expectations on individuals, each individual also exercises some agency in the development of their own gender identity by choosing certain gendered roles over others, generally within the bounds of socially acceptable behavior (Kimmel, 2013). In fact, the construction of gender can be described as a dynamic interplay between three forces: the individual, other social actors, and the institutions within which they interact (Addis, Reigeluth \& Schwab, 2016). Such a dynamic interplay means that gendered behavior also changes according to time and place. Kimmel (2013) described the dynamic construction of gender as:

A set of activities that one does. When we do gender, we do it in front of other people; it is validated and legitimated by the evaluations of others. Gender is less a property of the individual than it is a product of our interactions with others. (p.

In order to reinforce expectations of appropriate gendered behavior, individuals and institutions may "police" (p. 357) behavior seen to be inappropriately masculine (Watson, Kehler, \& Martino, 2010). They may do so through the use of peer pressure, physical force, or homophobic language such as “\#Nohomo" or "That's so gay!” (Pascoe, 2012). 
It is important to note that socially constructed gender roles are so normative that they may appear to be innate; therefore, social constructionists believe it is impossible to differentiate an individual's biological characteristics from those characteristics molded by social circumstances (Howard \& Hollander, 1997). Therefore, the most important implication between biological determinism and social constructionism is the perceived capacity for change: biological determinism is essentialist, assuming that sex traits are natural and therefore generally immutable, whereas social constructionism assumes that gender is constructed and therefore can be shaped and changed (Howard \& Hollander, 1997). This does not mean that changing gendered behavior norms is an easy feat- they are in fact so resistant to change that they may appear to be stable biological traits.

\section{Masculinities and Education}

Social constructions of gender are deeply embedded within all educational environments and thus have strong implications in the boy debate. In fact, Lingard, Martino, and Mills (2009) posited that "anti-school behaviours of some boys, to which ["boy-friendly"] pedagogical approaches are a response, is actually a playing out of dominant constructions of masculinity and...such constructions often have a detrimental impact on the learning of both boys and girls" (p. 46). A number of recent research studies support this assertion. For example, in a year-long ethnographic study of two neighboring high schools, Morris (2012) found that certain young men who subscribed to dominant masculinities considered striving in school as consistent with the behaviors of young women, and therefore inconsistent with dominant masculinity. Morris used the terms academic nonchalance and contrived carelessness to describe the style of 
resistance he observed: young men publicly advertising their low grades, jokingly telling peers they "forgot" to study, arriving late to class, and slouching behind their desks. Morris connected his observations to Goffman's (1959) theory of presentation of self in which people behave in particular ways to present a distinct identity to others around them. For Morris' young men, the identity they presented "willingly and contentedly projected a semblance of inattention at school" (p. 54). Interestingly, Morris also found little correlation between displays of academic nonchalance and the value these young men placed on grades or education. In fact, the young men did not want to be perceived as stupid; they simply wanted to appear unconcerned with the academic and behavioral expectations of authority figures. In other words, academic participation was a public, gendered act for these young men, and engaging and disengaging with teachers was part of a complex interplay between the young men, their peers, their teachers, and the educational institution, through which dominant masculinities were constantly being constructed and negotiated.

Morris (2012) and other researchers have found that English/language arts is a particularly gendered academic subject — one in which the typical styles of discourse and instruction (highly verbal, emotive, and physically passive) align with qualities named earlier in this paper as feminine and, by definition, in opposition to masculinity (Martino \& Pallotta-Chiarolli, 2003). While boys and young men may frequently engage in literacy practices such as posting on social media, they are less likely than girls and young women to embrace the official literary practices of the school, such as reading assigned novels or publicly discussing poetry (Frosh, Phoenix \& Pattman, 2002; Smith \& 
Wilhelm, 2002). This also suggests that acts of academic nonchalance may be more emphasized in the ELA classroom than in other classrooms where the content area is more consistent with dominant masculinity, such as physics, welding, or engineering classes (Newkirk, 2002). These findings align with my own experiences working with young men as an English teacher at the secondary level, and in Chapter 4 I posit that my participants' behaviors and comments about their academic life is also largely consistent with this research.

\section{The Role of Institutions}

Kimmel (2013) argued that individuals do not construct their identities in isolation. Other individuals and institutions (family members, teachers, peers, schools, and sports teams) implicitly reinforce dominant constructions of masculinity (Watson, Kehler \& Martino, 2010). This means that, as community institutions, schools are important sites for the production and reinforcement of gender roles. For example, play areas in daycares and elementary schools may be tacitly segregated according to genderspecific toys and activities. Thus, girls may gather in one area to play with stereotypically feminine objects such as dolls and miniature plastic shopping carts, while boys may gather in another corner to play with stereotypically masculine objects such as trucks and blocks (Chu, 2014). Children use these public spaces to construct and maintain their gender identities and to hold others accountable for conforming to gender expectations as well. Thus, gender nonconforming behavior at this young age - such as boys playing with dolls or wearing pink tutus - may be interrupted by peers, teachers, or parents. 
Bausch (2014) documented how third grade boys interacted with institutional structures to align themselves with dominant masculine norms and disassociate themselves from boys considered to be less dominantly masculine. She observed boys dividing themselves by "insiders" and "outsiders" when participating in literacy groups and activities. The "insider" group was often male only; its members exhibited more acts of resistance than other groups, with members often supporting each other in their acts of resistance. The "insiders" also frequently displayed behaviors consistent with hegemonic masculinity, such as co-authoring stories featuring gore and violence. Bausch noted that "the work was less of a [literacy] exercise and more of a method of aligning themselves to each other as an entry ticket into their literacy clubs" (p. 97). Bausch's research demonstrates how institutions, and the actors within those institutions, are important components in the construction of each boy's gender identity. It also reflects Morris' (2012) findings that "men behave in masculine ways in order to demonstrate manhood. This means that academically relevant behaviors become vehicles for the dynamic production of gender" (p. 9). Masculinity, then, does not influence behavior; people do not do things because they are masculine. Rather, they choose their actions and negotiate with the individuals and structures in their environment in order to demonstrate a particular masculinity. While young men may gain social power among their peers through these demonstrations of masculinity, there are also hidden costs (Morris, 2012). These hidden costs will be explored further in the next section of this chapter. 


\section{Youth, Cultural Dominance, Hegemony, and Resistance}

Schools are important sites in the reproduction of pre-existing social structures such as class-based hierarchies, social norms, and gender roles (Giroux, 1983) In fact, schools are structured to maintain the status quo, a phenomenon that critical theorists call hegemony. Peter McLaren (2003) defined hegemony as:

The maintenance of domination not by the sheer exercise of force but primarily through consensual social practices, social forms, and social structures produced in specific sites such as the church, the state, the school, the media, the political system, and the family. (p. 202)

In academic institutions, hegemony primarily appears in the form of moral and intellectual leadership, which favors the culture and values of the dominant class. Since teachers and administrators are the leaders of moral and intellectual development in schools, they often unwittingly take on the role of agents of oppression (Giroux, 1983; McLaren, 2003). These academic leaders tend to believe the institutional myth that a school is a meritocracy and that their role within the institution is to foster equity for all students. Frequently, the system accomplishes exactly the opposite: it upholds policies and structures that maintain the status quo (Willis, 1977).

One particularly compelling word in McLaren's (2003) definition of hegemony is consensual, in that hegemony is not established through coercion or outright domination, but rather by winning the consent of subordinate groups to follow the rules of the dominant class. This consent is achieved in many subtle ways. For example, the school's structural problems are often framed as student failures. When a student does not adhere 
to the school's dress code because they find it unfair or unnecessarily controlling, school officials may target the student as insubordinate or in violation of school rules. And despite protests from students and parents about unfair practices, the school often continues to stand by its policies. Framing the students as culpable rather than critically examining the structures behind the disagreement protects school officials and essentially renders them blameless (Giroux, 1983). Because the school's structural problems are so often framed as student failures, oppression may appear to be chosen by the oppressed (McLaren, 2003). Consent may also be achieved by silencing dissenting voices. That silence is then normalized, and alternative voices are defined as irrelevant (Gallagher, 1992). In my experience as a teacher at a secondary school, for example, students are not frequently given the opportunity to author policies (such as dress codes or disciplinary procedures) that affect them on a daily basis, or to defend themselves against policies they perceive to be senseless or unfair. Although some students have opportunities to speak their truth, perhaps during a school board meeting or in a student council meeting, it is quite unusual. My study may very well represent the first time my participants have been allowed to clearly and safely voice their opinions about their experiences in the public-school system.

\section{Schooling and Education}

Any discussion of cultural hegemony in schools must make a distinction between the concepts of schooling and education. Giroux (1983) and Freire (2000) both defined schooling as a structured, standardized system developed for social control. They distinguished it from education, which is individualized and flexible, with the potential to 
transform both the learner and society (McLaren, 2003). Both Giroux and Freire drew from Foucault (1995), who described school as a system of control that transforms "the confused, useless, or dangerous multitudes into ordered multiplicities" (p. 148). Foucault's description of schooling as a mechanism of control mirrors Freire's (2000) banking metaphor, which situates students in modern schools as receptacles to be passively filled with information in the interest of order and productivity.

Foucault (1995) elaborated on his analysis of control through an examination of the history of punishment in Western culture. Foucault argued that punishment and control evolved from physical and public torture, to a more private punishment no longer connected to physical pain:

The body now serves as an instrument or intermediary: if one intervenes upon it to imprison it, or to make it work, it is in order to deprive the individual of a liberty that is regarded both as a right and as property. The body, according to this penality $[$ sic $]$, is caught up in a system of constraints and privations, obligations and prohibitions. (p.11)

Likewise, punishments in modern U.S. schools tend to focus on the deprivation of liberty. This includes detentions, suspensions, and expulsions. Potential applications of Foucault's ideas extend beyond disciplinary procedures, however. I commonly hear U.S. students use institutional imprisonment as a metaphor for how they experience school: the factory-like bell system, the lack of control over coursework and standards, the preponderance of discrete standards valued over intellectual rigor, the physical constraints of where and how a student must sit, the requirement that students request 
permission to use the restroom or otherwise leave the classroom - all elements of school that make it feel more like an experience of discipline than an institution of liberation.

Consider the teaching desk as the locus of control: it is an area typically barred from student entry. It is generally more imposing than other furniture in the room, reflecting its importance and, by association, that of its owner. Most padded teacher chairs roll, which presents another stark contrast to the small, hard, unwieldy desks the students typically occupy. Consider also the surveillance of common spaces, such as the corridors that are policed by hall monitors and closed-circuit camera systems. Consider the teacher's role as planner, assessor, and director of conversations. Consider the teacher's expectations of the student as quiet, compliant folks who follow rules, adhere to deadlines, raise their hand for permission to speak, and refrain from any behavior not initiated by the teacher. These mechanisms are in place to allow school officials to maintain hegemony and propose a tacit offer to the student: follow our rules and you will be left alone; break the rules and we will punish you by revoking your freedom.

Connell (1996) found that most young men learn to accept this trade-off and negotiate the system with few problems. Some might simply choose to follow the rules, while others find ways to challenge the system without directly defying school staff, through symbolic acts of resistance such as joking with the teacher (Morris, 2012). However, some young men approach this system of discipline and control as a challenge. Connell (1996) called this "taking up the offer" (p. 220) and found that those young men may take up the offer to challenge the system in multiple contexts, including teachers' expectations of academic engagement. That being said, some masculinities, especially 
those of middle-class and upper-middle class White men, emphasize masculine power through other means such as competition, rather than through confrontation. The result is a great deal more conflict between teaching staff and working-class young men and young men of color (Connell, 1996).

\section{Youth Oppression}

When Foucault (1995), Giroux (1983), Freire (2000) and Willis (1977) described the controlling mechanisms of the dominant class through schooling, they were primarily concerned with the politics of race and social class. However, if schools situate youth as an inferior and compliant class of people, I argue that youth can be defined as an oppressed group in a similar manner that people of color or working-class people can be defined as oppressed. For example, Nakkula and Ravitch (1998) observed that youth are rarely perceived as contributing members of society who have something to offer, such as unique worldviews, creative solutions to modern problems, or valuable critiques of modern society. Hebdige (1988) similarly illuminated the concept of youth oppression in his discussion of youth and resistance:

In our society, youth is present only when its presence is a problem, or is regarded as a problem. More precisely, the category "youth" gets mobilized in official documentary discourse, in concerned or outraged editorials and features, or in the supposedly disinterested tracts emanating from the social sciences at those times when young people make their presence felt by going 'out of bounds,' by resisting through rituals, dressing strangely, striking bizarre attitudes, breaking rules, breaking bottles, windows, heads, issuing rhetorical challenges to the law. (p. 17) 
Giroux (1994) agreed that youth "as a social construction, has always been mediated, in part, as a social problem" (p. 289). As an example, he demonstrated how the media typically portray White youth as lazy and entitled. Such a portrayal is problematic because the media rarely address the social conditions that may contribute to their behaviors and attitudes (This is not to say the media does not also stereotype youth of color in discriminatory ways).

\section{Faces of Oppression}

Young (1992) defined oppression as the act of reducing the potential of a group of people to be fully human and clarified this definition by identifying five "faces" of oppression: exploitation, marginalization, powerlessness, cultural imperialism, and violence. I posit that all youth learning in U.S. public schools, regardless of ability, social class, ethnicity, gender, or sexuality, are subject to at least three kinds of oppression at some point in their youth, simply as a function of their age: marginalization, powerlessness, and cultural imperialism.

Marginalization. According to Young (1992), one key "face" of oppression is marginalization, which McLaren (2003) defined as the exclusion of a person from full participation in social life, including working and voting. Youth marginalization in the U.S. manifests itself in a variety of ways. For example, while U.S. youth have the right to work under certain conditions, all youth are legally obligated to attend school full time until the age of 16, which prohibits them from working full time if they choose. Furthermore, youth do not have the right to vote or otherwise participate meaningfully in civic life until the age of 18 , regardless of their interests in politics or their understanding 
of local and national governance. Laws often prohibit youth from making choices about their personal welfare, including purchasing birth control, obtaining medical care, and choosing where and with whom they will live. I do not argue that these limitations are universally negative for young people, just that youth are restricted from making personal choices in ways that adults are not. Although the legal threshold for making adult decisions is defined by age limits based on principles of developmental and cognitive psychology, the implementation of those laws lacks the nuance necessary to accommodate for inevitable human differences in development and ability.

Powerlessness. A second key face of oppression is powerlessness. While youth are often powerless over many aspects of their lives, they are particularly powerless over their school experience, especially when they are attending schools serving primarily working-class or middle-class students (Anyon, 1980). Anyon (1980) found that most students in these schools are afforded little voice in choosing their coursework and often complain that creativity is largely stifled in school. In an era of education focused on standardized test scores and grades, students often (erroneously) learn that there is one right answer and one way to find the answer to a problem. They have little control over their intellectual labor and constantly encounter rules governing how they should speak, dress, and act. And upon breaking these rules, there is little opportunity to appeal punishment or otherwise engage in dialogue with teachers or administrators. In general, the school will position itself on the side of the adult during a conflict with a student, operating under the assumption that adults are more astute thinkers and decision makers. 
Cultural imperialism. A third face of oppression is cultural imperialism. Newkirk (2002) suggested that in most schools, adult, anglo-centric subject matter is privileged over most other ways of knowing. In particular, youth culture is regarded as both separate from and inferior to so-called "classical literature" and as youth approach adulthood, young adult literature, art, and media are often disregarded or even banned outright in the classroom (Lurie, 1990). In this way, the school institution prioritizes the “official knowledge" of learning, including subjects that students disregard as too far removed from their own needs and interests (Apple, 1993). Young (1992) argued that such cultural subordination renders youth culture as both invisible in the classroom and positioned in opposition to what teachers and administrators deem to be appropriate and challenging.

\section{The Hidden Curriculum}

Giroux (1983) identified cultural subordination as one component of a school's hidden curriculum, which he described as a set of "structured silences" that legitimizes some cultural practices and marginalizes others, essentially framing them as deficient. Like gender, knowledge is socially constructed and the official curriculum of the school - comprised of elements such as state standards, department guidelines, common assessments, and standardized tests - determines what is important to know, drives the classroom's daily activities, and is visible to students, staff, and community members (McLaren, 2003). The hidden curriculum also determines what is important to know, yet is unintentional and almost completely invisible to all parties, including students, teachers, and administrators. Giroux (1983) theorized that the hidden curriculum consists 
of cultural norms, values, and beliefs embedded within the structure of the school, including its routines, rules, and social relationships. The hidden curriculum varies from school to school and from teacher to teacher and determines what behaviors are appropriate in the classroom and in the hallways, how staff will respond to transgressions, whose voices are heard in the textbooks and at assemblies, and which activities win students the most respect and praise from their teachers and their peers. Students who challenge these norms are often labeled as "defiant" and reprimanded. Foucault (1995) suggested instead that such behavior be labeled as "resistance," which is a more positive term than defiance, describing a response Foucault felt was both natural and inevitable in such a restrictive environment.

\section{Differentiation and Resistance}

I have established that dominant groups establish hegemony by naming the ideas, behaviors, and customs that are considered normal and by extension, natural and inevitable (Bourdieu, 1986), and people who feel excluded by these normative claims tend to oppose them, choosing resistance as a reaction against domination (McLaren, 2003). Willis (1977) used the term differentiation to describe the process that subordinate classes may use to resist cultural norms and redefine them into a new and less formal paradigm that benefits subordinate classes. This process of differentiation produces a counter-school culture or resistance embedded within the daily life of the student: "It is lived out in countless small ways which are special to the school institution, instantly recognized by the teachers and an almost ritualistic part of the daily fabric of life for the kids" (p. 12). By contrast, Willis argued, teachers engage in "integration," which is an 
effort to convince students that the system functions on their behalf. In supporting the system, teachers become adept conspiracy theorists, identifying and punishing the "culprits" who have broken the cultural norms, and cementing an "us vs. them" mentality. This battle between processes of differentiation and integration characterizes the daily interactions between resistant students and their teachers.

Although resistance is situated in opposition to the institution and its purveyors, it still operates under a set of rules unique to the institution itself, with variants among social groups and individuals. The rules of resistance establish recognizable patterns, such as those identified by Willis (1977): students getting up to sharpen a pencil just as the teacher begins speaking, walking in just as the bell rings, putting their head down during a lecture, or wearing a shirt with a beer advertisement on it, for instance. For my students, the patterns are similarly predictable: resistant students might attempt to get away with wearing a shirt displaying a voluptuous and scantily dressed woman, walk in late because they "needed a Pop Tart," text or SnapChat with their neighbor during work time, or shout obscenities to their friends across a busy hallway. They may roll their eyes when I lecture them on their behavior, but they also high-five peers when they witness similar behavior. It is also my experience that any acts of resistance purposely walk the line between compliance and rebellion, allowing students to critique or test the system, but avoid punishment. Acts of resistance that result in suspension or expulsion are relatively rare, but for some students, the school day may be littered with small, but meaningful acts of resistance and predictable responses from teachers, ranging from strong eye contact, to public admonition, to hallway lectures. 
Agency, power and resistance. Resistance is motivated in part by a young person's drive for self-efficacy — the need for an individual to make their own decisions and develop their own identity, free of institutional constraints. Since every person requires agency to some degree, it is common for youth who feel marginalized to regain personal agency through acts of resistance (McLaren, 2003). Toshalis (2015) eloquently expressed the relationship between resistance, agency, and power: “A person's ability to define themselves depends on their capacity to resist how others want them made" ( $p$. 52). In discussing power and oppression, however, it is important to note Foucault's (1995) suggestion that power is not a unilateral, top-down process, nor is it a possession; rather, it is dynamically created between all parties. Resistance, therefore, like hegemony, is the production and use of power-it is an attempt by one party (in this case, the student) to gain agency in relation to another party (teachers and administrators). Applying this concept to the classroom, power is constantly constructed by both students and teachers and resistance can be defined as a student's production of power in response to the power institutionally conveyed to the teacher. And because they are social constructions, power and resistance necessarily vary according to the environment and over time.

Defining resistance. Whereas classic resistance theorists such as Giroux (1983) and Foucault (1995) conceptualized resistance as a conscious political response to an oppressive system, modern theorists understand that resistance can occur for myriad reasons, including increasing status in peer relationships, reinforcing personal agency, challenging boundaries, and experimenting with new identities. For example, Nakkula 
and Ravitch (1998) described resistance as any action or reaction youth use to circumvent, respond to, or cope with existing power structures. They argued that resistance may incorporate multiple methods, including:

Dissociating from educational discourses (school lessons) from which [students] feel alienated, adopting inflated social images of strength and beauty to compensate for deflated personal images of worth and efficacy, and learning not to share intimate truths for fear of being violated, patronized or disrespected. (p. 31)

Valenzuela (1999) provided a slightly different explanation of resistance. It emphasizes student responses to the uncaring nature of schooling:

What looks to teachers and administrators like opposition and lack of caring feels to students like powerlessness and alienation. Some students' clear perception of the weakness of their position as a form of resistance not to education, but to the irrelevant, uncaring, and controlling aspects of schooling (p. 94).

Nakkula and Ravitch and Valenzuela described resistance as a clear response to a lack of personal agency in the classroom, but none of them considered resistance strategies to be political acts, or even necessarily intentional in nature. This definition of resistance represents a significant widening of earlier conceptualizations of resistance. Helpfully, Toshalis (2015) drew heavily on social reproduction theories, psychology, resistance theory, and his own observations to create a sweeping, multi-pronged definition of resistance, which includes: 
- Any behavior by one or more students that is perceived by the educator or the student or students to initiate a course of action that differs from, alters, inhibits, or prevents the general direction or intention of activity in the classroom or school.

- Any student verbal or nonverbal communication that withdraws from, questions, critiques, refutes, or refuses a perspective, a norm, or knowledge presented by the educator, by peers, or by the school.

- Any situation in a school setting in which a student decides not to comply with an implicit or explicit expectation.

Toshalis' definition is remarkable in its sweeping scope, making space for a variety of resistance responses. I have drawn from each of the definitions of resistance offered in this section, as well as from my own experiences as a high school English teacher, to formulate a personal definition of resistance. First, I distinguish resistance - a productive force in which the actor actively constructs and negotiates power relationships in the interest of enhancing autonomy and agency, from deviance - a derogatory term used by those in power to describe what they interpret as destructive behaviors that should be responded to with pressure or punishment. Second, I identify resistance, at its very foundation, as a symptom of significant disconnect between the learner and the learning environment, rather than a problem in and of itself. Finally, because the concept of resistance is so closely tied to social reproduction theory and is deeply embedded in a critical perspective, I sometimes choose to differentiate my broader definition of resistance from the more circumscribed definition of resistance borne from a critical 
framework, by using alternative terms, such as disconnection or disengagement. Such terms help to clarify the relationship between the patterns of behavior my participants described and the origins of that behavior. By using a variety of terms to describe a pattern of behavior, I hope to convey that this research is not about the different kinds of resistance strategies a young man might employ; rather I am exploring the social environment of students who, whether intentionally or unintentionally, experience a disconnect between their own behaviors and the behavioral expectations of their teachers and school culture. Further, this study recognizes the various causes of resistance acts while exploring the potential of authentic caring relationships to mitigate alienation and disengagement. The power of authentic caring relationships will be explored in a later section of this chapter.

\section{Cultural Capital}

Borrowing from social exchange theory and critical perspectives in education, Bourdieu (1986) originally used the concept of cultural capital to explain the inequitable academic performance among children of various social classes. He argued that cultural capital can be understood as non-monetary resources with the potential to be converted into economic capital and social advancement. For students, cultural capital can exist in terms of material goods such as books, computers, and school supplies (the objectified state); habits and dispositions of the mind that take substantial time to acquire (the embodied state); and modes of thinking, which are legitimated by the dominant class and learned through formal schooling (the institutionalized state) (Bourdieu, 1986). In particular, students with more cultural capital have more in common with teachers, have 
access to more physical resources, and have developed stronger academic skills. These students generally feel more accepted and supported by the academic system than students lacking in cultural capital and thus tend to believe in the value of that system (Bourdieu, 1986). When students have adequate cultural capital, they often engage in a cycle of mutual support within the school culture: they invest their energy in a system that affirms their efforts, and that system further invests in them in return. The resulting positive working relationships with teachers and other school personnel may then result in greater "dividends" or payoffs of their labor investment, including higher grades and more post-secondary opportunities (Bourdieu, 1986; Coleman, 1988).

Students with strong connections to dominant cultures come to school with substantially more cultural capital than students from marginalized groups, in part because the dominant class has delegitimized modes of thinking, dispositions, and other cultural wealth held by marginalized groups. This means that many White students and students from upper-class and middle-class families enter school with more powerful cultural capital than many students of color or students from working-class backgrounds. In fact, Bourdieu (1986) went so far as to argue that the sole purpose of cultural capital is to reproduce a class society by maintaining the hegemony of those at the top and denying advancement to those who are not.

Gender and cultural capital. Gender can add complex and unexpected layers to cultural capital in the classroom. We have established that girls and young women are more likely than boys and young men to strive academically and to experience positive student-teacher relationships at school, in part because traits such as academic 
engagement and compliance with rules are highly consistent with femininity (Newkirk, 2002). By contrast, dominant masculinity is generally characterized by traits such as autonomy and power, so young men are much more likely than young women to engage in acts of resistance against schooling (Lingard, Martino \& Mills, 2009). In particular, the academic nonchalance and contrived carelessness that Morris (2012) observed among high school males involves a range of resistant behaviors constructed to present a distinctly masculine identity to peers. Morris found that, for many boys and young men, the social credibility earned from peers through contrived carelessness is contrary to the dominant cultural practices of schooling but can still feel more powerful or beneficial than striving in academic pursuits (Willis, 1977). Through such acts of resistance, some youth (and especially young men) may present themselves as uncaring about school and about their teachers, which can cause teachers to dismiss them as lazy or unmotivated. This may perpetuate a cycle of ambivalence or even antagonism between student and teacher.

If teacher approval and striving for good grades are generally more socially acceptable in female peer groups than in male peer groups, girls and young women are better placed to accumulate cultural capital in a school setting (Valenzuela, 1999). Research studies have documented this phenomenon in a variety of ways. For example, in a longitudinal study, Downey and Vogt Yuan (2005) found that girls and young women generally enjoy an advantage in grades in every subject (including mathematics) over boys and young men, which the researchers attributed to cultural capital in the form of "more agreeable classroom behavior" (p. 299). Similarly, Mickelson (1989) found that 
female students are more likely to be "compliant" in a classroom: following the teacher's instructions, completing assignments, and dutifully adhering to school policies ${ }^{1}$. In more focused observations about relationships between young men and their teachers, Jones and Myhill (2004) found that teachers often approach boys and young men using a deficit framework, viewing the typical male student as underachieving and the typical female student as high achieving, despite the teachers' own reported beliefs that students of all genders are capable of high achievement. Valenzuela (1999) arrived at similar conclusions based on her own observations of students of color, noting that teachers “tend to overinterpret urban youth's attire and off-putting behavior as evidence of a rebelliousness that signifies that these students 'don't care' about school. Having drawn that conclusion, teachers then often make no further effort to forge effective reciprocal relationships" (p. 22). As a result, young men in Valenzuela's study who engaged in acts of resistance against schooling were sometimes rejected and even alienated by school staff, further amplifying an already strained relationship.

Unfortunately, these acts of resistance and the ensuing conflicts can also make it more challenging for youth to achieve commonly recognized forms of success within the traditional U.S. educational system. In the interest of effectively supporting all students, Valenzuela cautioned against a reliance on deficit frameworks. She argued that although

\footnotetext{
${ }^{1}$ Ironically, while girls and young women enjoy the dividends of cultural capital in their educational careers, working-class and middle-class women (and especially women of color) still earn less on average than men for equal work and continue to occupy fewer positions of power in both the professional and political spheres of the United States (Mead, 2006; Mickelson, 1989). This is a central component of the conversation on dominant masculinities, feminism, and the impact of cultural capital, and represents an opportunity for further study in the field.
} 
teachers must rely on students' self-representations for information about their interests and motivations, teachers must also be willing to look beyond those representations. Way (2011) agreed, noting a disconnect between the cultural constructions of academic nonchalance, or cool masculinities, and boys' actual lived experiences. In fact, she found that boys value and seek deep emotional connections with other boys around them, contrary to appearances and cultural assumptions we may make about the nature of boys.

While Bourdieu's critical lens is helpful in understanding the role of capital in social reproduction, especially when combined with gender role theory, I do believe that reducing a complex cultural environment to a single cause risks overlooking other important factors - such as the psychological role of motivation in learning or the role of trauma and stress on cognitive functioning - that may also strongly impact a student's experience in an educational institution. Cultural capital is but one way of understanding a student's academic performance in school.

\section{Relationships and Authentic Caring}

Like Freire (2000) and other critical theorists, Noddings (2005) repudiated impersonal, prison-like modern classrooms. Noddings argued that the primary purpose of school should move well beyond academics to "promote the growth of students as healthy, competent, and moral people" (p. 10). When schools focus solely on academics, Noddings said, methods, assessments and standards threaten to dominate classroom interactions, while the needs and interests of the individual are largely ignored. It is this prioritization of academic skills, standards, and outcomes — which Noddings called 
aesthetical caring - that results in teachers treating students as receptacles for information rather than as people (Freire, 2000; Noddings, 2013). Valenzuela (1999) suggested that teachers prioritizing aesthetical caring assume that students entering their classroom already care about school. However, many students, particularly those marginalized by race or class, report needing to be cared for by their teacher before they can learn (Valenzuela, 1999). Noddings (2013) defined this type of caring as authentic caring, which emphasizes an exchange of caring between individuals and an engrossment of teachers in their students' lives. That is, authentically caring teachers empathize with how students think and feel about their world and respond by creating a learning environment that is structured to meet the intellectual and emotional needs of each individual student. Again, Valenzuela and Noddings both cited institutional encumbrances such as state standards, standardized curricula, and mechanized systems of instruction as major barriers to learning environments characterized by authentic caring.

Valenzuela's (1999) and Noddings' (2013) theories of caring are supported by empirical studies exploring classroom relationships. For example, Raider-Roth (2005) found that while the young men she interviewed described good teaching through descriptions of their teachers' personalities, teachers described good teaching almost exclusively in terms of curriculum and pedagogical approaches. Raider-Roth was unable to identify a style of teaching or communication that was particularly effective in engaging students, but she did find that the young men in her study were willing to suspend resistance strategies for teachers they could relate to. Kleinfeld (1975), who conducted research with Native Eskimo youth, concluded that students in standardized 
classrooms "learn to accept being treated as a member of a category. As relationships with teachers become more limited and specialized in the upper grades, the student learns to accept a detached, narrow scope of one person's concern with another" (p. 310). Thus, as students move through the traditional school system, authentic connections with teachers become increasingly rare.

Kleinfeld (1975) also used data from her observations of classroom relationships to posit four typologies of teachers based on their professional distance and the overall rigor of their expectations. Traditionalists, she stated, keep a professional distance from their students and actively demand that their students strive and grow. They focus exclusively on the academic aspect of the classroom and largely ignore the interpersonal facets of their work. This kind of teaching is effective for students who are already engaged in the subject matter, but may alienate students who are not engaged, or who feel marginalized by the learning environment, as is the case for many boys and young men. A second typology, the sophisticates, keep their professional distance and simultaneously hold low expectations for minority populations and for students who engage in resistance strategies in their classroom. This typology is perhaps the most damaging for disengaged or marginalized students, because these teachers typically disregard them by focusing on high-performing students whom they believe want to learn. The third typology is sentimentalists - teachers who demonstrate great caring for their students, but demonstrate that caring, in part, by holding students to low standards. In an effort to free students of burdens, these teachers instead ensure that their students do not learn or grow. Finally, Kleinfeld named warm demanders as the most impactful teacher typology. Warm 
demanders, she argued, maintain an explicit focus on building authentic caring relationships in the classroom and earning their students' trust, but are also competent educators who demand engagement and effort. Such teachers spend significant amounts of time early in the term building relationships with students rather than jumping right into the academic content, then become academically demanding once the relationship has been established. In turn, such demands are interpreted as a personal concern for the student's well-being, as opposed to an academic elitism or bossiness. The warm demander typology was echoed by Noddings (2013), who found that students typically respond best to teachers who establish authentic caring relationships with their students, but also set clear and high expectations for their work.

Reichert and Hawley (2014) described productive student-teacher relationships in a slightly different way. They referred to teachers as relationship managers who are responsible for the creation and maintenance of classroom relationships; they characterized relationally effective teachers as reaching out to individual students' needs and interests, sharing common interests and characteristics, being willing to share personal experiences and express some vulnerability, and being willing to accommodate some amount of opposition in their students. According to Reichert and Hawley, teachers must be relationship managers in part because students have limited personal agency in the school environment and are thus less able to maintain an objective point of view regarding the relationship. Teachers skilled in building relationally successful alliances with students do not expect their students to take on the responsibilities of relationship managers, thus freeing the student to learn on their own terms. 


\section{The Primacy of Relationships}

For many boys and young men, the personal connections they make with their teachers is more fundamental to the learning process than the teacher's lessons. Reichert and Hawley (2014) found that boys and young men are particularly likely to "experience their teachers before they experience the lessons they teach" (p. 11). In a similar study of 1800 male high school students in South Australia, Slade (2001) found that whether the young men felt their teachers cared about them was central to their enjoyment and success in school:

Despite the broad and complex association of factors, it seems that all but a small number of boys consistently and emphatically see their retention and achievement problems primarily in terms of their relationship with teachers, and what they see to be a proliferation of 'bad teachers' who don't listen, don't care and who are given too much power. A uniformly repeated view is that a 'good teacher' changes everything. One good teacher, alone, can make a bad lot tolerable and make achievement, in what is seen to be an otherwise repressive, oppressive environment, seem possible. (p. 241)

Notably, in this excerpt and throughout his article, Slade not only referenced boys' focus on authentic caring relationships, but also used language invoking the politics of resistance, including terms such as "power," "repressive," and "oppressive." Slade found that teachers labeled as "bad" were often perceived as power hungry, boring, and overly authoritarian, while teachers labeled as "good" were often perceived as respectful, engaging, highly transparent, and relaxed enough to laugh and smile. Students 
emphasized that they were more likely to finish a "boring" or difficult activity for a teacher they liked and respected.

\section{Of Love and Learning}

Hayward (1998) moved beyond Noddings' (2013) definition of authentic caring to make a bolder statement: He identified authentic caring using the word "love." Hayward found that while teachers are in a position of authority over students in a traditional sense (characterized by their power to control classroom behavior), such authority also comes with the power to love students unconditionally. Hayward understood that love and related demonstrations of affection can be complex in educational settings, and therefore must be approached with caution. But he also understood that love must be nurtured despite these complications, as the consequences of withholding love and respect are too severe: Withholding love disempowers students, making them feel unworthy of such a response (Hayward, 1998). In fact, loving relationships ultimately have the power to level the metaphorical playing field by minimizing the power imbalance that so often characterizes student-teacher relationships. Loving and authentic caring relationships acknowledge the student's agency, cultural identity, and humanity (Buber, 1965). As Noddings (2005) stated, "Kids learn in communion. They listen to people who matter to them and to whom they matter" (p. 36).

Caring is love. Caring is communion; it is confirmation. It is seeing the best in your students. It is seeing who they want to become and doing everything in your power to help them soar. 


\section{Research Framework: A Qualitative Approach}

I begin describing my research design by drawing on Carr and Kemmis (1986), who made a distinction among three separate forms of educational research. According to Carr and Kemmis, the oldest method of inquiry is positivist. Positivism conceives of education as a system of delivery and assumes that any knowledge gained from research about education is quantifiable and objective. Positivist methodology relies heavily on the scientific method and attempts to reduce complex human interactions to quantifiable data sets. The other two methods of inquiry named by Carr and Kemmis, interpretive inquiry and critical inquiry, both draw from social constructionism and represent important departures from the positivist paradigm. Interpretive inquiry considers school to be a lived experience and relies primarily on interviews and observations to capture participants' lived realities. Interpretive researchers also assume that meaning is socially constructed through interactions between the participants and the researchers (Merriam, 1998). Finally, critical inquiry assumes that school is a social institution designed

primarily for social reproduction, and thus critical research in the field of education critiques the power structures embedded in school systems and often contains a participatory or emancipatory component (Guba \& Lincoln, 2005).

\section{Ontology and Epistemology}

Throughout this chapter, I have drawn on both social constructionist and critical theory frameworks in my discussion of gender and education; therefore, I have chosen a post-positivist paradigm to guide my research. However, there are important differences within the post-positivist paradigms of interpretivism and critical research. For example, 
they are epistemologically at odds in one key respect: where the researcher believes truth lies. Interpretivism leans toward an antifoundational approach, which implies that there are no objective standards by which truth can be understood. In fact, communities negotiate what is accepted as truth through dialogue among community members (Guba \& Lincoln, 2005). By contrast, critical research is much more foundational, which means that critical theorists understand knowledge as embedded within historical, economic, social, and racial structures of oppression. Guba and Lincoln (2005) explained:

Knowers are not portrayed as separate from some objective reality, but may be cast as unaware actors in such historical realities ('false consciousness') or as aware of historical forms of oppression, but unable or unwilling, because of conflicts, to act on those historical forms to alter specific conditions in this historical moment ('divided consciousness'). (p. 204)

In other words, the dominant culture both creates and perpetuates a master narrative that is so normative, it is accepted as truth by the majority of the community. Marginalized groups are either unaware of the power embedded within the dominant culture, or unable or unwilling to change the narrative. Although I have drawn on critical theory in my theoretical framework, my research focuses more on capturing the lived experiences of each of my participants than on any kind of emancipatory action. Therefore, I chose to use an interpretive approach (instead of a critical approach) as the primary foundation for my research methodology. In drawing from an interpretive approach, I was able to leverage the power of the relationships I had built with the young men I work alongside in the interest of co-constructing knowledge with them through individual interviews. 


\section{Bricolage}

In constructing my qualitative research procedures, I drew heavily from Guba and Lincoln (2005), who, as social constructivists, described post-positivist paradigms as fluid and interwoven: "There is great potential for interweaving of viewpoints, for the incorporation of multiple perspectives, and for borrowing, or bricolage, where borrowing seems useful, richness enhancing, or theoretically heuristic" (p. 197). The bricoleur, then, adds tools and frameworks as they become useful to the meaning-making process, rather than assembling them rigidly in advance: it is pragmatic and strategic, depending on the research questions, the researcher, and on the context of the research (Denzin \& Lincoln, 2005). Kincheloe (2001) further expanded on Guba and Lincoln's discussion of bricolage, adding that bricolage is a natural extension of an academic world in which boundaries between academic disciplines have been blurred, and advocated for a deep awareness of the diverse tools available to the researcher. Geertz (2000) described this perspective in similar terms, supporting a researcher's freedom to shape their research design as is appropriate to each individual project:

Freed from having to become taxonomically upstanding, because nobody else is, individuals thinking of themselves as social (or behavioral or human or cultural) scientists have become free to shape their work according to its necessities rather than according to received ideas as to what they ought or ought not to be doing. (p. 21)

In being faithful to an antifoundational ontological stance, and drawing from social constructivist approaches, I have become a bricoleur, drawing from a variety of 
frameworks, depending on how best to answer my research questions, with the ultimate intent of better understanding the experiences of my participants. With this in mind, I define my research methodology loosely as qualitative research, with an interpretive approach that focuses on constructing meaning within a particular context, requiring methods of data collection that are sensitive to that context, to the researcher, and to the purposes of the research (Merriam, 1998). The goal of the qualitative researcher is to capture the varied perceived realities of several individuals, and to understand how those realities are constructed in part by the social environment of each individual. For this reason, my research process was inductive rather than deductive and remained flexible throughout.

\section{Participant Voice}

Guba and Lincoln (2005) named five criteria for "authentic, trustworthy, rigorous, or 'valid' constructivist or phenomenological inquiry" (p. 207). Each of their five criteria were connected to the research participants to some degree, including the inclusion of participant voices, raising awareness in participants, and spurring action with participants. Most critical for my research is Guba and Lincoln's suggestion that all stakeholders' voices should be represented in the text; a balanced inclusion of voices is meant to prevent marginalization of any single group. In addition, such a balanced inclusion of authentic voices enhances the internal validity of interpretive research; knowledge resides in the participant and therefore cannot be proven (as is the case in positivist research), but can be falsified (Popper, 1959). Earlier in this chapter, I defined youth as a marginalized population. For that reason, I am hoping the interpretive methods 
I used in this study will provide these marginalized students with a voice that is often denied to them. In a sense, this is the primary purpose of my study. 


\section{CHAPTER 3: RESEARCH METHODS}

The purpose of this study was to describe how authentic caring relationships are of value to young men at the secondary level who engage in acts of resistance against schooling. Four research questions guided my work:

1. How do young men engaging in resistance strategies at Sherwood High School describe the methods and purpose of their resistance?

2. How do young men engaging in resistance strategies at Sherwood High School describe their relationships with their teachers?

3. According to young men who engage in resistance strategies at Sherwood High School, what are the characteristics of teachers who are skilled at fostering authentic caring relationships?

4. According to young men who engage in resistance strategies at Sherwood High School, what distinguishes caring teachers from uncaring teachers?

As I stated in Chapter 2, I drew primarily from an interpretive approach, with a focus on capturing the perceived reality of my participants. Because interpretive research requires methods of data collection that are sensitive to the participants, to the interests of the researcher, and to the purpose of the research, I used individual interviews to answer each of my four research questions, all of which asked young men about various aspects of their educational experiences (Merriam, 1998). 


\section{Participants}

The primary intended population for this study was young men who engaged in acts of resistance against schooling. To learn more about the experiences and constructed realities of these young men, I interviewed eight study participants individually for up to one hour. As a teacher at the school site where I conducted my research, I relied on my knowledge of the student population to recruit my participants, whom I chose based on several key factors. First of all, because this study was about young men's experiences in a school setting, I only interviewed students who identified and presented as male. Secondly, I only recruited young men with whom I had a strong, positive, and previously-established relationship. Because I was interviewing young men who might have negative emotions regarding school and their teachers, I felt that a previouslyestablished relationship with each participant would be essential to engaging them in a natural and honest conversation. Finally, I identified participants whom I felt had engaged in resistance strategies against schooling. This meant I sought students whom I had witnessed regularly demonstrating any of the following behaviors: off-task behavior, reluctance to complete class work, aggressive behavior towards staff members (including flipping teachers off, walking out of class, and cursing in class), tardiness, talking out of turn during class discussions, skipping class, or turning homework in after the deadline. I began identifying a pool of potential participants by brainstorming a list of students I knew who fit within the aforementioned criteria. I primarily recruited participants from this list by stopping to speak with them when I passed them in the hallway, or when they visited my classroom to chat about other topics of the day. The hallway ended up being a 
rich source of potential participants - as I moved through the hallways during my day, I often encountered a new potential participant to add to my list whom I had not originally considered for this study. Overall, this process yielded a list of 20 potential participants.

Recruitment. Because each of the actions I identified as acts of resistance can have multiple potential causes beyond resistance (a parent living with a chronic illness, for example, can make it challenging for a student to arrive to school on time), I did not want to assume these students were engaging in resistance strategies against schooling. As such, when I approached each potential participant individually, I explained the focus of my study and allowed them to determine whether they fit into my criteria: "I'm working on a research project where I'm interviewing young men who engage in resistance strategies against school. Do you feel like you fit that description?" Most of the young men I approached agreed immediately, although several of them wanted to know more about what I meant by "resistance strategies." I explained that I was thinking of behaviors such as showing up to school late, not completing homework, talking back, or skipping class. Incidentally, every young man I approached agreed that they fit the description of a student who engaged in resistance strategies against schooling (some of them even smiled enthusiastically as they accepted my invitation: "Yes! That's me!"). Once they affirmed that they fit my criteria and were interested in participating in an interview, I explained that I would simply find a time to interview them within a short period of time, and we would discuss how they felt about school and their teachers.

Those students who expressed an interest in participating were given a statement of informed consent (see Appendix A), which both the participant and a parent or legal 
guardian signed before the interview. For ethical reasons, I did not interview students who were enrolled in any of my classes, either during that trimester, or in future trimesters. Because my students at the time of the interviews were all freshmen and sophomores, I made the process of participant selection simpler by only inviting juniors and seniors to participate. After receiving informed consent documents, I consulted each potential participant about their availability during the school day and scheduled the interview. To avoid any disruption to their learning, I required all participants to have availability during a "free period" such as late arrival, early release, or teacher's aide (TA).

Of the original list of 20 potential participants, I ultimately interviewed eight young men. The remainder of the participants were essentially unavailable for interviews. For example, I was unable to interview several potential participants because they did not have the required free period for the interview. I was also unable to track down several potential participants after our initial conversation about the project, as they were frequently absent from school. Finally, several potential participants simply did not return their statements of informed consent. Once I approached the point of saturation with my data, I stopped following up with students who had not yet returned their forms or whom I had unsuccessfully attempted to track down.

Sample size. The final sample size of eight participants was close to my initial target number of ten. I felt that eight interviews were enough to create a functional data set that would not constitute an overwhelming amount of data to analyze for this dissertation. Furthermore, once I had completed each of the eight interviews, I was 
satisfied that I had reached a point of data saturation. I used three criteria to determine saturation. First, the interviews generated over 100 pages of notes and transcripts, through which clear patterns in the stories of each of the participants began to emerge. Second, I felt that eight interviews provided enough data to answer each of my research questions. Finally, the rich quality of the data gathered from each interview further ensured that I would have many layers of meaning to explore in my dissertation.

Vulnerable populations. It is important to note that three of my participants were legal minors below the age of 18 at the time of the interview and all of them were students enrolled at the research site. As minors and students, these young men constituted a particularly vulnerable population. To protect the participants' identities, I chose pseudonyms to identify them in the interview transcripts and in this dissertation, and because names are an important factor in an individual's identity, I clearly explained to them why their names would be changed. I also used pseudonym initials for individuals such as teachers or other students who were incidentally mentioned during the interviews. The coding key for the pseudonyms was stored separately from the transcripts on a password-protected document and that key was later destroyed. Finally, I also refrained from using any highly specific details (such as specific course names or content areas) in my dissertation that would allow readers to identify a particular participant or teacher. 


\section{Research Site}

Sherwood High School is a comprehensive, suburban high school serving more than 1700 students in grades 9-12. The student body is predominantly White and middle class, with a growing Latino population and a large economic divide between rural working-class families and more economically privileged, middle-class, suburban families. The school regularly returns some of the strongest educational indicators in the state of Oregon, including high graduation rates and strong standardized test scores. The school enjoys strong support from the community of Sherwood and sees little year-overyear turnover in staff.

I am currently a full-time English teacher at this school, and it was in the context of my work there when I first began to wonder about the connections between the boy debate, masculinities, resistance, and student-teacher relationships. Because I teach at Sherwood High School on a full-time basis, conducting this research in such a familiar context provided me with immediate access to the building and the benefit of wellestablished relationships within the school setting. Likewise, I am deeply familiar with a wide range of contextual factors that play into the school-based experiences of the students participating in this study.

\section{Methods and Procedures}

I used an interpretive research model that would represent my participants' voices as authentically as possible, in part because my participants were youth whose voices are frequently overlooked in educational research. To that end, my inquiry had to remain 
responsive to my participants and make room for procedures to evolve as the project progressed. However, I recognized that flexibility does not preclude a well-supported research design (Hammersley \& Atkinson, 1995; Lincoln \& Guba, 1985); Maxwell (2013) used the term interactive to describe a research design that is both strategically structured and inherently flexible. I created an interactive research plan that involved a variety of interviews, but also conceptualized a plan that would remain elastic and open to change. That flexibility ended up being a critical factor in my study, because, while I had initially planned on using both focus group interviews and individual interviews, I found that scheduling focus group interviews in a way that did not interrupt the participants' school day was nearly impossible, so I chose to cancel the focus group interviews and proceed solely with individual interviews.

\section{Interviews}

Maccoby and Maccoby (1954) defined an interview simply as a "face-to-face verbal interchange, in which one person, the interviewer, attempts to elicit information or expressions of opinion or belief from another person or persons" (p. 449). Mishler (1986) countered that interviewing is actually a much more complex undertaking in that interviews are a form of contextually dependent discourse mutually constructed by both the interviewer and the participant. Talk, Mishler argued, is governed by the same complex and contextually dependent rules that govern all other social interactions, meaning that interviewees take cues from the interviewer about which responses are appropriate within the context of the interview. Therefore, in qualitative studies, the researcher's relationship with each participant is complex and sensitive and can either 
facilitate or hinder the research process (Maxwell, 2013). In this way, the procedures I chose for my interviews had a strong impact on the outcome of those interviews: they were the procedures most likely to result in open, safe, and honest conversations facilitated by the interviewer, rather than controlled by the interviewer.

Focus group interviews. I originally planned to begin my data collection process by conducting focus group interviews. Focus groups can be beneficial in that they can stimulate critical thinking by helping participants socially construct new ideas and challenge existing ones (Wibeck, Dahlgren \& Oberg, 2007). But because reality is socially constructed (Kimmel, 2013), the social dynamics of focus groups are complex; therefore, participants will express themselves differently depending on the mood in the room, which is impacted by a variety of factors, including the time of day, the location, the participants' relationships with the interviewer and the other participants, and the moods of the individual participants at the time of the interview (Merriam, 1998). Because group interviews are such a socially complex phenomenon, I intended to use them not as a primary research tool, but as an exploratory tool meant to orient myself with salient themes around engagement and resistance. I also planned to use group interviews to identify what Merriam (1998) called informants for individual interviewsparticipants who understand the culture and are both willing and able to comment on it. As I was scheduling interviews, however, I quickly realized just how logistically complex it would be to gather enough participants for a group interview without interrupting anyone's school day. Therefore, I abandoned my plans to hold focus group interviews and chose instead to proceed directly to individual interviews. However, engaging with 
participants in a focus group setting would have allowed me to experiment with question types, listen to a wider range of voices, and identify informants for individual interviews, and eliminating them meant that I would be less certain of who would be a good informant, and less confident with my questions in my individual interviews.

Individual interviews. As I stated earlier in this chapter, I identified participants according to who had indicated, either through my observations of their behavior or through their own commentary, that they regularly engaged in resistance strategies in school. They were also individuals who appeared to be willing and able to articulate their experiences in school. I interviewed eight students in total for 25-50 minutes each.

Because I asked my participants to describe their experiences with school and their teachers, protecting their privacy was an important ethical concern. Therefore, I conducted all interviews in a small office that provided a private, neutral space on school grounds. Identifying and then using this office was challenging because most spaces are constantly occupied by students or staff during the school day, but I ultimately found a small office that I could reserve in advance. Because the school administration discourages teachers from being alone with students, I chose to use a private office used frequently for testing, which features viewing windows and connects directly to a larger faculty office, yet afforded the privacy and confidentiality required for participants to talk about sensitive issues without being overheard by other students or school staff.

Ethically, it was important to schedule interviews during a time of day that did not interfere with the participant's other responsibilities as a student, employee, athlete, club member, or family provider. Therefore, each interview was scheduled during a free 
period in their day, whether it was during a teacher aide (TA) period when the teacher did not require the participant's services, or during an "early release" or "late arrival" period when the participant could spare a bit of time for the interview. Additionally, each interview was audio recorded to ensure faithful transcription of the participant's words and ideas. Prior to asking the first interview question, I made it clear (both orally and through the informed consent document in Appendix A) that I would record the interview for transcription purposes, but any personally identifying information would be kept confidential.

The researcher is the primary instrument in a qualitative study; therefore, the establishment of trust between the researcher and the participants was a key component in my qualitative research design. In each of my interviews, my first task was to establish an environment of mutual respect and safety, reminding participants that any information provided during the interview would remain entirely confidential and that pseudonyms would be used in transcribed documents, personal notes, and the final dissertation. I notified each participant of their right to refuse to answer questions and reiterated that they should feel comfortable stating their beliefs openly, without fear of negative repercussions. I also reminded them that I was a mandatory reporter and as such, I was required by law to report any concerns I had about participants who were being abused, who were harming themselves or in danger of harming themselves (through self-harm, suicidal thoughts, or drug abuse), or who appeared to be in danger of harming others.

According to Lincoln and Guba (1985), establishing and reinforcing trust in an interview is a developmental process - the level of trust is fluid and changes in response 
to elements such as the questions asked, the mood of the participant, and the researcher's body language and verbal responses to the participant. The structure of the interview is one key element in the establishment of trust because it helps set the tone (Merriam, 1998); I engineered my interview protocol (see Appendix B) to provide the necessary structure for the early stages of each interview, while allowing enough flexibility for natural conversation to develop (Merriam, 1998). The first question I asked was specifically intended to break the ice: "Do you like school?" From there, the conversation progressed organically, according to the interests and experiences of both the participant and the researcher (Merriam, 1998). To accomplish the fluid conversation I was aiming for, I asked mainly open-ended questions designed to encourage the participants to explore their own experiences with resistance, school, and student-teacher relationships, and often used follow-up questions to probe interesting lines of thought. I also asked a few questions intended to provide some basic background information on the participant's academic performance, such as their grade point average (GPA), and their strongest and weakest subjects.

\section{Researcher Memos}

Maxwell (2013) recommended using researcher memos throughout the research process to encourage reflection and analytic thought. Regularly keeping memosincluding reflective journal entries and summaries of the day's research — allowed me to evaluate my assumptions, record my realizations, and resolve the problems and questions that inevitably arose during the research and writing phases of my work. I wrote researcher memos throughout the data collection and data analysis phases of my research. 
Merriam (1998) noted that the researcher is the main instrument for data collection and analysis, and their identity as a researcher is therefore central to the investigative process. For that reason, I also used memos to interrogate my own positionality as a White, middle class, academic adult woman. I am aware that this positionality has provided me with a particular perspective and a particular set of privileges that are virtually invisible to me if they are not critically examined. Although the qualitative researcher can and should acknowledge their researcher identity, they must also be self-critical throughout the process, so keeping critical researcher memos helped me examine the assumptions I was making about my participants and ask deeper questions. Although I kept regular researcher memos, I used them primarily for reflective purposes. For that reason, I did not code my memos, nor have I referenced them in any meaningful way in this document.

\section{Research Timeline}

Because I am a full-time teacher-researcher, much of my project timeline was dictated by the rhythms of the academic year. I gathered interview data between the months of March and May 2017. I was initially concerned that spring sports and field trips, combined with state testing, would make those months exceptionally busy, but it was relatively easy to find mutually agreeable times to interview each participant. All participants were able to find a time during a TA period within the school day (with explicit written permission from their supervising teacher), so they could speak with me without interrupting any other activities or obligations. I interviewed each participant once, for a time period that ranged from 25 to 50 minutes. As soon as I collected the data, 
I started the transcribing and coding process, and I began to keep research memos at that time as well.

\section{Ethical Considerations}

Qualitative inquiry generates some ethical challenges, mainly because most of the data in a qualitative study originates through human respondents relaying information through highly personal means, such as through stories, rather than through less personal means such as anonymous surveys (Lincoln \& Guba, 1985). Adding a layer of complexity to this study is my positionality as a teacher at the research site, and the positionality and vulnerability of the research participants as students and minors. All of these circumstances offered a number of ethical dilemmas that I will address in this section.

\section{Informed Consent}

Because most of my participants were legally minors and all of them were students at my workplace at the time of the study, I needed to be deliberate in seeking informed consent. Regardless of the participant's age, both the participant and a guardian signed an informed consent document, which clearly explained the participant's rights during and after the study, what mechanisms I used to protect their identity, and what (if any) harm might be caused by participating. It was important that the participants' parents or legal guardians understood and approved of the research I was conducting, but their approval did not necessarily constitute complete and unfettered access to their child's interview transcripts. Any parent request to review transcripts would have 
required the participant's consent to release the data. A copy of the informed consent document can be found in Appendix A.

\section{Positionality of the Researcher}

One of the most important concerns during this study was my positionality as a teacher; the participants of my study were students in the school where I worked and where I conducted my research. Regardless of how well developed my research procedures were, it was simply impossible to avoid an asymmetry of power in the interviews. To minimize that asymmetry, I did not accept participants who were enrolled in or registered for any of my classes during the remainder of the academic year. Because all of the students I was teaching in the second and third trimesters were underclassmen when I conducted my research, I simply did not accept underclassmen as participants in this study. However, despite these concerns about my positionality as a person of power in the lives of my participants, I believe the relationships I cultivated with each of my participants prior to their interview facilitated rather than hindered authentic conversations.

In addition to my concerns about my positionality with the participants, I was also cognizant of my positionality with my colleagues. While gathering data, I maintained an atmosphere of mutual respect with my colleagues by communicating with them clearly throughout the research process while prioritizing the confidentiality of the participants. A small number of staff members were curious about my research and I received several inquiries about what I was learning. Because participants inevitably made personal statements about their teachers and because I have an ethical obligation to protect 
participant identities and maintain privacy regarding the information they provide, I did not share any raw data with any district staff member. I also anonymized the identities of any teachers mentioned by the participants by assigning pseudonyms and leaving out specific details about course names. At the discretion of my building principal, I may eventually present some key conclusions to staff members, without presenting any personally identifying information. Sharing my findings would be a key step towards discussing the impact of relationships on our students and is one potentially strong outcome of this research project.

As mentioned in a previous section, one key factor in my positionality is my awareness of my personal lens as a White, middle class, academic adult woman and the set of privileges and perspectives embedded in that lens. In fact, my perspective is radically different from that of my participants, so some of the interview questions I asked were intended to support my understanding of the role of gender, race, and class in the construction of participant perspectives and identities. And although I did come to this research as an academic, most students know me as "Ms. Wegg," so I believe their familiarity with me as a supportive member of the greater learning community overrode any intimidation or trepidation they might feel in divulging personal details to an academic researcher. The candor of the participant responses throughout each of the interviews reflects the power of our established relationships. In fact, on completion of their interviews, several participants even smiled and exclaimed, "That was a lot of fun!" In preparation for my interviews, I reviewed a great deal of literature regarding the nature of resistance, caring, masculinities, and other related theoretical frameworks; 
however, my understandings of this literature cannot override the value of my participants' voices. My hope is that by staying true to the words of my participants and keeping frequent self-critical researcher memos, my positionality did not unnecessarily compromise the quality of my data collection or my analysis of that data.

\section{Data Security}

I kept all electronic data on my personal laptop, which was password protected and stored at home on days when I did not conduct onsite research. Any written data or electronic devices that were not password protected (including audio recording devices) were kept in a locked cabinet in my classroom. During the transcription process, I coded raw data to protect the identity of each participant and stored the codes in a separate, password-protected document.

\section{Data Analysis}

Systematic transcription procedures are necessary for valid analysis of interview data (Mishler, 1986), so I created a system of transcription to accurately capture not only the dialogue, but also any perceived emotions (uncertainty, frustration, anger, and happiness, for example) present in the voices or the body language of the participants. Such transcription required a coding system that accounted not only for speech, but also pauses, redirections, and body language. Because I audio-recorded each interview, I took notes on body language during the interview so I could revisit that data during the coding process. Furthermore, in the interest of maintaining privacy for my participants, 
remaining close to my data, and maintaining control over my coding system, I transcribed all interviews myself.

Describing the data analysis process as cyclical, Lincoln and Guba (1985) suggested engaging in four interwoven analytic stages: unitizing, categorizing, filling in patterns, and member checks. Unitizing refers to locating key incidents—or "units"amongst the various documents and recording those units on index cards or in a word processing program. Each unit should be coded in multiple ways-for example, according to the type of participant or respondent and the source of the data. This step may likely generate large numbers of units, leading to the next step: categorizing, in which the researcher identifies larger categories and sorts the individual units into those categories. During the process conflicts, contradictions, and anomalies emerge, causing the researcher to revise the rules for a category, create new categories, or rearrange existing categories. Once categories are complete, the researcher should fill in the categories by reviewing them, looking for overlaps or connections between categories, and attempting to categorize events that do not yet fit existing categories. The process, then, is a fluid and cyclical one, with codes and categories emerging from what appears to be important in the raw data, then being reconfigured as necessary (Maxwell, 2013). A member check is the final step of this data analysis process, in which the researcher verifies that the reconstruction of the participants' words and actions have been authentic and reliable in the eyes of the participants.

A code in qualitative data analysis is generated by the researcher with the intent of capturing the meaning of raw data (Saldaña, 2016). In other words, a researcher's job is 
to essentially create context for the participants' responses by seeking patterns within the data. Mishler (1986) noted that the quality of the coding manual is essential to the successful interpretation of participants' responses, and during the coding process, the researcher relies on their own prowess as language users. In fact, the codes a researcher chooses to use will reflect both the constructs and theories they used to structure the study, as well as the researcher's own subjectivities (Saldaña, 2016).

Codes can be separated into two distinct categories. Emic categories are those that represent the understandings and constructions expressed by the participant, while etic categories represent the researcher's understandings and constructions (Lincoln \& Guba, 1985; Maxwell, 2013; Merriam, 1998). Because one major goal of interpretive research is to integrate the participants' personal experiences with relevant theoretical frameworks and the researcher's understandings, I used both emic and etic categories in the coding and sorting process.

During the research process, I systematically coded data from the interview transcripts, beginning as soon as I collected the data, and continuing well beyond the data-gathering phase of this study. Because one important goal of this study was to amplify the voices of the young people participating in my study, I used In Vivo coding, or coding using participant-generated language, during the first and second cycles of coding. To connect raw data to theoretical frameworks, I relied heavily on concept codes. As Saldaña (2016) suggested, I used emotion and values coding for exploring social relationships. Finally, causation coding helped me understand what my participants believed about the relationship between a cause, which in this case was school-related, 
and an outcome, which in this case was related to observable resistance behaviors. I coded much of my data on printed copies of transcripts or using Microsoft Word and then used a spreadsheet to categorize the coded units.

Some researchers argue that coding is a reductionist process that distances the researcher from their participants and enacts a symbolic violence on participants' words and stories (Saldaña, 2016). While I believe it is critical to remain close to the participants and remain faithful to their constructions of reality, I also believe that coding is a fundamental part of any process involving reading for meaning. As an English teacher, I spend much of my time "coding" texts during the process of literary analysis. I find that such a process prompts me to draw closer to my texts, to listen more purposefully, and to think more clearly. The coding process in qualitative research can have much the same value, if done purposefully and with the participants' voices in mind.

\section{Evaluation of Research}

The interpretive paradigm holds that meaning emerges from the research process. While validity is not a central concern in interpretive research, I have identified several methods and procedures that may strengthen the interpretation of my data. This may include member checks, prolonged engagement, rich data, and theoretical frameworks.

\section{Reflexivity}

Interpretive inquiry draws from social constructionism in that it conceptualizes schooling as a lived experience and relies primarily on interviews and observations to capture participants' lived realities. Interpretive researchers also hold that meaning is 
socially constructed through interactions between researchers and study participants (Merriam, 1998). However, one clear limitation of the interpretive framework is that it does not acknowledge the potential impact of dominant power structures on the constructed realities of the participants and the researcher. Because I occupied dual roles as a teacher and researcher at the time of my data collection, the impact of my potential dominance over the youth I interviewed was a key concern for me and I was wary of what Lincoln and Guba (1985) called “distortions” of data arising out of the researcher's positionality, including: bias, assumptions, errors in data gathering techniques, or even the researcher's presence at the site. My goal, therefore, was to monitor the potential impact of my dominance, rather than attempting to dismiss or eliminate it. Guba and Lincoln (2005) called this approach reflexivity: the "conscious experiencing of the self as both inquirer and respondent, as teacher and learner, as the one coming to know the self within the processes of research itself" (p. 210). Sensitivity to both my own subjectivity and my inherent dominance as a teacher and researcher, and to the constructed realities of my participants, helped me stay faithful to telling their stories accurately. I monitored my own subjectivity by keeping critical researcher memos to help me recognize distortions arising out of my positionality as a dominant figure in the interview.

While interpretivism makes space for the researcher to interpret the understandings of the study participants and co-construct reality, it is still possible that respondents may choose to answer questions and participate inauthentically in the dialogue in an effort to please the researcher or to confirm what the respondents think the researcher wants to hear. For this reason, Fontana and Frey (2005), advocated for an 
empathetic response to participants, since empathy allows the researcher to bridge the gap between the constructed realities of the participants and those of the researcher. This empathy becomes particularly important when participants discuss sensitive issues implicating other students, other study participants, or staff members. Throughout the interviews, I demonstrated empathy by confirming the validity of each response through verbal cues such as, “That's interesting. Tell me more." and "Ah. That makes sense." I provided visual cues of my engagement by nodding my head and taking written notes. Finally, I looked for any suggestion that participants were wary of what they could or should say in the interview. When they hesitated during a response or asked if they were allowed to use certain language, I reiterated that they should express themselves authentically. Since it was essential that participants be comfortable expressing the full range of their opinions in front of an adult and a teacher, I also avoided taking sides on any issues, including affirming or contradicting participant opinions about other staff members, or arguing about statements I disagreed with. I recognize that this is a controversial stance to take when implementing an interpretive approach. However, the setting of the interviews for this study was imbued with power structures inherent in formal schooling environments. Therefore, I took steps to mitigate these power structures, allowing authentic conversation and construction of meaning to happen.

I also took several other steps to minimize the ethical implications of my positionality as a teacher-researcher. I did not accept any participant for my study who was (or would be) enrolled as a student in any of my classes. I also safeguarded participant identities by using pseudonyms and withholding details from teachers or staff 
who were curious about my findings. Finally, participants needed to feel safe

withdrawing from the study without negative repercussions, which is a protection clearly promised to participants in the informed consent document they signed before participating (see Appendix A).

\section{Member Checking}

One imperative method of strengthening the interpretation of data in a qualitative study, especially one whose goal is to amplify the voices of a marginalized group, is to conduct member checks. Lincoln and Guba (1985) explained:

The investigator is to be able to purport that his or her reconstructions are recognizable to audience members as adequate representations of their own (and multiple) realities, it is essential that they be given the opportunity to react to them. (p. 314)

Member checks, then, are opportunities to assess the findings of something as small as a single interview or something as large as the entire study. They give participants the opportunity to correct researcher errors, suggest potential alternate interpretations, and assess the overall quality of the data and the analysis (Mishler, 1986). In my study, I had planned for member checking to constitute its own, final round of informal conversations, during which insights and responses from participants would be compared with my formal analysis of that data. Unfortunately, the data analysis and writing stages of my dissertation took longer than anticipated and by the time I was ready to conduct member checks, all of my participants had graduated and moved on; therefore, I was unable to conduct any member checks of my research. 


\section{Prolonged Engagement}

A strong familiarity with the culture of the research site can only be achieved by a prolonged engagement with it (Lincoln \& Guba, 1985). Such a familiarity with participants (as well as their comfort and familiarity with the researcher) facilitates an openness to speak authentically and candidly during interviews. At the time of this study, I had been a teacher for over seven years within the school where I conducted my research. Therefore, I was very familiar with the context of the school environment and enjoyed a healthy relationship with each of my participants. The deep contextual understanding of the culture of my research site helped me understand the cultural forces at work within my participants' school lives.

\section{Rich Data}

Recording interviews and transcribing them accurately, as well as taking descriptive notes during interviews, helps the researcher avoid implicit bias and helps them confirm participant statements (Merriam, 1998). As I have stated, I audio recorded each interview and I fully transcribed the individual interviews myself. I also took notes during each interview to record the context of the conversation, to enhance reactivity, and to help me filter my thoughts as the interview progressed.

\section{Theoretical Frameworks}

The interpretation of data is enhanced when it is consistent with existing theoretical frameworks (Lincoln \& Guba, 1985). In Chapter 2, I drew from a variety of theoretical frameworks - including gender theory, resistance theory, and caring theoryto frame this dissertation and the early thinking for my research data itself. Using existing 
theoretical frameworks to support my interpretation of raw data was particularly important, considering the limited sources of data for this study, as data from interview transcripts have not been triangulated with other potential forms of data such as observations.

Unfortunately, data from interviews can be challenging to interpret because it may be contradictory at times, and although it often represents an authentic personal truth, it does not always represent an understanding of deeper, subconscious cultural structures such as gender constructions. Willis (1977) described this problem clearly:

Direct and explicit consciousness may in some senses be our poorest and least rational guide. It may well reflect only the final stages of cultural processes and the mystified and contradictory forms which basic insights take as they are lived out. Furthermore, at different times it may represent the contradictory moments of the cultural conflicts and processes beneath it. In this, for instance, it is unsurprising that verbal questions produce verbal contradictions. Not only this but practical consciousness is the most open to distraction and momentary influence. (p. 122)

Willis added that consciousness is an important form of self-expression, but must be contextualized and understood as only one moment and only one piece of a complex and variable puzzle. For this reason, all verbal questioning strategies (including interviews), however well designed, suffer from the same internal flaw: they are incapable of distinguishing between comments which are truly honest and revelatory from those made out of sheer politeness toward the interviewer, or in mimicry of others, or as attempts to 
adhere to cultural norms. Connecting interview results to existing data and theoretical frameworks helps the researcher make sense these varied responses.

\section{Study Limitations}

There are several key limitations to this study. First of all, I conducted my research in a single high school, through interviews involving eight participants. Working with such a small sample size limits the study's generalizability. That being said, I used an interpretive framework in part because I wanted to amplify the voices of my participants. In that sense, this research is not meant to be generalizable; rather, it is meant to amplify the voices of my participants, which are necessarily different from the voices of other students who have different lived experiences and different constructed realities.

Secondly, my participant selection was restricted by the realities of conducting research in a public-school setting. All participants had academic schedules, teachers, and parents that were supportive of their participation in the interviews and such extraneous factors limited my available pool of participants.

As explored in the previous section, a third limitation to interviewing as a research method is that data collected from interviews is essentially one person's statement about one particular topic at one particular moment. It does not necessarily reflect the participants' true views or behaviors, nor does it represent the full range of a person's experience; reality, after all, is far too complex to summarize in a single conversation (Maxwell, 2013). Therefore, generating conclusions based on the 
participants' lived realities requires a great deal of inference on the part of researcher, a disciplined understanding of the extant literature, and a carefully designed research process and coding manual.

\section{Conclusion}

Precluding any inferences or research designs or theoretical constructs, however, is the need for the researcher to have empathy for their participants, endeavoring to not only understand what the participants are saying, but also, to the greatest extent possible, understand reality as the participant (Bentz \& Shapiro, 1998). In this way, interviewers become co-creators of truth and meaning. It is my hope that I have listened to my participants with empathy and care and that I am able to authentically represent their voices in Chapters 4 and 5 of this dissertation, speaking with them and through them, rather than for them. 


\section{CHAPTER 4: FINDINGS}

The purpose of this study is to investigate how authentic caring relationships are of value to young men at the secondary level who engage in acts of resistance against schooling. To accurately capture participant voices, I used an interpretive approach in which I collected data from eight individual interviews with male high school students, ranging from 25 minutes to 50 minutes in length. After those interviews, I transcribed the audio recordings, coded the data using primarily thematic and In Vivo codes, and then analyzed the patterns that emerged. Furthermore, I used the theoretical frameworks discussed in Chapter 2, such as masculinities theory, caring theory, resistance theory, social constructionism, and social exchange theory to support my data analysis and inquiry.

In this chapter, I address the four research questions that guided this study:

1. How do young men engaging in resistance strategies at Sherwood High School describe the methods and purpose of their resistance?

2. How do young men engaging in resistance strategies at Sherwood High School describe their relationships with their teachers?

3. According to young men who engage in resistance strategies at Sherwood High School, what are the characteristics of teachers who are skilled at fostering authentic caring relationships? 
4. According to young men who engage in resistance strategies at Sherwood High School, what distinguishes caring teachers from uncaring teachers? However, rather than answering each question in turn, I answer the questions holistically throughout this chapter and organize my findings within thematic categories. I do so in the interest of remaining faithful to the salient themes that the participants and the researcher co-constructed during the interviews. In this way, Chapter 4 centers on the voices and lived experiences of this study's participants.

\section{Participant Profiles}

I interviewed eight participants for this study. The participants were all young men who engaged in resistance strategies against schooling, which means that at some point in their high school careers, the participants demonstrated behaviors that contradicted the expectations of their teachers, both in terms of academic performance, and in terms of classroom behavior. It is important to note that each study participant independently identified himself as a student who engaged in resistance strategies against schooling before he was aware of the purpose of the study.

Incidentally, many of the participants were familiar with each other at the time of the interviews and several participants were even close friends. Because of their familiarity with one another, some of the participants referenced other participants during their interviews. I will describe each of the participants below, identified with pseudonyms to protect their identity, as they were considered members of a vulnerable population when I interviewed them. 


\section{Ryan}

Ryan was a senior in his final term of high school when I interviewed him. He was my student in two different writing classes: one during his junior year, and the other during the first trimester of his senior year. Ryan was staunchly and proudly conservative and felt that too many of his teachers attempted to advance a liberal political agenda in their classes. Ryan and I often discussed politics, but despite my liberal perspective, he said that he enjoyed our conversations, since he did not feel that I was trying to indoctrinate him.

Ryan had many interests outside of school. He was a passionate supporter of the military and enlisted in the U.S. Army as soon as he was legally eligible to do so. He enjoyed shooting and collecting firearms and he was well-educated on the 2nd Amendment. He was also an athlete throughout his high school career, playing both football and lacrosse, and trained at a local mixed martial arts (MMA) gym.

Academically, Ryan said that he succeeded best in classes that included active and hands-on learning opportunities, such as welding and physical education, and struggled the most in more academic classes where teachers were very rigid in their pacing and grading practices. In terms of grades, he was never considered at risk of leaving high school without a diploma, but he did need to retake several classes he had previously failed in order to graduate on time. I would describe Ryan as outspoken, independent, and persistent. 
Jared

Jared was a junior when I interviewed him. I knew him well, as I was his teacher for a full year of English during his sophomore year, and his friend group frequently gathered in my classroom before class started in the morning. He was from a workingclass family that owned a local landscaping and construction company, and he proudly spent most school holidays working full time for them. He was also interested in cars and trucks and often talked about the new truck he wanted to buy and would provide great detail on his plans to modify it: lift kits, roof racks, flood lights, bigger tires; he was always planning a new and exciting project. He also spent a lot of time talking about his father, whom he greatly admired.

At the time of the interview, Jared planned on living at home for a few years after graduation. He felt that living with his parents would allow him to study business at a local university and help him save money for a new truck and his first home. However, based on our frequent early-morning conversations, I got the sense that Jared struggled to understand the balance between saving hard-earned money to buy a house and spending it impulsively on big-ticket item such as car stereos and speedboats.

Jared struggled academically, entering his senior year with a 2.0 GPA. However, he was always on track to graduate on time and had never failed a class. I would describe Jared as outspoken, confident, and hard-working.

\section{David}

I was David's writing teacher during the first trimester of his senior year. We shared similar political leanings and we bonded over the politically heated atmosphere of 
the 2016 presidential election cycle. David was very social and enjoyed getting to know new people, although he had moved schools and homes quite a bit over the course of his life. David was closely connected to his family and voiced a strong appreciation for the support they offered him throughout his life. He was especially close to his mother, and spoke frequently about his brother, who had special needs.

David clearly enjoyed connecting with his teachers during his senior year, although he said that he had struggled through difficult relationships with many of his teachers in the past. In fact, his educational journey changed dramatically as he entered high school, when he found it easier to engage in his classes and to connect with his teachers. His grades varied widely in high school; he often received $B$ 's and $C$ 's, but also received the occasional $A$ and $D$ (especially in subjects where he struggled, such as math). I would describe David as a light-hearted, happy, and introspective person.

\section{Jack}

I knew Jack well at the time of his interview. He had been my student for a full year during his sophomore year and he had also served as a teacher's aide for me during his junior year. Additionally, I was his writing teacher during the first trimester of his senior year. Even when he was not taking one of my classes, he tended to visit my classroom every now and then to say hello.

Jack was very close to his family, especially his younger sister, his maternal grandfather, and his mother. However, for much of his life Jack struggled through a challenging, but functional relationship with his father, who lived with an addiction to alcohol. His mother owned a construction business, where he worked for several years 
during high school. In fact, Jack observed her working hard and struggling through the recession of 2008 and he spent long hours during his summer vacations working alongside her, pouring concrete and laying rebar in the hot sun. This work experience instilled in him a healthy understanding of the value of money and convinced him that he did not want to be a laborer for the rest of his life.

After high school, Jack attended community college in a different part of the state to study business. When he started college, he moved out of his parents' house and lived with several close friends from Sherwood. His friends were an important part of Jack's life, and he tended to function as a big brother to many of them. He had been close friends with participant Cade (described below) for years. However, their personalities clashed frequently when they were in high school, as Jack felt that he had matured more quickly than Cade.

Jack was a large young man at 6'1" and 220 pounds. During his high school years, he played football and wrestled. He also saw his physical size as an important personal characteristic, as he believed it afforded him a certain amount of power within his peer group. He was observant and quite adept at expressing the peer dynamics and school relationships that guided his life, both socially and academically. I would describe Jack as loyal, hard-working, and realistic.

\section{Cade}

Like Jack, I knew Cade well, in part because I was his teacher in a small academic intervention class during his sophomore year. Small, yearlong classes meant that I often developed strong relationships with my students, and Cade and Jack were no exception. 
Cade moved to Sherwood High School during his freshman year, which was a year of great transition for him. He made the football team that fall, and it was during the time spent with his teammates when he first heard his peers talk about mature topics he had never before explored: girls, sex, and drugs. He then began to experiment with activities he knew were against his parents' rules, which ultimately caused a lot of tension at home.

By his sophomore year, Cade was frequently attending classes under the influence of marijuana. He then started skipping school, experimenting with harder drugs, and having unsafe sex. This behavior escalated the severity of the conflicts at home, culminating in explosive confrontations with his parents, especially his father who had strict expectations for Cade. As a result, Cade's family decided to enroll him in a residential program with a quasi-military structure developed for youth who were at risk of leaving high school without a diploma.

Cade agreed to attend the program and was away from Sherwood for nearly a year. He credited the program with helping him feel accomplished, responsible, and proud of his strengths and capabilities, and he returned to Sherwood High School at the beginning of his senior year with a healthy new work ethic, a new respect for his family and his sobriety, and a new vision of his future. Although he was failing multiple classes during his sophomore year, he was able to catch up on the credits he needed for graduation during his time in the residential program and earned $A$ 's and $B$ 's during his senior year. I would describe Cade as daring, sensitive, and loyal. 
Sam

Sam was from a supportive family that maintained a strong focus on education. Most of his immediate family, including his parents and his sister, attended competitive four-year colleges and Sam had always intended to do the same. And while he certainly valued education and the power of critical thinking, he did struggle to fit into the traditional classroom environment, not in terms of academics, but in terms of having the motivation to strive. He frequently struggled to finish his coursework in high school, experiencing significant highs and lows in academic achievement. He easily earned $A$ 's in classes that engaged him, yet he often struggled to complete work in classes that did not engage him, resulting in several C's and D's on his transcript.

Sam was complex young man, whom I found to be uniquely sensitive to others, as well as highly introspective. He was ethnically Jewish and was raised to observe Jewish cultural traditions, but he chose to attend a Christian church during his high school years. He considered himself to be open-minded and fairly liberal, so he enrolled in a conservative Christian university where he could grow in an environment with people who shared his faith, yet likely did not hold the same political beliefs as he did. I would describe Sam as intelligent, intense, and inquisitive.

\section{Riley}

I met Riley at the beginning of his senior year of high school, when he worked as a teacher aide (TA) in my classroom. Riley greeted me every day with a laugh, a smile, and a high five. He was a constant jokester, who liked to laugh and have fun, often pushing the boundaries of what was appropriate. Since elementary school, his sense of 
humor had caused many conflicts with his teachers and coaches; he believed they frequently misinterpreted his laid-back attitude as a sign of disrespect. Riley also tended to be loud, commanding the attention of everyone around him, and often lamented that his shoulder-length hair (which he had worn since elementary school) only added to his teachers' negative misconceptions of his personality.

Although Riley's social group included students who were known to be "partiers," Riley insisted that he neither smoked marijuana, nor drank alcohol. However, his teachers and the school administration tended to assume that he frequently broke school rules and engaged in illegal activities; this was a source of great frustration for Riley. Despite his conflicts with his teachers, and despite the reputation as a "slacker," Riley consistently earned A's and B's in his classes. He really did care about his academic achievement, and he attributed much of his success to his mother, who held him to high standards in many areas of his life. I would describe Riley as fun-loving, intelligent, and loyal.

\section{Jacob}

Jacob was a very close friend of Riley's and they shared a similar laid-back attitude regarding school. Jacob was shy and socially awkward in his early teen years, but credited Riley with helping him learn how to befriend large numbers of people by striking up conversations with strangers. By the time Jacob was an upperclassman, he identified himself as a person who thrived on social connections. Jacob was known among peers to be a partier, and often held legendary parties, complete with guest lists in the hundreds, DJs, and warehouse venues. His parents financed and organized the parties, 
although limited parental oversight sometimes resulted in wild parties featuring alcohol and drug use. While Riley claimed that he neither drank alcohol, nor abused drugs, Jacob situated himself as the epicenter of his school's party culture.

It is fair to say that teachers also made assumptions about Jacob's party habits and work ethic based on his Supreme-brand clothing and his general relaxed demeanor, but he felt less misunderstood by those perceptions than Riley did. Jacob also maintained healthier relationships with many of his teachers than Riley did, mainly because his sense of humor was not as sarcastic or as inappropriate as Riley's. Jacob generally received $B$ 's and $C$ 's in all of his high school classes. He reported receiving one $F$ during his junior year, which resulted his parents taking his phone away for several weeks. He regarded that time period as one of the most difficult and lonely of his high school career, as his phone served as a lifeline to his social world. I would describe Jacob as sensitive, funloving, laid-back, and social.

\section{Conclusions About Participants}

The data presented in Chapter 4 is a faithful representation of the lived experiences of these eight young men. Since maintaining participant voice and identity is an important goal of this research project, I have included Table 1 (see below), which presents a concise summary of the information offered on the preceding pages. 
Table 1

Study Participants and Summary of Characteristics

$\begin{array}{llll}\text { Participant } & \begin{array}{l}\text { Year at } \\ \text { time of } \\ \text { interview }\end{array} & \text { Interests } & \text { Descriptors } \\ & \end{array}$

Ryan Senior MMA, military, Conservative, outspoken, firearms, 2nd independent, persistent Amendment rights, football

Jared Junior Cars and trucks Outspoken, confident, hardworking

$\begin{array}{llll}\text { David } & \text { Senior } & \text { Politics } & \begin{array}{l}\text { Liberal, social, family-oriented, } \\ \text { light-hearted, happy, } \\ \text { introspective }\end{array} \\ \text { Jack } & \text { Senior } & \text { Football, wrestling } & \begin{array}{l}\text { Family-oriented, loyal, hard- } \\ \text { working, realistic, social }\end{array} \\ \text { Cade } & \text { Senior } & \text { Football } & \text { Daring, sensitive, loyal, social } \\ \text { Sam } & \text { Senior } & \begin{array}{l}\text { Philosophy, } \\ \text { religion, human } \\ \text { behavior }\end{array} & \begin{array}{l}\text { Intelligent, intense, inquisitive } \\ \text { Lacrosse, fashion, } \\ \text { Rusic }\end{array} \\ \text { Jacob } & \text { Senior } & \begin{array}{l}\text { Fun-loving, loyal, intelligent, } \\ \text { funny, social }\end{array} \\ & \text { Senior } & \text { Fashion, music } & \begin{array}{l}\text { Sensitive, fun-loving, laid-back, } \\ \text { social }\end{array}\end{array}$




\section{Findings}

Eight individual interviews yielded over 100 pages of raw data, which I primarily analyzed using thematic and In Vivo codes. After analyzing the raw data, two key findings emerged, both of which I will address in turn. First, participants stated that they generally found little meaning in their high school experience and, as a result, they engaged in resistance strategies against schooling. Second, participants expressed how they valued authentic relationships with their teachers and they were less likely to engage in acts of resistance with teachers who clearly liked them and cared about them.

\section{Resistance in High School}

The first key finding of this study was that participants generally did not find much meaning or enjoyment in their overall high school experience, something they primarily attributed to a lack of meaningful relationships with teachers and a lack of engaging academic content. Furthermore, this lack of meaning and enjoyment in the participants' high school experiences was clearly connected to resistance practices. In fact, participants revealed two key motivations for their resistance practices. First, the practice of academic nonchalance provided participants with a means to ease the tedium and stress of academic work and demonstrate their masculine identity to their peers. Second, practices such as opting out, underperforming, and pushing back provided participants with a means to regain personal agency when they felt either marginalized by an oppressive system or generally rejected, ignored, or alienated from the learning environment. 
Do you like school? In order to better understand my participants' experiences in high school, I began each interview with the same question: "Do you like school?" Responses to this question provided rich data that revealed one central theme: While participants did generally appreciate the concept of education, they did not generally find substantial meaning in their high school academic experiences.

"I tolerate it." Each participant stated that important aspects of the school experience — such as intellectual stimulation and meaningful growth — were lacking in key ways. In fact, Jack's comment about school seemed to clearly encapsulate how the other participants felt: when asked whether he liked school, Jack said, "I tolerate it." Although he struggled to imagine his life without school, Jack also said that attending school was not something he ever looked forward to doing:

For me it's just sitting and note-taking. I can't sit for a very long time. And I feel like also trying to see that I'm as smart as everyone else. Like, being nervous, oh crap we have a speech. Not 'cause I'm having problems talking in front of people, it's more of me messing up the work or something.

For Jack, it was the tedium of the school day, as well as the stress of high-stakes tasks such as tests and presentations, that made school so challenging.

Jared was another participant who also struggled to enjoy school and felt the coursework during his freshman and sophomore years was particularly boring because his teachers tended to use less engaging teaching styles: "It's more or less, they are telling you what to do and you just got to, you know, do it with a pen and paper." David also reported struggling through his first three years of high school but ended up enjoying his 
senior year. He attributed this change in opinion to his realization that adulthood was approaching and that high school was not going to be a part of his life forever: "The real world is scary. It's coming fast." Jared's and David's observations about grade level and engagement align with comments I have heard other students make during informal conversations. In general, young men tend to take their education more seriously as they mature and approach the intimidating reality of life beyond high school.

One aspect of school Riley did not enjoy was what he considered to be poor academic offerings. In particular, he felt the course selection process in school was encumbered by senseless rules. First of all, he said that "Sherwood doesn't offer good electives." He also expressed a frustration with the plethora of rules governing elective courses, which by definition should provide students with some freedom and independence in their academic studies:

I don't think you should have to have a certain amount of electives before you graduate. I think that's kind of dumb. If you don't want to take an elective, you shouldn't have to. I don't know. Like, you have to have four years of English credits. But we don't offer four years of actual core English classes and so you have to elect to take them. I think that's kind of dumb because you just waste your elective on something that you didn't want to take, but you had to.

For students who are not engaged by traditional core subjects such as math and English, the electives a school offers may become an important factor in how students experience school. For example, Jared stated that he appreciated his cooking and weightlifting classes because they were practical and would benefit him later in life. Ryan also enjoyed 
electives such as welding and wood shop, which he found much more engaging than his core classes: “[Core classes are] not entertaining. I mean, it’s not very dangerous I guess. Like say woods class or welding class or something like that. I like that kind of stuff." Notably, Ryan used the word "entertaining" to describe classes that provided fun and danger and positioned those classes in opposition to more academic core classes, suggesting a preference for classes that actively engage students.

“Trapped in school.” Several participants expressed strong appreciation the concept of high school, which should theoretically consist of meaningful and varied opportunities for learning and socializing. However, the participants also reported feeling either disappointed by or anxious about the reality of high school. In particular, Cade said, "I enjoy the idea of [school]," but he found the reality of his daily coursework to be stressful and unstimulating, and lacking the social opportunities his middle school teachers had promoted:

When you're younger and you think about high school, you think about prom and all this fun stuff that you're going to do. And then when you actually get to high school, it's extremely stressful, there's a lot of work and stuff they don't like, talk to you about or warn you about when you're younger. They just make it out to be something a lot more fun.

Like Cade, Riley was another participant who felt particularly troubled by the daily obligations of high school, but he actually reported feeling trapped in the system: "I guess as you grow up you still feel trapped in school and this thing you have to go to every day, whether you like it or not.” In my experience as an educator, Riley's use of the word 
"trapped" echoes the language used by many youth learning in U.S. public schools. Cade and Riley both sensed the difference between education, which they valued as a concept, and schooling, the realities of which interfered with students' abilities to enjoy, and perhaps even to access their education (Foucault, 1995).

Resistance practices. The participants in this study linked their boredom and dissatisfaction with formal schooling to the resistance strategies they used in the classroom. And while each participant told his own unique story and described his resistance in unique ways, several clear patterns emerged from the interviews. One common purpose of the resistance strategies my participants used was to construct and perform dominant versions of masculinity in academic settings to enhance social capital amongst peers (Lingard, Martino \& Mills, 2009). In this setting, the style of resistance participants described was academic nonchalance, a term Morris (2012) used to identify a social construction of masculinity in which young men "willingly and contentedly projected a semblance of inattention at school" (p. 54). Acts of academic nonchalance might include young men slouching behind their desks, arriving late to class, cracking jokes at inappropriate times, or publicly boasting about their low grades or forgetting to study.

A second common purpose of resistance described by participants was to circumvent or cope with power structures imbued with cultural imperialism and hegemony (Nakkula \& Ravitch, 1998). The styles of resistance described by participants for this purpose were varied: participants opted out of or withdrew from a teacher's lessons, and sometimes actively challenged teacher authority. For participants in this 
study, resistance behaviors included: refusing to learn from the teacher, tuning out during lectures, arriving late to class, openly mocking teachers, challenging rules, and choosing not to complete non-essential assignments.

Academic nonchalance: Demonstrating dominant masculinity. Many young men, especially those who subscribe to dominant versions of masculinity, find striving academically to be inconsistent with masculinity (Lingard, Martino, \& Mills, 2009). For these young men, academic participation is often one of the public acts through which their masculine identity is constantly negotiated (Goffman, 1959). Therefore, they may engage in acts of academic nonchalance to publicly advertise how unconcerned they are with academic and behavioral expectations of figures of authority (Morris, 2012). In simpler terms: for some young men, it is cool to appear aloof and in control, rather than be perceived as a student who strives and aligns himself too closely with the teacher. Such aloof behavior may translate to enhanced social capital amongst peers, but often results in diminished social capital with teachers (Bourdieu, 1986; Morris, 2012). In fact, young men practicing academic nonchalance must find a middle ground between participating in the academic environment, maintaining their own agency, and enhancing cultural capital with their peers.

David was one participant who spoke at length about his own acts of academic nonchalance. When I asked him to describe his resistance strategies, he explained how he would often crack jokes or play small pranks in order to make his peers laugh. He described himself as a student who liked to "speak out sometimes and have a little fun" to lighten the mood in the classroom, and he often participated in what he described as 
harmless pranks, such as "doing devil horns behind a security guard with my middle fingers.” For David, playing the class clown made the learning environment more palatable; he reported being frustrated with his elementary and middle school experience and he played the class clown by purposely resisting or breaking the rules in ways that he thought would make his peers laugh.

Unfortunately, when David's frustration manifested itself in disruptive behaviors, his teachers often reacted negatively, which he interpreted as teacher prejudice against him. He felt that his hard work was consistently overlooked and he was instead labeled as a "bad kid": "They just assume completely that, 'Oh, this is the bad kid. I have to do something about this or I have to be pissed off at him.' It's just terrible." Teachers frequently responded to David's behaviors by sending him to the office or assigning him detention, which only accelerated his cycle of frustration and loathing with school. He struggled to attend school and his grades suffered as a result. This is an example of how acts of academic nonchalance can both disrupt the learning environment and diminish the social capital a student might otherwise have with his teacher. For David, what started off as what he considered to be an attempt to lighten the mood in the classroom and gain positive attention from his peers often devolved into toxic relationships with his teachers, whom he believed assumed the worst of him.

But once he entered his senior year, David's acts of resistance and the resulting antagonistic relationships with his teachers largely dissipated: "Senior year so far, I've actually wanted to come to school. It's very odd for me, specifically, 'cause [I] hated freshman year, hated sophomore year, junior year was eh, but senior year, I'm liking 
coming to school." David did not attribute this change in perspective to the classes he was taking, or to any change in his social milieu, but to a sense of trepidation about the impending uncertainties of adulthood: "I'm not gonna be here for long anymore, and let me enjoy it before I have to go out in the real world. The real world is scary. It's coming fast." As David inched closer to graduation, he held an increasingly greater appreciation for the safety and reliability of high school, where a student's daily schedule was largely determined for him. This appreciation resulted in more positive and productive relationships between David and his teachers, and a greater enjoyment of his time spent in the classroom.

Jack provided another clear depiction of academic nonchalance from his experiences mentoring eighth grade boys who engaged in resistance behaviors that were directly impacting their success in school. One particular student he mentored exhibited disruptive behaviors in the classroom, so his teacher sent the student into the hallway and asked Jack to accompany him. Of the incident, Jack remembered: “The kid wouldn’t even look at me. He was looking away, trying to be as cool as possible. He was like, 'Hey, I just got kicked out of the class. I'm cool for being kicked out of class.'” Jack interpreted the boy's response to being removed from class as an act of academic nonchalance engineered to gain notoriety from his peers. But Jack also recognized that the behaviors of the boys shifted, depending on who was watching them:

In lunch [detention], there's always those kids in there that are always in there and when their friends aren't there, they'll kind of talk to you, and I've talked to the teachers before and they're like, they're actually good-working kids. I've always 
been that kind of kid, the good-working kid, but then you kind of put on a different facade when your friends come into the room.

For Jack, the performative quality of some acts of resistance became even more obvious when he discovered the boys behaved differently in different contexts. They transformed from the "cool" kid who was getting kicked out of class to the "good-working kid" who was willing to open up to Jack and work productively with him. The difference in behavior depended on who was watching. Connell (1996) suggested that challenging a teacher's authority may engender several benefits for boys and young men: It allows them to appear brave and strong in front of their peers, and it also allows them to maintain some personal agency in the presence of discipline and control. Connell referred to this masculine behavior that challenges the school disciplinary system as "protest masculinity" (p. 220) and suggested that challenging authority to enhance social standing and protect personal agency was a central aspect of dominant masculinity. As such, many young men, including the boys Jack worked with, were keen to emphasize their masculinity by confronting the power systems controlling them.

Jack did not only encounter academic nonchalance when he mentored middle school boys; he also recounted similar scenarios within his own peer group. For example, Jack felt he often earned some notoriety and admiration among his peers when a teacher expelled him from class or when he received a note from the principal's office. Like the boys he mentored in middle school, the gaze of his peers motivated his resistance behaviors: "You'll stop working, you'll stop doing whatever you were doing before, you lose all that work 'cause you're like, 'Oh, I got to be the badass again.'” Unlike the 
middle schoolers, however, Jack understood that resistant behavior can negatively impact a person's future:

[The eighth graders] got so used to kind of have that structure about, "The school is not going to let me fail. They're just gonna, going to set it up for me to do my work, so I can have that freedom after school.” High school? They don't care. They care, but you need to learn responsibility. 'Cause, at the job site...you don't have someone telling you you have to do this. Now: "Hey, you didn't do it, so I'm going to give you this extra time."

As an upperclassman reflecting on acts of academic nonchalance in the classroom, Jack was capable of seeing the bigger picture. He understood that acts of resistance may in fact win the attention and admiration of peers, but at some point a student's need to learn, build skills, and graduate from high school outweighed the need for peer acceptance. It is interesting to note that Jack did not recognize the consequences of academic nonchalance until his junior year of high school, when he started to understand the value of hard work in the rapidly approaching world of the adult labor force.

Jack's differentiation between the 8th graders' attitudes about work and his own attitude about work suggested that student engagement in acts of nonchalance typically evolves as the student matures. Echoing Jack's observations, Cade suggested that young men engaging in acts of academic nonchalance may do so because they are comfortable with their current life circumstances; they are not concerned about their future or any potentially negative repercussions from engaging in acts of academic nonchalance. To make this point, Cade described his own reactions to the low grades he received during 
his freshman and sophomore years in high school: "I got a $C$. Oh well, I'll just get yelled at one time....And it's not that we don't care, it's that we're not really thinking about it. It's: 'I'm doing alright so I can go do other things." Cade felt that many young men engaging in acts of academic nonchalance did not carry the sense of urgency necessary for a student to fully engage in the learning environment. However, Cade's opinion of his own work ethic and his peers' work habits shifted as he grew older and began anticipating the impending reality of adulthood. At the time of his interview, he was able to recall his earlier years of high school with a wider perspective and began to understand just how little responsibility he carried relative to his later years in high school, when he was preparing to enter the adult world. I asked him about the acts of resistance I had observed as his sophomore English teacher and how his perspective had since changed:

My freshman and sophomore year, even now I think back, it was awesome. I was worry-free. I'd show up to class and maybe do an assignment. I'd just screw around with friends and have a good time. Then as I got older, I was like, why didn't I do this? I was so dumb....Now, I believe [trying hard] shows that you're determined. If you are trying and you suck, you just need to try a little harder, you need to work a little longer, or maybe it's just not for you.... Now it seems stupid: why would I have to learn Algebra if I'm never gonna use it? However, you never know what you're gonna do in college, how things are going to change, and you just need to be prepared for every outcome. But we're really not thinking about the outcome, we're thinking about the now. 
Cade understood that the carefree nature of his freshman and sophomore years was specific to that period of his life and engaging in acts of academic nonchalance was not going to serve him well in the long term. As he entered his junior year, he began to reassess his mindset and his behaviors in the interest of preparing himself for a future that was no longer guaranteed. It was his broader understanding of the purpose of school, and of the role of education in his adult life, that moved him towards a more balanced understanding of the role of purposeful preparation for adulthood, which requires hard work, skill and dedication.

In addition to indicating a sense of comfort with current life circumstances, Cade identified academic nonchalance as an indication of emotional comfort in the learning environment. For example, he stated that being off task and "razzing" peers generally happens in classrooms where the students are both comfortable with each other and with their teacher. When talking about his experience in my classroom, Cade stated:

Because we were your year-long class, and we had been together the year before, we were very comfortable with each other. We knew each other. And in [Mrs. S-'s] class, we did the same thing: we talked out, we made jokes while others were reading, just to razz each other, and stuff like that. And then I think it just kind of carried over in your class, and because you were so relaxed at the beginning, as soon as we figured it out, we started doing that and it kind of escalated, just a little bit.

Cade noted that the extended period of time his peers had spent learning together was an important factor in their level of comfort in the classroom, and he directly attributed acts 
of resistance to that strong level of comfort. It is important to note that this level of comfort is remarkable at a high school that operates on a trimester system in which teachers rarely have the same students for more than 12 weeks at a time-it speaks to the ability of authentic caring teachers to develop strong student-teacher relationships, even in challenging circumstances.

Cade, Ryan, and Riley all used a unique term to describe young men engaging in behaviors that were discrepant with acts of academic nonchalance: try-hards. Try-hards were consistently defined as male students who strive to distinguish themselves academically from their peers. They may eagerly volunteer answers to teachers' questions, sit straight and prim in their chairs, demonstrate pride in strong grades, or enthusiastically complete assignments. In particular, Cade said he would define a try-hard as 'anyone who has straight $A$ 's or $A$ 's and $B$ 's; someone who tried very, very hard in school, or tried to outdo others in class." Cade, Ryan and Riley all explained how young men engaging in acts of resistance may regard try-hards with disdain; try-hards may be interpreted as trying to embarrass peers who are not performing well, or as attempting to align themselves too closely with the teacher ("brown-nosing"). Such behaviors threaten to compromise the dominant version of masculinity that many young men have constructed, and labeling young men who strive academically as try-hards is a way to reinforce and protect behaviors that are consistent with those dominant versions of masculinity (Weaver-Hightower, 2003). In fact, for several of the young men I interviewed, there was a strong distinction between someone who strived in academics and someone who strived in athletics: try-hards were almost always young men and only 
existed in academic settings, whereas young men who strived in athletic settings, such as on the football field, generally earned praise, especially if they were talented and successful. Ryan explained:

So if somebody does really well and, like I said, tackles somebody, and they stop the touchdown, or you know, loss of yards, something or other, that's really good for everybody, not just that one person. Whereas in academics, it's good for just that one person. And then sometimes, I've seen this too: Some person will ask him or her for help and they'll be like, "No, I'm just going to be-.." They get done and then stop and then they give all the answers and don't worry about teaching you. So I guess it's more of a team thing.

For Ryan, young men who strive in sports typically benefit the team, even if they lack skill or talent. By contrast, team spirit does not exist to the same degree in the classroom, and therefore the joys and benefits of hard work and achievement are no longer shared entities. In fact, a peer's academic achievement and hard work can even feel threatening to some young men.

Riley explained how some young men go to great lengths to avoid being labeled as a try-hard. He even went to the extent of lying about his grades to his peers, despite carrying a 4.0 GPA:

Once you get into high school, and especially upperclassmen years, I feel like a lot of people just stop caring at that point and if you think they're a try-hard, then cool. Like 8th grade, definitely people are like, “Oh, yeah, I don't care about good grades. But I've got a 4.0 and do all of my homework." I was definitely like that 
in 8th grade. My entire middle school career I had a 4.0. And all my friends would ask me what my grades are and I'd be like, “Oh, yeah, I've got like, straight D's.” They'd all be like, “Oh my God, that's so funny. You're savage!”

When I pressed Riley further about the utility of lying about grades, or bragging about low grades, he echoed language describing the performative nature of masculinity: It's proving the fact that you don't care. People think you're a lot chiller and cooled out if you don't care about stuff. So I think that's the point they're trying to prove. It's like, I don't care, and I'm a really chill dude. But in all reality you care a lot and you're just trying to be successful.

Riley’s observations about academic nonchalance echo Morris' (2012) findings that young men seek to appear unconcerned with the expectations of school and suggest that academic nonchalance is a kind of gendered performance, as young men obscure their interest in being successful students in the interest of bolstering their social capital amongst their peers. In Riley’s case, he clearly achieved his peers' admiration, which was delivered through affirming phrases such as "You're savage," emphasizing his perceived strength and courage. Interestingly, as Riley progressed through his adolescent years, his friend group did not radically shift, but his opinions about grades and try-hards had changed dramatically:

It's not that it's funny when someone says that they have a $D$. I laugh, but it's not that I think that it's funny. I think it's funny that you're screwing your life up and you just don't care about it. And, I don't know, sometimes I think to myself like, that'd be kinda tight to just not care about anything, but at the same time, I'd 
rather have a future and be able to be successful in school and learn how to study and do homework.

While Riley admitted to publicly lying about his grades to improve his social capital amongst his peers, and laughing when his peers did the same, he also understood the importance of grades to his future and worked hard to maintain them, despite his public displays of academic nonchalance. In this way, Riley appeared to be caught between two worlds during much of his adolescence: the world of responsibility and achievement typically championed by adults, and the world of play and levity championed by many of his peers. Each option embodied both negative and positive repercussions: Aligning too closely with the world of adults might improve his academic achievement but negatively impact his social standing, whereas aligning with the world of his peers might improve his social standing but negatively impact his academic achievement.

While lying about grades was one effective way for young men like Riley to distance themselves from the try-hard label, Ryan added that physical posture may be another effective way for young men to demonstrate academic nonchalance and distance themselves from the try-hard label. For example, Ryan contrasted the upright posture he linked to try-hards and "brown-nosers" with another kind of posture that included slouching, unnecessarily taking up space, and limply raising a hand to volunteer an answer:

They like to do the lean back in the chair [leaned back in his chair to demonstrate]...but a lot of them still learn and stuff. They'll still raise their hands, but they'll raise their hands like, "Eh, I don't care" instead of a perfect posture 
straight up in the air. I feel like it's more of like a- I don't know how to say this - it's a peer thing, more or less than, actually trying to make the teacher happy. 'Cause that goes back to, if you're a try-hard, you're gonna try and make the teacher happy, or brown nose, or whatever.

Ryan explained this body language as a performative act designed to accomplish two key tasks: to distance young men from authority figures and more academically engaged students, and to construct and reinforce dominant masculinity. And when I asked Ryan whether he thought some boys and young men might "adopt that posture to show others that they don't really care," he replied: "Yeah. I do it too. I don't think I consciously do it, but I'll do this [placed arm loosely over the neighboring chair], and I'll just sit there. I'll still learn." Adopting a nonchalant posture in the classroom makes space for a young man to participate in an academic setting while simultaneously maintaining a masculine identity.

Conclusions about academic nonchalance. In general, I found that participants who engaged in academic nonchalance were willing to define themselves as "resistant students" but tended to engage in resistance strategies in subtle and even subconscious ways. Although they wanted to claim the title of "resistant" as a badge of honor, they were far less likely to describe themselves engaging in aggressively defiant behaviors than to describe simply attempting to appear indifferent to academic work. This tension between active and passive forms of resistance may reflect two key realities. First, students did not always want to directly challenge authority, which often has direct disciplinary consequences. Second, most acts of resistance are not the result of anger or 
an active dislike for any teacher or administrator, but as a performative demonstration of masculine control and power.

Opting out and pushing back: Reactions to domination. For some students, the reproductive nature of the school system, which maintains class-based and age-based hierarchies, social norms, and gender roles, feels inherently oppressive (Giroux, 1983). If a student believes they operate within an inherently oppressive system, resistance may become an important expression of that student's personal agency (McLaren, 2003). Several participants in this study responded to domination in the classroom by opting out of classroom learning activities or acting out against their teachers' directives.

Ryan was one participant who experienced great frustration with teacher domination. In particular, he felt alienated by the reproductive nature of school. As a conservative-leaning thinker, Ryan felt that his politics were often in conflict with those of his more liberal teachers. In fact, he believed that many of his teachers deliberately embedded their liberal agendas into the curriculum of their classes; this frequently resulted in his withdrawal from classroom activities. Of teachers or classroom materials with a perceived liberal agenda, Ryan said: "They're more one-sided kinda thing. And you just wanna stop listening." However, the problem for Ryan was not simply in having a liberal teacher who discussed politics with him; he was able to learn from and get along with teachers of different viewpoints as long as they valued a variety of perspectives and respected Ryan's conservative opinions:

[One teacher and I] had very opposite opinions on a lot of things in class, but I was still able to learn and I was still able to get through that class and stuff. But 
that's usually the kind of class where I'm not able to focus because [the teacher's] telling me their opinion of say, an economics class or something. They're telling me. I mean, they're not supposed to, but they're hinting at it.

Ryan's repetition of the word "telling" and his statement that teachers are "not supposed to" share their political opinions suggests that Ryan believed that his conservative values were marginalized by this school's hidden curriculum (Giroux, 1983), which both legitimized and privileged liberal viewpoints, essentially framing his own views as deficient. Ryan's words echo the work of resistance theorists such as Giroux (1983), Foucault (1995), and Freire (2000), who described cultural reproduction in schools as a phenomenon that working-class students like Ryan are more likely to notice.

Ryan found that subject areas covering potentially politicized topics, such as government, sociology, and economics, were more likely to have a liberal bias than subjects such as geometry or welding. It was within these liberal-leaning social science courses that Ryan was most likely to feel marginalized and react by using resistance strategies:

It's easier to learn from an open-minded person than it is from a closed-minded: “This is my agenda, this is what you're doing, don't go against it or you're not going to graduate." I feel like that would be-. That that's the kind of classes I don't like to learn in. Whereas classes where I don't have my own agenda, and their opinions would trump everything that I think and I'm trying to understand of the world, kinda thing. It's weird. I dunno. That's when I stop learning. When the opinions start kicking in. 
This single comment provides rich insight into Ryan's acts of resistance. First, Ryan described teachers who expressed a liberal bias as "closed minded" and characterized the learning environment they created as controlling and oppressive. Second, he characterized his resistance style in clear and simple terms: "I stop learning." Third, Ryan differentiated between his choice to opt out and his interest in engaging with new ideas: "Not that I don't want to learn, just that I don't wanna participate in what's going on." Although Ryan wanted to learn, his reservations about participating in a classroom environment dominated by liberal bias effectively silenced his conservative-leaning voice.

By contrast, Ryan often engaged enthusiastically as a student in my own writing class, during which frequent discussions on politicized topics such as gender and gun control occurred. When I pressed him to say more about difference between his relationship with me, whom he understood to be an outspoken liberal, and other teachers with similar viewpoints, Ryan said:

[You had an] understanding [that] other people have other opinions and they shouldn't have your opinion. If you're teaching you shouldn't teach your opinion, you should teach the idea of: there are multiple different opinions, and you can believe whatever you want. Compared to our conversations, where, you know, that's YOUR opinion. MY opinion was_- You know? And we didn't get angry at each other or anything like that.

Ryan's comments about me, a liberal teacher with whom he engaged in productive dialogue, underscores the power of cultural dominance to disrupt learning in the 
classroom, and the power of individual teachers to disrupt the paradigm. He was sensing the difference between education, where he enjoyed engaging in political discourse, and schooling, where he had been situated as a receptacle for information, under the physical and intellectual control of the instructor (Foucault, 1995).

For Ryan, cultural imperialism also played strongly into the concept of trust, which he believes is established from the first days of a class:

If they want me to trust them, it's the way they present themselves in the first. You know, first impression is what's going to make me trust you somewhat and then actually make me want to talk to you. So if your first impression is, you know: "Okay, in this class we're going to learn about fiscal policy. And Trump does not have a good one." [The teacher wouldn't] say that, but, hinting at, you know, Trump's fiscal policy is not going to be good. Well, I'm not going to be [open-minded] because you're not. You're not [open-minded] about the whole class. You're gonna teach me your way, so I'm not gonna wanna trust you and learn your curriculum.

When Ryan enrolled in classes (such as Economics or English) that were likely to cover politically controversial material, he was immediately vigilant, monitoring teacher behavior for signs of implicit bias. When Ryan perceived a political bias, he opted out of the learning environment. He would still complete the requisite learning tasks, but he would not exhibit the same engagement as he would if he believed the teacher was willing to accommodate and honor his ideas. For Ryan, engaging in a teacher's curriculum required trust that they would not attempt to indoctrinate him. 
Riley was another participant who reported engaging in resistance strategies as a response to teacher domination. In fact, Riley struggled through frequent conflicts with his teachers and engaged in defiant acts of resistance that landed him in "terrible trouble" throughout his academic career. But unlike Ryan, Riley did not link his resistance to cultural imperialism. Rather, his resistant behaviors, as well as the ensuing conflicts with his teachers, were the result of his perception that most rules and regulations were ineffectual or oppressive. He provided a narrative of one particular classroom conflict to illuminate his perspective:

[Mr. Q_- ] I didn't like at all....'cause I was expecting a call from my mom. 'Cause one of the times I had work at like, 3:30, and I couldn't make it that day, so I was expecting a call from her, 'cause she was trying to help me get it covered because we both worked at the same place. So I checked my phone for a call from her and [Mr. Q- ] got on me about my phone, which I understand because I never told him about it. But at the time I explained the situation to him and he was like, "Well, class time is not the time to get on your phone." And I was like, "Okay, well, this is kind of important." I don't intend to be a dick, but there's some things that take priority over school and one of them is definitely work. 'Cause I mean, a source of income. Essentially, you're taking school to get a job, and make money, and be successful. And, I don't know, I feel like [Mr. Q- ] just didn't respect that. Although Riley understood his teacher's justification for asking him to put his phone down, Riley also felt a respectful teacher would have empathized with his situation and accepted his justification for taking the phone call, thereby prioritizing Riley's needs over 
the existing rules. Instead, the teacher appeared to prioritize his rule over Riley's needs, and Riley felt that he did so in an oppressive manner. It was the teacher's perceived lack of individual consideration, and thus a lack of respect, that agitated Riley and caused him to resist his teacher's directives. Essentially, this scenario underscored Riley's need for equality in the classroom. For him, equal status and respect should be afforded to all individuals in a room, regardless of their age or social position: "I can't wrap my mind around giving respect to someone just because they're older than me and then having no respect or no regard for my personal feelings, like at all, back." Riley's words reflect his frustration regarding dominant teachers who marginalized youth voices, including his own, and his struggle to persist in an environment in which he was expected to surrender his personal agency.

For Riley, one teacher attribute that denoted equality in the classroom was their willingness to joke with students, rather than taking student resistance behaviors too seriously. Jokes were particularly important to Riley in part because he viewed them as a disruption of the hegemony that compromised his personal agency (McLaren, 2003). One particular story about a teacher's sense of humor clarified Riley's perspective:

[Mr. Z- $]$ and I have a really similar sense of humor. I like it when you can joke around with a teacher and I don't wanna say they can make fun of you back, but you have a mutual relationship where you can give them shit and they'll give you shit back. Like, [Mr. Z-]. I can't remember what he said, but I remember I was in [class] and he was giving [N-] shit for smoking weed. 'Cause $[\mathrm{N}-]$ like, so you're supposed to wear glasses at all times in [this class] just...safety. And [N-] 
wasn't wearing glasses, and [Z- ] told him to put his glasses on or else he'd go blind and can't find the bong tomorrow. And it was so funny. And from that point on, I've just had a great relationship with [Z- $]$.

And last year on 4-20 I walked into class and he goes, "[Riley], you're here?” And I was like, “Yeah?” And he was like, “Oh, I already marked you absent because it's 4-20." I was like, “What?” And just to be clear, I don't smoke weed at all. I mean, I had my fun 8th grade and freshman year, but yeah. And he's also not afraid to take it, too. There's some teachers — and people in general— they'll give you shit, but as soon as you say something back: "Office!” And just the fact that some teachers will honestly treat you equal to them.

Unlike this teacher, Mr. Z-, Riley felt that most of his teachers did not seek to foster equality in their relationships with their students. Instead, he found that while teachers could use sarcasm or wit with students, the students were not permitted to respond in kind. The emotional dominance in such situations is subtle, but clear: students are told that they cannot express themselves as freely as teachers can and their self-expression must be within the bounds of what the teacher deems appropriate.

A teacher joking with students in the classroom was also important to Riley because humor was a key aspect of his personality. In fact, he was one of the few participants in the study whose resistance strategies included intentionally making a teacher angry just for the fun of it: "It's honestly more about joking around and getting in trouble with it and taking it way too far. It's never about proving a point." For example, he often experimented with how much he could prod substitute teachers "before they 
would freak out" and send him to the office. He also recounted one particularly problematic relationship with a teacher in which he found himself explicitly challenging her from the very beginning of the year:

Well in eighth grade, me and my teacher didn't get along at all from the first day. And so anytime she would say something, I would always have something to say back to it. It didn't even matter who she was talking to, I would just say something back to her just to make her mad.

Unfortunately, this antagonistic relationship soon developed into a situation where the teacher began to profile Riley as a bully who was likely to treat his peers with similar disrespect. Such profiling resulted in additional conflict for Riley, in a space where conflict was already a common occurrence. To illuminate his perspective, Riley recounted one particular story of a peer tutoring session that ended in conflict: [My teacher] gave us an assignment one day and I was sitting with [W-] and I was like, "Oh, this math. This assignment is so dumb." I was just frustrated, and she pulled me outside of the classroom, and was yelling at me "cause she overheard part of it and thought I called him dumb. Which I didn't. I would never say something like that about someone that I don't know. And I would never say that to someone and be serious about it. I don't think I've ever insulted someone and meant to hurt their feelings, specifically. I'll insult people, but I'll make sure they know it's a joke. And if they don't, then I feel really bad about it. And yeah, I told her the story and she was like, "That's not acceptable. I know you're lying" and all this stuff and I was like, "Okay. And so she sent me to the office and I got 
in-school suspension for the rest of the week.

This episode appeared to be a particularly difficult one for Riley because he felt so strongly misunderstood and had been accused of something significant that he did not do. Once Riley had established a pattern of behavior characterized by resistance strategies, his teacher engaged with him under the assumption that his resistance was a sign of disrespect toward both the teacher and his peers. I asked Riley whether he felt that teachers often made such assumptions about him based on the way he acted. He said it happened frequently and he attributed his teachers' assumptions to a lack of caring on the teacher's part:

[Some teachers], I don't wanna say don't care enough, but don't make the effort to have a personal connection with their students. 'Cause I feel like I'm kind of a hard person to understand. My jokes, if you don't know me at all, or just teach me for 30 minutes a day, they can come off as really rude and sarcastic. And if you actually get to know me and understand, I don't mean them like that. It's just my sense of humor.

Riley recognized he could be a challenging person to understand, but also felt that teachers who never attempted to get to know him would simply never understand him or respect him. He viewed it as the teacher's responsibility to dismiss his inappropriate comments, taking a more mature stance in order to work productively with him. Riley seemed to believe that if any of his teachers had taken the role of relationship manager (Reichert \& Hawley, 2014), working to understand why Riley was behaving the way he was, and opting to ask questions and engage in open dialogue before making decisions 
about discipline, they might have avoided these damaging conflicts with Riley. It is interesting that, despite his need for a sense of equality between him and his teachers, Riley still expected his teachers to act as responsible managers of classroom relationships:

Honestly, [being respectful is] not even that big of a deal. It's just treating someone like an adult, even if they don't act like one at times. I feel like everyone should be granted the opportunity to be treated like an adult....Any time a teacher- even if I do something to make them think that I don't deserve their respect—I still feel like you should be, like, you're the one in charge, and my elder. So I feel like you need to respect me first before I can respect you because I can't respect someone that's that childish.

Riley's comments reflect Reichert and Hawley's (2014) description of teachers as relationship managers, in the sense that Riley felt his teachers were responsible for creating and maintaining classroom relationships. For Riley, this meant teachers should respect all students from the first day of class, regardless of whether those students demonstrate the same level of respect for the teacher. Riley believed this even as he acknowledged he might not have been playing an equal part in supporting and nurturing the relationship.

Jacob felt many of his teachers discriminated against him because of assumptions they made about the kind of person he was. Based on how he dressed, Jacob's teachers assumed he was a "skater" and therefore a troublemaker. He said, "I'm sure the way I dress, people assume I'm a skater or a pothead or something. But I'm not any of those." 
When I asked why he believed that certain teachers discriminated against him, Jacob described subtle signs denoting acts of favoritism for others, such as body language and inequitable responses to off-task behavior: "You could get this vibe from them. You could be just be sitting there and be doing something and another kid could be doing the same thing and you're the one that gets called out." Jacob found it discriminatory for a teacher to call out one student for breaking a rule, but to fail to call out another student nearby for the same activity. This discriminatory "vibe' Jacob described impacted his ability to comfortably seek help on his classwork, making an already strained relationship even more challenging:

It just feels so awkward because if you have to ask a question, you're kind of just stuck in that position of like, "I know you don't like me, and I'm not liking you anymore either because you don't like me." This will go two ways and we're both just trying to act as civil as possible.

I was disheartened to hear that Jacob believed one or more of his teachers simply did not like him, which caused a disruption in the working relationship between him and his teacher and made basic academic tasks such as asking questions a challenging prospect.

David was another participant who experienced frequent and distressingly negative relationships with several teachers, beginning in late elementary school and lasting through his sophomore year of high school. Like Riley and Jacob, many of David's conflicts with teachers seemed to focus on what he perceived as unfairness and "power trips." In particular, he often found teacher directives and punishments to be unfair, which he illustrated through a story about one particular 6th grade teacher: 
There was nothing there. She would yell if you did something wrong. It's like, “Oh, I showed you how to do this. What's wrong with you?” Why wouldn't you help? You know? Do you really expect us to be doing everything completely right the first time?

I was gone one day. This what really-. This is what got me going. I was gone one day. This is within the first week that class started and she had a paper that was due the day I was gone. My mom brought in a note from the doctor saying I was good to go and stuff like that. I came in there with my piece of paper to turn it in and she was like, “Oh, no. I can't accept that." So I went back to my mom. She called the school. So that's where my battle began.

In this narrative, David recounted examples of a teacher whom he felt regularly belittled him for making errors and punished him unfairly. Eventually David found himself relying on his mother to support him in this conflict, as he was essentially stripped of his voice during the disciplinary process. Additionally, David's dramatic description of his relationship with this particular teacher as a "battle" reflects the impact of this teacher's hegemony over her student, as well as the need for David to respond to the conflict by exercising his personal agency.

The battle with this teacher continued throughout the academic year and David's memories of those events were both vivid and distressing:

Lots of other stuff happened between that. Like, in the computer lab, we were doing some pamphlet thing, and she told me to get off the video games on there. And I told her I was already done. I wasn't trying to be completely rude or 
anything. She goes, "No. I want you off the video games now." Only to me. Everyone else is playing video games. Like, we had some battle going on. And I told her no. Specifically, I was like, "I'm done. I'm playing video games." Like that. So she, immediately, without trying to help. Not like, "Well maybe you could just do this instead," or something like that. No. She goes straight to the phone and called the officer that was there to pull me out and take me to the office.

David's frustration mirrored the story Jacob recounted, in that both young men experienced discrimination when a teacher called out one student for breaking a rule but failed to call out another student nearby for the same activity. I asked David if he felt he had been unfairly targeted by teacher in some way and he emphatically agreed: "I was unfairly targeted by her. Yeah. Completely." When I asked why his teacher would target him unfairly, David explained that she "had no desire to be there" and lamented that "there was nothing there," referring to her perceived lack of capacity for empathy and caring. This teacher's dislike for David manifested in aggressive and unfair disciplinary decisions - decisions that effectively ruined their relationship from the beginning of the academic year. David reported that he missed 58 days of school that year and sobbed every morning before going to school due to such distressing conflicts with his teacher. Clearly, the conflicts and the teacher's perceived lack of empathy impacted David's ability to access his education.

Not only did David respond to teacher conflict by missing school, he also began to openly resist teacher directives during class. When I asked him whether he ever 
purposely resisted a teacher's academic or behavioral expectations as a result of their prejudice against him, he narrated yet another stressful encounter from middle school: There was a teacher that yelled at me one time. I was just like, why you gonna yell at me for coming into the class a little late, with a note. So I was like, "No I'm not going to do any of your stuff. That's bull crap." I understand that there's rules to follow and stuff like that, but if a person comes in late and you yell at them because of that, just because you're having a bad day. You're a teacher. You can't be doing that. To a little kid. Seriously. There's no fairness. Just because I'm a young child, stuff like that. There should not be some sort of disrespect or some sort of thinking that you're higher up than me.

David used this interaction to explain one particular teacher's domination, which he classified as disrespectful and unfair. The teacher's acts of disrespect caused David to withdraw from the educational setting. In fact, the acts of resistance David described align with Connell's (1996) theory of "taking up the offer," in which David chose to respond to his teacher's domination by challenging her expectations of academic engagement.

Like both David and Riley, Jack also interpreted some teachers' disciplinary actions as acts of domination. In particular, Jack resented teachers who lectured arrogantly and established rigid rules:

When [controlling teachers] come in, or when I come to a class, they automatically have to show that they're superior. I already know they're superior, but they don't have to show it. Like, no talking, no this. Just, let it be your class, 
kids will enjoy it. If you're, how I see it, how I've always seen it, if you're talking, make it at least a little interesting, I'm going to work. If you just "blah blah blah," get to the point, and then just all you have to do is sit there and work and they don't let you do anything, then I'm just going to zone out. That's just my personality. I have to be involved in it.

Interestingly, Jack's point of view shifted from first person to second person during this explanation, as if he was directly addressing the teachers in question. Using this second person point of view, Jack explained how teachers could bridge the gap created by acts of domination by loosening up the rules and engaging students in a more active way. For Jack, his engagement in the material and the extent of his resistance activities depended heavily on his relationships with his teachers. He explained that he might not put strong effort into an assignment if he did not like a teacher; however, he also said, "I'm not gonna be like, you know what, I'm not going to do this assignment because I don't like this person." In this sense, Jack opted out in subtle ways, by not engaging fully in a lesson, but did not opt to engage in more outright acts of resistance.

Conclusions about reactions to oppression. The participants' perspectives explored in this section match Kleinfeld's (1975) research, which found that "since students tend to merge the task and interpersonal aspects of a situation, they often interpret academic difficulties in terms of the teacher's personal feelings toward them" ( $p$. 312). For resistant students who do not accept the utility of formal schooling, and who are sensitive to institutional hegemony, the teacher's personal feelings can be the determining factor on whether they choose to engage in their education (Foucault, 1995; 
Giroux, 1983). The next section explores the relationship between student engagement, student resistance, and authentic caring relationships.

\section{The Role of Caring Relationships in Acts of Resistance}

In stark contrast to narratives of classroom conflict, frustration, and student resistance, the participants of this study also told stories about the teachers they respected and for whom they were willing to work diligently. These stories led to the second key finding of this study: participants valued authentic relationships with their teachers and were less likely to engage in acts of resistance with teachers who clearly liked them and cared about them. In particular, study participants seemed to experience their teachers in three different ways: There were teachers whom participants believed disliked them, there were teachers whom participants believed disregarded them, and there were teachers whom participants believed authentically cared about them. These findings reflect the work of Raider-Roth (2005), who suggested that young men are more likely to suspend resistance strategies for teachers they can connect with, and Noddings (2005), who argued that teachers who effectively manage caring relationships with their students can diffuse the tension and conflict that might develop as a result of acts of resistance to pave the way for more authentic connections between teachers and students.

“He doesn't like me.” Riley and Jacob were two participants who reported feeling as if some of their teachers actively disliked them. In the previous section, I described how both Riley and Jacob believed many of their teachers discriminated against them based on their acts of resistance and their appearance (Riley wore long hair and Jacob dressed "like a skater"). For both participants, these teacher beliefs directly 
impacted their academic engagement. For example, Riley told the story of a teacher (Mr. D-) who consistently disregarded his requests for help. Mr. D—'s treatment of Riley differed from his treatment of other students in the class, which caused Riley to believe that Mr. D- disliked him:

I had science with [Mr. D- ] and that is one of the teachers I wish I could have opted out of. Because I knew from the beginning, day one or two, that I wasn't going to get along with him. And the entire [trimester], he made no effort to help me outside of class. I'd come in and he'd be like, "Oh yeah, just read the book" and I was like, I don't know, I could have read the book at home. I didn't have to waste my time coming in after class. And in [that science class], I got a 72 in it. And I don't want to sound super basic and corny, but I still think that's just 'cause he didn't like me. 'Cause I would ask my classmates if they had the same experience with him and they would tell me that anytime they came after class, he was super willing to help them. And any time I came in, he would just make me read out of the book. And it was just like, I don't know, it was messed up.

From the beginning of the trimester, Riley sensed that he may not "get along" with this particular teacher. His intuition was confirmed when he requested help and Mr. D— told him to "just read the book." Because the teacher was unwilling to support him, Riley felt disregarded. But an even more pressing concern for Riley was his observation that this teacher appeared to treat other students differently from how he treated Riley: According to Riley's peers, Mr. D — seemed quite willing to help everyone except him. Intended or not, the message Riley received from this observation was that Mr. D— simply disliked 
him. Moreover, Riley connected the lack of support he received in the class to his final course grade, which was a $C$. A grade that low was uncharacteristic of Riley, who typically earned $A$ 's and $B$ 's in his classes.

To further emphasize these frustrations, Riley contrasted the interactions with Mr. D — (a science teacher) and Mr. A— (another science teacher he had the following trimester), who happened to be far more helpful and inviting:

And then [Mr. A-], I'd stay after his class 'cause I'm not good at [that subject]. I mean anything I put time and effort into I can wrap my mind around pretty much anything. But just learning in class. [Science] was not my thing. And I went in after class, like with [my previous teacher's class] and I kind of expected him to just be like, "Oh yeah, read the book," but I took my chances with it. And he actually went over stuff and would re-teach me personally. And would let me ask him questions that I didn't understand or, I don't know, just helped me a lot. And he had basketball practice whatever [trimester] it was I had him. He had basketball practice every day at 5:30, and I would stay in his class until like 5:25. Until he'd be like, "Yeah, I like, really have to go."

Riley expressed a clear appreciation for Mr. A— who, Riley was surprised to find, was completely willing to support him outside of class. Some of Riley's language is particularly striking in this narrative. Mr. A- "let" him ask questions and would "personally" reteach the material. The level of appreciation and mild surprise Riley expressed regarding a teacher who was simply doing his job is disturbing, but reveals one key reason why supportive teachers may be so vital to some students who engage in acts 
of resistance: these students know how it feels to have a teacher who is unsupportive and perhaps even dismissive of their needs.

Jacob was another participant who believed that some of his teachers actively disliked him. I asked Jacob to share how learning experiences with caring teachers contrasted with learning experiences with uncaring teachers:

If you get along with the teacher, it's definitely way easier. Instead of having to think about, like maybe the teacher doesn't like me, or knowing that they-he or she-doesn't like you, you don't want to be in that room at all. You just want to get out of there; you don't want to pay attention, you just want to get up and go. Jacob used language that was nearly identical to the language Riley used in the previous paragraph. Jacob and Riley both talked about how important it was to "get along with" their teachers and how hard it was to engage if "the teacher doesn't like me." For Jacob, the perception that his teacher disliked him disrupted his willingness to learn and made the classroom an uncomfortable place to spend his time. In fact, it made the entire learning experience uncomfortable. By contrast, learning experience with caring teachers were typically far more enjoyable and productive for him:

I feel like teachers that I do like, I feel like I actually try to listen to them instead of just hear them. I actually try to get it into my head. And I try to actually get help. I'll go in after school and talk to teachers I like. But like the other teachers that don't like me or I'm not a huge fan of, I'll just wait and talk to another kid from the class. 
Jacob's use of the word "hear" describes ritual engagement, in which a student's sole intent is to pass a class, whereas the word "listen" describes authentic engagement, in which a student's primary intent is to absorb ideas and learn new skills. The distinction Jacob made between teachers who prompt students to "listen" rather than to simply "hear" suggests that a caring teacher has the potential to positively impact learning whereas a negative experience with a teacher may compromise a student's ability to seek the help they need to succeed academically.

Riley and Jacob were two participants who felt like teachers often discriminated against them, even from the first day of a new class. For them, the complexity of a relationship in which the teacher not only disregarded them, but also demonstrated active prejudice and dislike for them, had a strong overall impact on their learning. Kleinfeld (1975) referred to teachers who keep a professional distance and maintain a prejudice against students who engage in acts of resistance as sophisticates. Sophisticates hold high expectations for students who strive but hold little to no expectations for students who use resistance strategies. Kleinfeld found that these teachers can be a damaging presence for disengaged or marginalized students, who may implicitly sense their teacher's judgment and respond by either opting out of their learning or acting out against the teacher's directives.

Both Riley and Jacob, however, were also able to describe successful relationships in which teachers looked past the participants' physical appearance and acts of resistance to successfully forge positive working relationships. Both students, despite building a strongly masculine exterior, still greatly appreciated teachers who 
demonstrated caring for them. It is perhaps these negative experiences with prejudiced teachers that reinforced the importance and power of caring relationships.

“She didn't want to sit down with us." While some participants keenly sensed that their teachers disliked them, others perceived a somewhat less hostile, but still damaging truth: their teachers were simply indifferent to their existence. These teachers revealed their disinterest by working behind their desk during in-class work time, planning lessons that centered around PowerPoint presentations and lectures, and making little effort to know their students on a personal level. Although there is a clear difference between a teacher who actively dislikes a student and a teacher who simply disregards a student, both situations have a similar effect on student engagement. Two participants, Cade and Jack, were particularly sensitive to teacher disinterest.

Cade perceived a subtle, yet important difference between teachers who interact with their students in supportive ways and those who implicitly pass judgment on their students through a disapproving glance or other subtle actions. Cade used his experiences in my classroom as an example:

I remember sophomore year. You would hand our papers back with our grades and you wouldn't look at it and discuss like, "Oh you got a 50" or say, "Oh you got a hundred. Good job." You'd just hand it back and you would say, "You need to work on that, prove that, turn it back in, I'll regrade it and it'll be fine." Whereas other teachers are like, "You need to work on that" and slide it under your paper, or they'll put it upside down and like, look at you with, I dunno, they're thinking, "You're not paying attention in my class. You don't care." 
Cade felt that even subtle actions such as how teachers handed back graded assignments belied how they felt about their students and their work. He believed that sly teacher comments and acts such as placing below-standard work under other papers on a student's desk reflected implicit judgments of the student's quality of work and often felt like a stinging reminder of a teacher's lack of regard for their students. For Cade, supportive and caring teachers do not make assumptions about a student's work ethic or character, they simply hold the student accountable for completing quality work and provide the support necessary to do so.

Cade also understood that a caring teacher can engage a student and prompt them to work harder, while an uncaring teacher can cause that same student to withdraw completely. To clarify this concept, Cade recounted an experience he had while he was writing an essay for my class during his senior year:

Oh, yeah. For sure. Like when we were writing essays for you, I would come in early and work on that and I put a lot of time into that. Whereas if I had another teacher, I probably would have submitted a paragraph the last day. But I know that, because we have a relationship, you know what I've been through in the past, and it helped me come up with an idea for my paper and it helped me write my paper, like getting good ideas, and it made it so much better.

The writing project Cade described was a personal narrative about a recent struggle he had experienced, and his teacher's knowledge of this struggle allowed him to both express himself more honestly and seek help during the writing process. Cade recounted how he showed up early and spent hours perfecting this assignment for a class with a 
teacher he trusted, whereas he realized that he might have written the same essay in a single sitting, without regard for its quality, if that positive and supportive relationship had not existed. Cade provided several other examples of how his work quality and habits might decline with an uncaring teacher:

When me and [participant Jack] had [our Cadet Teacher class] first trimester, he would have early release and I would have [Ms. J-] at the end of the day, and we would be like, "Let's go get Dutch [Brothers Coffee]" and then he'd be like, "Do you have class?" and I'd be like, "Yeah, I have [Ms. J—], but it's whatever!" and I'd show up 15 minutes late to her class just because I didn't care. Her attitude towards me did not change. It was always like, "Are you kidding me? Where's your note?" or something like that....[Or] maybe if she would assign us a homework packet and I knew I had time to do it, I'd just be like, you know what, she's not going to do anything, so I just wouldn't do it...

Cade described how he disregarded the expectations of a teacher with whom he had a strained relationship: he would show up late after making a coffee run or decide not to complete homework assignments. Interestingly, Cade also noted how the teacher's attitude toward him never changed, even after he frequently challenged her rules. Cade's words suggest that he might have made different choices if the teacher had somehow responded to his behavior. He seemed to be looking for an indication that she noticed him and cared enough to reach out in response to his actions. 
Like Cade, Jack also felt the quality of his work varied depending on his relationship with the teacher. He was more comfortable asking for help from caring teachers, and the relationship also made him want to work a bit harder:

If I like them, I can ask them a little more questions. Like, “Hey, I'm thinking about this. Is it okay if I put this in?” And then it kind of makes me wanna work a little harder. I feel like, instead of just a teacher that, I know they won't come up and talk to me and [say], "Hey why is this like this? I know you can do better than this." Or they just take [the assignment] for the grade, then I'm just going to put it down just to get a grade. If someone talks to me like, "Hey I know you're better than this, or come on [Jack], you can work harder, it's going to make me want to work harder....I think it's more that I want to please that person. Show hey, I actually do care about this class. I'm not just joking around [Jack] that I usually try to do. Jack voiced an enduring, yet simple truth: teachers who encourage students to work hard to reach their full potential are able to convince students to work hard to reach their full potential. It was Jack's teacher's caring, coupled with their lack of critical judgment, that inspired Jack to strive academically. By contrast, Jack felt that teachers who approach their work and students in a mechanical and impersonal manner naturally elicit academic results that are similarly mechanical in nature. Jack's language reflects Noddings' (2005) concept of aesthetical caring, which refers to a classroom focus on academics and procedures rather than on human relationships. Noddings noted that a teacher preference for aesthetical caring over authentic caring often results in students feeling uncared for. 
Cade also explained the damaging impact of teachers who do not actively engage their students. Those are the teachers who ask students to learn via lecture and textbook, retreating to their desk after the teaching is complete:

There's a few [teachers] like [Ms. E- ] that I have that aren't positive, or lean more toward negative...because she didn't want to sit down with us. If we were in class, it was, "Here's a PowerPoint, write this down, I'll explain a little, read the rest out of the book, do the homework, come back tomorrow, we'll do the same thing."

Cade felt that personal interactions with these teachers were rare, and a disinterested teacher, coupled with repetitive and under-stimulating lessons resulted in a strained learning environment. Jack voiced nearly identical ideas about teacher connections: For me, to be honest, just sometimes in bigger classes, it's harder to connect or the [teachers] that just come up in front of the class, give their little spiel, and then they go over to their desk and work. The ones that can walk around and have little conversations, that's the ones that you can build relationships with. And then it's easier to ask them for help when you need help, than just trying to figure it out on your own.

Interestingly, Jack and Cade made nearly identical observations about teachers who do not engage with their students; they both stated that it is nearly impossible to have a working relationship with a teacher who instructs primarily by lecture and spends the remainder of the period working at their desk. In particular, Jack's description of the teacher who gives "their little spiel" then spends the rest of the period behind the desk 
stands in stark comparison to the image of the teacher who is willing to walk around and have "little conversations" with students as they work. Jack's comment also suggests that those "little conversations" are the building blocks for more substantial relationships, resulting in a more comfortable and effective learning environment for the student. Kleinfeld (1975) used the term traditionalists to refer to teachers that maintain a professional distance in their work and largely ignore the interpersonal connections necessary for a productive learning environment. Traditionalists are likely to alienate students who engage in resistance strategies against schooling because caring relationships are critical to those students and their learning.

"He teaches you as a young man." The power of authentic caring relationships to enhance classroom performance is well documented. Valenzuela (1999) and Noddings (1984) both emphasized the importance of authentic caring relationships, which prioritize human connections over curriculum in the learning process. Many of the participants of this study were able to articulate exactly what a caring teacher looks like and how caring teachers might positively impact the learning environment.

Jacob was one participant who experienced teachers who did not care about him or even disliked him because of how he dressed and whom he chose to hang out with. However, Jacob also experienced a number of teachers whom he felt cared about him in meaningful ways. He described the impact of one particular teacher who reached out to make him feel cared for and supported:

At conferences, when my parents met [Mrs. K-], she just said, "If you ever need me, just come to my room. I'll help you with math or anything. If I need to talk to 
a teacher, I'll go talk to them for you." And she's definitely one of those people that has been there for me, too. [Other teachers] won't reach out like that. I feel like you have to more go to them. But she definitely reached out, especially in front of my parents. That was tight.

Jacob felt cared for by this teacher's offer to support him: she voluntarily reached out, not only to offer academic support, but also to advocate on his behalf with other teachers. Jacob showed appreciation, and even a degree of surprise, for teachers who actively advocate for their students and who make it clear that support is always available, even before the student requests it. It is the proactive act of reaching out that reveals a teacher's caring nature. Unfortunately, Jacob's words also suggest that such a high level of unconditional support is rare.

For Jack, caring teachers also show an interest in their students' lives beyond the classroom. When Jack described the teachers he most enjoyed learning from, he said, "I like teachers that try to have more of a relationship than just, straightforward classwork. They'll ask you how you're doing, how's your sports. Actually want to know how you're doing. They know who you are." Jack felt that one criteria of a caring teacher is seeking to know who their students are. They ask questions and are genuinely interested in hearing the answer to those questions because they care about the student as an individual. Later in the same interview, Jack expanded on his definition of "relationship" and what it meant to truly know him:

I think it's the teachers that I know, just deep in my heart, that if I tell them something important, or if I tell them something about a relationship with, like a 
parent that I'm having problems with, that I'll be able to talk to them. Or if someone's sick at home and I don't want to tell students because it spreads, and I don't really have anyone else to tell, I feel like a teacher is a nice person to tell. And it's definitely easier to tell people that you know that's there and that they talked to you before, they asked you before how you're doing, how's this. And they follow up: "How is your family member doing?"

This statement took Jack's definition of caring beyond his original definition by describing the trust he held in some teachers to listen faithfully to him, to hear and understand his story, and to hold that information sacred (notwithstanding mandatory reporting guidelines). Jack clearly appreciated the teachers who stepped beyond their role as an instructor to help him navigate other aspects of his life. Perhaps more than any other example of caring in this chapter, Jack's perspective reflects Hayward's (1998) suggestion that authentic caring relationships are essentially about love, which has the capacity to minimize existing barriers between students and teachers.

Like Jack, David also invoked the language of authentic caring when he described his teachers as parents that he would never want to let down:

It was more of a level, like a parent or something. I'll let them down. That's what will make me do my work and stuff. It's like, I don't want them to be mad at me.... If I don't care about a teacher and you're not engaging and you're not having fun, I won't care. What's the point?

David understood how important caring relationships were to his academic engagement. He knew that the teachers who cared about him and invested in his education were also 
likely be emotionally invested in his failures. In fact, David believed that a teacher's emotional engagement in his successes and his failures is one of the only reasons he might engage in a class. Without that support and connection, "What's the point?" Moreover, David also appreciated the teachers who were willing to be flexible with him, especially when external circumstances affected his ability to maintain his school work: I failed [Mr. K-'s] one [math] class because I was only missing a couple days since I was sick a lot. It was during the snowstorm, but I failed the final, yet he let me retake it. And I passed the class because of that and it was amazing that he let me do that. He's just all around a good person.

Again, David connected Mr. K-'s flexibility to excellent and helpful teaching, but also viewed it as a sign that his teacher cared enough about him to shift his policies to support David. Mr. K-'s work successfully bridged the gap between teacher and human being by showing a sensitivity to his needs outside of his class.

For Jack, equality was a key factor in positive student-teacher relationships. In particular, he appreciated when his teachers treated him more like a young adult than a child: "I noticed that this year, [Mr. S- is] a really relaxed guy. He doesn't teach you as a student, he teaches you as a young man. That's the thing [unintelligible] teaches not like kids, they teach you like adults." For Jack, teachers addressing their students as young men and young women situates teachers and students as equal parties in the learning relationship. This is contradictory to the balance of power that typically exists between teachers and students, often rising to the level of youth oppression (Hebdige, 1988; Nakkula \& Ravitch, 1998). Because youth oppression and other forms of prejudice 
are embedded in the institution of the school, resistance as a means to regain personal agency is a natural response to the schooling environment (McLaren, 2003). Jack recognized the power of small, but meaningful signals of respect from teachers to mitigate alienation and disengagement in the classroom.

Cade was one of several participants who surprised me by using the word "friendship" to describe strong relationships with his favorite teachers. When Cade described the teachers he connected with, including me, he said:

Well, you, [Ms. D-], and [Miss F-] are the only teachers I really connect with. Because a lot of the teachers feel very distant. Like, [Ms. F- ] was pretty cool, but I didn't spend much time with her. I feel like if I did, I might have become friends, or had a better relationship, but like, with teachers, it's them being open to listen to you and actually care about what you're saying, as well as time spent together.

Cade distinguished teachers who were "distant" from teachers who were "open to listen" and "actually care about what you're saying." He even suggested that his relationship with one particular teacher may have risen to the level of a friend if they had spent more time learning together. This statement makes sense in the context of Cade's previous comments about his teachers: he valued teachers who were willing to invest their own time and emotional energy in another person's success, just as a friend would do.

David was another participant who described his relationship with a teacher using the term "friendship." He described their amiable discussions about politics, when they spent entire lunch periods complaining about politicians and dissecting the news of the 
day, but always in a light-hearted manner. When describing the connection, he said, "And that's definitely something in common that we have that we can share and talk about. And there's a level there more of friendship than just a student-teacher type of thing." For David, being able to discuss topics outside of the context of normal classroom interactions made the connections feel more personal, which he appreciated. In fact, he viewed the time spent sharing his life with his teacher as time among friends. David used similar language around friendship to describe interactions with several other teachers he enjoyed:

[Mr. B- $]$ and $[\mathrm{Mr} . \mathrm{H}-]$ have fun, in a way of, they make the math more [understandable] to me. They explain it more than just, "You do this" and then sit down and not help and not have fun. They'll come around, they'll make jokes with you and stuff like that. They'll be more on a personal level than just a teacher teaching. It's kinda like a friendship of, "Here, I'm going to teach you a couple new things" - it's kinda cool.

David echoed many of the characteristics of both uncaring and caring teachers shared by other participants in this chapter. Whereas uncaring teachers simply lecture to their classes, and then retreat to their desks for the remainder of the period, caring teachers operate much more like a friend would. They approach students on a personal level, rather than on a merely professional level, showing the love and care that any good friend would show.

Conclusions about caring relationships. The participants of this study often stated that effective teachers assume the role of a warm, supportive person, rather than as 
a specialized professional. Kleinfeld (1975) used the term warm demander to identify teachers who maintain an explicit focus on building authentic relationships in the classroom but are also competent educators who demand hard work from their students. Kleinfeld's warm demander typology aligns with the work of Noddings (2013), who found that students typically perform best for teachers who establish authentic caring relationships, while simultaneously setting clear and strong expectations for their work.

By contrast, many participants of this study encountered teachers whom they interpreted as uncaring. These teachers either discriminated against certain students based on their appearance or actions, or simply displayed an impersonal professionalism that participants interpreted as disinterest or even outright hostility. Disinterested teachers appear to focus primarily on what Noddings (2005) referred to as aesthetical caringcaring premised on curriculum and learning structures as opposed to building human relationships.

\section{Conclusion}

As I pored over massive spreadsheets of information from my interviews, I realized that while youth may not explicitly seek out relationships with teachers or other adults, many youth do sense quite profoundly the absence of caring relationships with their teachers, with whom they spend an hour or more of their day, five days a week, for several months to a year of their lives. In particular, I was struck by how often I encountered one unexpected word: "friendship." With relative frequency, the participants of this study stated that teachers who were skilled in creating and maintaining positive, 
productive relationships with their students operated very much like friends in several key ways, and several participants explicitly used the word "friendship" to characterize their relationships with their favorite teachers. This finding stands in stark contrast to the stereotype of youth as self-absorbed and aloof, with little to no interest in engaging in relationships with adults.

In this and previous chapters I have established that many youth value authentic relationships with their teachers and are more engaged in their learning within the context of such relationships. This is especially true for young men who engage in acts of resistance, whether they are using resistance strategies as a way to enhance social capital amongst their peers, or as a reaction to oppression and institutional hegemony. In fact, Slade (2001) suggested that authentic caring relationships between young men and their teachers are particularly important because young men who engage in acts of resistance against schooling are often sensitive to the role of teacher domination in the classroom; therefore, they are more likely than young women to experience their teacher's personality before they experience their teacher's lessons. The words of the participants in this study clearly echo Slade's findings and serve to reemphasize the primacy of authentic caring relationships for young men who engage in acts of resistance against schooling. In Chapter 5, I will revisit the themes explored in this chapter and in previous chapters and suggest ways to build authentic caring relationships in schools to better engage young men who engage in acts of resistance against schooling. 


\section{CHAPTER 5: CONCLUSIONS AND IMPLICATIONS THE DISTANCE BETWEEN US}

It was late spring 2015. High school graduation was just days away. I sat huddled with several students on the floor of the computer lab, conferring about their most recent essay drafts. Out of the corner of my eye, I saw Ben approach me. He made eye contact, gave a sideways smile, and peered downward, studying the dirty, worn laces of his Jordans. He plunged his hands deep into his pockets and awkwardly tapped his toes on the stained blue carpet. Ben had been a student in my senior writing class the previous fall. Our personalities had conflicted frequently throughout the trimester, but on that spring day before graduation, Ben returned to thank me for helping him find his voice for the first time. He shared his frustrations with me: he talked about how challenging high school had been for him, both academically and socially. He talked about teachers who helped him and teachers who gave up on him. He talked about the days when he felt wholly invisible. About sleepless nights and sleepy mornings. About heavy textbooks and notebooks spilling over with frantic scribblings. And as he spoke, his shy smile belied a creeping pride in an accomplishment many people told him would never happen: high school graduation.

As I write this dissertation, I am reminded of Ben and of so many other young men who have passed through my classroom doors - their stories remain the very soul of my research. Every day I witness alarming patterns in the engagement and academic 
achievement of too many young men, starting when they enter my classroom as freshmen, and continuing through their senior year. The differences are as minor as how they feel about their handwriting (in my experience as a classroom teacher, boys tend to be far more self-conscious about it than girls) and as important as how many young men are receiving failing grades in my classes (last term, I made five phone calls home about failing grades; all five of those calls were to parents of young men). My

English/Language Arts extended support classes, which I have taught in various forms for over a decade, have typically comprised of one young woman for every two young men, and it is mostly young men who engage in acts of resistance against schooling.

The statistics tell an even broader story: In the United States, young men are significantly more likely than young women to leave high school without a diploma, receive failing grades in core classes, and be suspended or expelled from school. In fact, for every 100 young women expelled from public schools each year, 297 young men are also expelled (Fox, Connelly \& Snyder, 2005). For every 100 girls and young women diagnosed with a learning disability, 276 boys and young men are also diagnosed with a learning disability (Cortiella, 2011). And for every 100 girls and young women diagnosed with a behavior or conduct disorder, 200 boys and young men are also diagnosed with a behavior or conduct disorder (Perou et al., 2013). Yet the voices of the young men in this study are unequivocal: positive, caring relationships with teachers help young men engage in their education. Caring relationships help young men feel confident about themselves and their academic capabilities. Caring relationships can weaken and even destroy barriers to learning. 
The purpose of this study is to describe how authentic caring relationships are of value to young men at the secondary level who engage in acts of resistance against schooling. In Chapter 4, I answered the four research questions that guided this study:

1. How do young men engaging in resistance strategies at Sherwood High School describe the methods and purpose of their resistance?

2. How do young men engaging in resistance strategies at Sherwood High School describe their relationships with their teachers?

3. According to young men who engage in resistance strategies at Sherwood High School, what are the characteristics of teachers who are skilled at fostering authentic caring relationships?

4. According to young men who engage in resistance strategies at Sherwood High School, what distinguishes caring teachers from uncaring teachers?

To answer these questions, I used data from eight interviews to describe student resistance practices and identify how teachers fostering authentic caring relationships could reduce student resistance practices. In this chapter, I will synthesize my findings and explore how teachers, schools, and districts can nurture authentic caring relationships in the classroom, even in the era of elevated student needs, larger class sizes, and standardized testing mandates. 


\section{Synthesis of Findings}

As a classroom teacher who taught many courses involving extended academic support, such as Composition-ES ${ }^{2}$ and Yearlong English $10^{3}$, I frequently encountered young men engaging in acts of resistance against schooling. Because I was skilled at maintaining healthy, positive relationships with these young men, I knew the resistance was not typically a critique of my teaching. However, I still found myself wondering how I could be a better educator: I needed to understand the social and academic patterns I was observing so I could engage male students more effectively in their learning and eventually improve their educational outcomes. To that end, I interviewed eight young men I knew well from my work as an English teacher. I gathered over 100 pages of data in which the participants described their acts of resistance, the purposes of their resistance, and the many ways in which their teachers interacted with them and impacted their resistance.

The interviews yielded two major findings. First, participants stated that they generally found little meaning in their high school experience and, as a result, they engaged in resistance strategies against schooling. Second, participants expressed how they valued authentic relationships with their teachers and how they were less likely to

\footnotetext{
${ }^{2}$ Composition-ES is a class I created for all first-trimester seniors who have not yet met the state-mandated benchmark in writing and are required to produce two writing work samples as a precondition for graduation in the state of Oregon.

${ }^{3}$ Yearlong English 10 is a sophomore English class I created for students who benefit from smaller class sizes and more time to complete coursework. Students at Sherwood High School typically take two trimesters of English each year, but students in yearlong English extend the same content and skill development over three trimesters.
} 
engage in acts of resistance with teachers who developed authentic caring relationships with them.

\section{Resistance Strategies}

Each of the young men I interviewed engaged in acts of resistance against schooling; however, each of the participants simultaneously expressed a clear appreciation for a good education. The study participants valued education but believed that formal schooling did not meet their needs - it often felt too restrictive or too detached from what they felt they needed (Giroux, 1983). It was this alienation from the primary goals of formal schooling, coupled with their social constructions of dominant masculinity and their responses to the power structures embedded in formal institutions, that resulted in acts of resistance against school.

I have defined resistance as a productive force in which the student constructs and negotiates power relationships to enhance their personal agency (Nakkula \& Ravitch, 1998). Toshalis (2015) suggested that resistance includes any situation within a school setting in which a student deviates from the teacher's expectations of student behavior, whether those expectations were explicitly stated or simply implied. It is a complex and highly visible phenomenon, resulting from an environment composed of many actors, including teachers, peers, and administrators. As such, resistance may be enacted in myriad ways, on both conscious and subconscious levels. Some resistance can be described as outright acts of defiance. For example, Riley described refusing a teacher's request to put his phone away. Riley also described how he would "say something back to [a teacher] just to make her mad." David was another participant who engaged in 
outright acts of defiance, including refusing teacher's directives. By contrast, most daily acts of resistance described by participants were more subtle: they described losing focus during a lesson, not completing homework, and cracking jokes in class.

Participants' stories suggested two key motivations for their resistance practices. First, acts of academic nonchalance provided participants with a means to ease the tedium and stress of academic work and demonstrate their masculine identity to their peers. Second, practices such as opting out, underperforming, and pushing back provided participants with a means to regain personal agency when they felt either marginalized by an oppressive system or generally rejected, ignored, or alienated from the learning environment.

Academic nonchalance and dominant masculinity. For many young men, striving academically can be inconsistent with dominant versions of masculinity (Lingard, Martino, \& Mills, 2009). In fact, study participants commonly used acts of resistance in academic settings to construct and perform dominant versions of masculinity as a way to enhance social capital amongst their peers (Lingard, Martino \& Mills, 2009). Morris (2012) called this style of resistance academic nonchalance, referring to a social construction of masculinity in which young men "willingly and contentedly projected a semblance of inattention at school" (p. 54). Several participants, including David, Jack, Cade, Ryan, and Riley all described engaging in acts of academic nonchalance or observing acts of academic nonchalance from their peers. The acts they described included young men slouching behind their desks, arriving late to class, 
cracking jokes at inappropriate times, publicly boasting about their low grades, or forgetting to study.

Jack described acts of academic nonchalance by drawing on his experiences as both an observer of and as a participant in resistance practices. He recounted stories of the eighth-grade boys he mentored during his senior year; they frequently exhibited disruptive behaviors and appeared to draw personal pride from getting kicked out of class. Jack also recounted stories of his own experiences with acts of academic nonchalance. Like the boys he mentored, Jack received positive peer attention when he was kicked out of class or when he received a note from the principal's office.

Furthermore, Jack recognized that resistance practices varied depending on the audience and he concluded that these variations in behavior were the result of performative masculinity_-boys and young men used public acts of academic nonchalance to negotiate and construct their masculine identity. Jack found that many young men challenge authority for two reasons: to enhance their social standing with their peers and to protect their personal agency. Ultimately, Jack realized that the benefits of earning a high school diploma exceeded the benefits of peer admiration he earned through academic nonchalance; therefore, Jack's participation in resistance behaviors dissipated as he approached his senior year and graduation.

David regularly engaged in acts of academic nonchalance to make his peers laugh, but his subtle acts of resistance often frustrated his teachers and caused them to label him as a "bad kid." The more frustration his teachers experienced with him, the more David felt alienated from the learning environment and the more he engaged in acts 
of resistance characterized by defiance. Eventually he felt that he was constantly targeted by teachers and administrators, culminating in frequent absences and a strong resentment for school staff. David's story is an example of how acts of academic nonchalance might disrupt the learning environment and diminish the social capital a student might otherwise have built with his teacher.

Cade, Ryan, and Riley all used the term try-hard to describe male students who strive academically. They believed try-hards are male students who attempt to distinguish themselves academically from their peers and they described try-hards as young men who typically sit with an upright posture, enthusiastically raise their hand to answer questions, and often refuse to help their peers on assignment. For many young men engaging in acts of academic nonchalance, try-hards threaten to compromise the dominant version of masculinity that these young men are attempting to construct. In creating and using a label that carries strong disdain, young men have an easy way to reinforce and protect behaviors that are consistent with dominant versions of masculinity. The try-hard label is so powerful that young men often go to great lengths to avoid the label. Riley described lying about his 4.0 GPA because he felt his friends might criticize it. By proclaiming that he received a $D$ in a class, Riley won his peers' approval: his friends called him "savage" for appearing so ambivalent about his low grades. In a sense, Riley found himself simultaneously bound to two separate worlds: the world of his peers, where he earned admiration and social capital for engaging in acts of resistance, and the world of school and achievement, where he earned skills necessary for graduation. For Riley, these two worlds were often in conflict with one another. 
Academic nonchalance may translate to enhanced social capital amongst peers, but often results in diminished social capital with teachers (Bourdieu, 1986; Morris, 2012). David, Jack, Cade, Ryan and Riley all described how acts of academic nonchalance complicated learning, as well as their relationships in the classroom. In fact, each participant who practiced academic nonchalance had to find a middle ground between participating in the academic environment, maintaining his own agency, and enhancing cultural capital with his peers. Generally, the motivation to engage in acts of resistance to enhance social capital amongst peers dissipated over time, as the participants approached graduation.

Reactions to oppression. Schools are important sites in the reproduction of preexisting social structures and most schools are structured to maintain domination through consensual social practices (Giroux, 1983; McLaren, 2003). For that reason, formal schooling can feel inherently oppressive to some students (Giroux, 1983). If a student believes they work within an oppressive system, resistance may become an important expression of that student's personal agency (McLaren, 2003). Unfortunately, authority figures often view resistance as a threat and may act to eradicate acts of resistance to maintain legitimacy and preserve hegemony (McLaren, 2003). The result is a power struggle between the authority figure and the student attempting to preserve their own agency and gain social capital by publicly defying authority (Connell, 1996).

Several participants in this study responded to domination in the classroom by opting out of classroom learning activities or acting out against their teachers' directives. Ryan described many classroom conflicts that developed because his conservative 
politics were often in conflict with those of his more liberal teachers. Since he believed that many of his teachers deliberately embedded their liberal agendas into the curriculum of their class, Ryan frequently withdrew from classroom activities. He described "onesided" teachers who attempted to indoctrinate their students rather than teaching them to think critically and honoring a variety of viewpoints: "If you're teaching you shouldn't teach your opinion, you should teach the idea of: there are multiple different opinions, and you can believe whatever you want." As a result of these conflicts with his teachers, Ryan withdrew from the learning environment; he completed the work necessary to pass the class, but he did not exhibit a high level of engagement. In a sense, the cultural imperialism that Ryan experienced erased his presence from the classroom and silenced his voice.

Like Ryan, Riley was also highly sensitive to teachers whose practices he found to be oppressive and for that reason he frequently engaged in acts of resistance that got him into "terrible trouble." Riley felt that equality and respect were important factors in his relationships with his teachers and he frequently rejected any power structures that situated students as inferior to adults: "I can't wrap my mind around giving respect to someone just because they're older than me and then having no respect or no regard for my personal feelings, like at all, back." Riley expressed his frustration with teachers who marginalized his youth voice, and his words reflect his struggle to persist in an environment in which he was expected to repress his personal agency. For Riley, classroom equality revealed itself in small but meaningful ways; for example, Riley appreciated teachers who could be sarcastic with students and would allow students to be 
sarcastic back, and he appreciated teachers who changed classroom rules to meet the unique needs of each student. Riley also attributed negative classroom relationships to teachers who were unwilling to look beyond his physical appearance and his acts of resistance to get to know him personally: “[Some teachers], I don't wanna say don't care enough, but don't make the effort to have a personal connection with their students. 'Cause I feel like I'm kind of a hard person to understand." And like a few other participants, Riley engaged in a negative feedback loop, consisting of resistance and negative teacher responses to resistance, which intensified Riley's frustrations with school. He believed it was the teacher's responsibility to dismiss his acts of resistance and take a more mature stance in order to work productively with him.

Jacob and David also encountered discriminatory teachers, whom they both felt favored their peers over them. This perceived discrimination made it difficult for Jacob and David to achieve academically. However, the two participants responded to challenging relationships in different ways. While Jacob felt uncomfortable approaching teachers for help and thus tended to fade into the background of his classes, David chose to exercise his agency by engaging in what he called "battles" with his teachers. Jacob's strategy negatively impacted his learning but did not further damage his relationship with his teachers, whereas David's strategy both negatively impacted his learning and increased the animosity between him and his teachers.

For resistant students who do not recognize the value of formal schooling, or who are sensitive to cultural domination, their teacher's personal feelings about them can determine whether they choose to engage in their education (Foucault, 1995; Giroux, 
1983). For participants of this study, it was the teacher's ability to nurture relationships characterized by equality and caring that differentiated productive student-teacher relationships from problematic student-teacher relationships.

\section{Caring Relationships and Acts of Resistance}

Noddings (2005) argued that schools must move well beyond academics to "promote the growth of students as healthy, competent, and moral people" (p. 10). Noddings used the term authentic caring to describe classrooms in which teachers empathize with how students think and feel about their world and use that empathy to structure a learning environment that meets the intellectual and emotional needs of each particular student. By contrast, when schools prioritize academics over caring relationships, methods, assessments and standards typically dominate classroom interactions, resulting in teachers treating students as receptacles for information rather than as people (Freire, 2000). Noddings (2013) used the term aesthetical caring to refer to this prioritization of academic skills over emotional connections. Valenzuela (1999) suggested that teachers who prioritize aesthetical caring typically assume that students enter the classroom already caring about school. However, many students, especially those who are marginalized, must feel cared for by their teachers before they can fully engage in the academic environment (Valenzuela, 1999). Every participant of this study expressed an appreciation for authentic relationships with their teachers and were less likely to engage in acts of resistance with teachers who clearly liked them and cared about them. In fact, study participants seemed to experience their teachers in three distinct ways: There were teachers whom participants believed disliked them, there were 
teachers whom participants believed disregarded them, and there were teachers whom participants believed authentically cared about them. Each type of teacher elicited a different learning response from the participants.

Feeling disliked or disregarded. I have described how both Riley and Jacob believed many of their teachers discriminated against them based on their acts of resistance and their appearance, and because of this discrimination both Riley and Jacob believed that several of their teachers actively disliked them. For both participants, the perception that a teacher disliked them disrupted their willingness to learn and made the classroom an uncomfortable place to spend their time. In addition, both young men struggled to reach out when they needed support and often expected an outright refusal of their request for help. Finally, these participants expressed how uncaring teachers often prompted ritual engagement from them - they would generally complete assignments, but otherwise would not fully engage in the classroom learning environment. Of his ritual engagement, Jacob explained, "I feel like teachers that I do like, I feel like I actually try to listen to them instead of just hear them. I actually try to get it into my head." This style of ritual engagement seems to be a pattern amongst young men engaging in acts of resistance against schooling.

While some teachers appeared to actively dislike some of their students, other teachers appeared to be indifferent to their students' existence. Teachers who were indifferent revealed their indifference in concrete ways: by working behind their desk during in-class student work time, planning lessons that centered around PowerPoint presentations and lectures, and making little effort to know their students on a personal 
level. Although there is a clear difference between a teacher who actively dislikes a student and a teacher who simply disregards a student, both situations have a similar effect on student engagement.

Two participants, Cade and Jack, were particularly sensitive to teacher disinterest. Cade recounted how he would show up early and spend hours perfecting assignments for teachers he trusted and liked, whereas he would write essays in a single sitting, without regard for quality, when positive and supportive relationships were absent. Likewise, Jack explained that teachers who approach their work and students in a mechanical and impersonal manner also elicit academic results that are mechanical in nature. And both Jack and Cade stated that they found it nearly impossible to have a positive relationship with a teacher who instructs primarily by lecture and spends the majority of the class period working at their desk.

Feeling cared for. Noddings (1984) emphasized the importance of prioritizing human connections over curriculum in the learning process. Many of the participants of this study were able to articulate exactly what a caring teacher looks like and how caring teachers might positively impact the learning environment. Participants appreciated teachers who connected with them beyond the classroom, showing an interest in their lives outside of school and demonstrating concern when they were struggling. Jack described teachers who connect beyond the classroom in simple, but meaningful terms: “They'll ask you how you're doing, how's your sports. Actually want to know how you're doing." In this way, participants appreciated teachers who, like friends, reached beyond the academic material to know who they were, show they cared, and share a part 
of themselves in equal participation. Participants also named enthusiasm and levity as key traits of good teachers; as with peer-aged friends, caring teachers appeared to enjoy the time spent with their students. And while students may appreciate the rigorous expectations of their teachers, classes with caring teachers still felt lighthearted and welcoming. Like friends, good teachers also recognized when their students were struggling; they supported students unconditionally, both on their academic work and in their emotional lives. They added words of encouragement, and sometimes offered some flexibility and grace by making accommodations on assignments. For example, David was grateful that a teacher accommodated him during difficult circumstances beyond David's control: "I passed the class because [he let me retake the test] and it was amazing that he let me do that. He's just all around a good person.” By contrast, teachers who appeared to disregard or even dislike their students contributed to an emotional distance that frequently resulted in lower levels of engagement, greater levels of discomfort, and compromised achievement.

\section{Building Bridges: Recommendations for Change}

Throughout my conversations with these young men, parallels between caring relationships and friendship emerged: participants sought relationships with teachers who exhibited the qualities of friends, including good listening skills, a willingness to help, and an effort to know and be known. Unfortunately, too few student-teacher relationships exhibit such a high level of caring. As a student eloquently expressed in a written communication to me: 
No teacher has ever asked me how I'm doing and actually cared what my response was. I'm sure I can almost speak for every kid out there as well. No one cares here. No one cares what you're thinking about. But if you can regurgitate history that happened 500 years ago then you're an amazing kid. Right? No teacher in their right mind would care because they have a hundred other kids to worry about. They just choose not to care, just like they did with the last kid. But no. I'm good, I'm not the kid you have to worry about. (Student Communication, September 2017)

The student voice in this statement is haunting. The emphasis and repetition of the words "care" and "worry" suggest a visceral need to experience a meaningful connection in the classroom - one that transcends basic formalities and approaches something closer to friendship or kinship. These words reflect Hayward's (1998) notions of love and learning: authentic love in the classroom has the potential to bridge the gap between teachers and the students who engage in acts of resistance in their classroom.

Any approaches endeavoring to bridge the emotional gap between teachers and young men who engage in acts of resistance must address two social barriers to learning: the social construction of dominant versions masculinity, which generates acts of academic nonchalance, and institutional hegemony, which generates a wide range of both passive and active acts of resistance. To disrupt acts of resistance derived from dominant constructions of masculinity, I propose two potential solutions. First, teachers can implement student-centered instructional practices to better engage boys and young men in the learning. Second, schools can implement programs that support healthy social 
relationships among boys and young men and interrupt problematic constructions of gender. To disrupt institutional hegemony and improve the quality of teacher-student relationships, I propose that schools and school districts engage in a multi-pronged approach to change. First, school officials should engage boys and young men in a listening campaign to discern how they feel about their education and their teachers. Second, school officials should use the information culled from student interviews to build professional development workshops and structured programs that support teachers in the development of authentic caring relationships.

\section{Male-Friendly Curriculum and Instructional Practices}

As I mentioned in earlier chapters, much of the literature produced on the boy debate is practice-oriented, with proponents arguing that boys and young men learn in fundamentally different ways from girls and young women; therefore, proponents of practice-oriented literature argue that teachers must change their instructional practices to better engage boys and young men and improve their academic outcomes (WeaverHightower, 2003). Practice-oriented literature derives from a range of epistemological frameworks. For example, Gurian (2005), a nature-based theorist, grounded his claims in biological research. He claimed that boys and young men possess a natural "boy energy" (p. 44) and a brain structure that results in a mismatch between traditional classrooms and male learning styles. On the other hand, Bausch (2014) contended that practitioners and curriculum specialists must consider factors beyond biological differences, since gendered peer relationships and teacher beliefs have a stronger impact on learning and achievement than a student's biology. In a study of third grade boys in a literacy-rich 
classroom, Bausch (2014) found that "the literacy spaces in the third-grade classroom were constructed, maintained, and at times constrained by peer relationships and teacher belief systems about what counted as educationally and socially appropriate" (p. 97). Bausch (2014) concluded that educators must critically examine their own preconceptions about what constitutes appropriate academic literacies and make space for multiple literacies that connect more clearly to boys' lives and in which multiple perspectives are heard and valued. Smith and Wilhelm (2002) fell somewhere between Gurian's (2005) and Bausch's (2014) beliefs, arguing that both biology and sociallyconstructed masculinities play important roles in how boys perform in academic settings. In terms of implementing curriculum and instructional practices that better suit boys' and young men's needs and interests, Gurian (2005), Bausch (2014), and Smith and Wilhelm (2002) all supported several key approaches. Because I am a language arts teacher, and because language arts can be a highly gendered discipline (Smith \& Wilhelm, 2002), I will focus my recommendations on recommended practices specific to the language arts classroom. First of all, Gurian, Bausch, and Smith and Wilhelm argued that educators must increase the level of choice offered, inviting in non-traditional forms of literacy that match their students' interests. At the secondary level, such nontraditional forms of literacy may include: graphic novels, magazines, zines, bestselling novels and personal writing projects that represent a wide variety of personal interests and a wide range of voices. (Bausch, 2014). These literacy offerings must acknowledge the varied social and cultural backgrounds that boys and young men bring with them into the classroom (Alloway, Freebody, Gilbert \& Muspratt, 2002). Secondly, educators must 
provide wider opportunities for collaborative work in which boys and young men can connect meaningfully with peers on literacy tasks in intellectually and emotionally safe spaces (Smith \& Wilhelm, 2002). This may mean supporting boys and young men in relating more authentically with others, collaborating effectively, and engaging in critical conversations around sensitive topics such as gender, power, friendship, and community (Connell, 1996). Third, educators must create a more dynamic learning environment that accommodates a wider range of learning activities. This could entail the implementation of games or competition, modern technology, hand-on activities, and realistic projectbased tasks (Alloway, Freebody, Gilbert \& Muspratt, 2002). Finally, Alloway, Freebody, Gilbert and Muspratt (2002) recommended reconfiguring power structures in the classroom, which allows all students, including boys and young men, to share authority and agency and to co-construct a learning environment in which the contributions and opinions of all students are valued and respected. This final suggestion is particularly relevant for boys and young men who engage in acts of resistance in order to gain agency in an inherently inequitable setting.

Implementing such curriculum and instructional practices would require a dedicated teacher-led team that is willing to dedicate some time to researching instructional methods and writing new curriculum. This scenario is especially likely in schools that clearly acknowledge the value of a boy-friendly approach and have an established professional learning community (PLC), which could provide the time and space necessary for such work (Garvin, Edmondson \& Gino, 2008). More likely, however, such a change would require paid release time for teachers to write new 
curriculum and consider new instructional practices. Teachers implementing a boyfriendly approach could also benefit from a consultant who can propose materials, educate teachers, and assist in troubleshooting and policy assessment (Fowler, 2013). Finally, an expanded curriculum often involves purchasing new materials, such as trade books and teacher's guides.

One potential benefit of implementing a boy-friendly approach is more engaged boys and young men, which may result in higher levels of achievement, especially in boys and young men whom schools have historically struggled to serve appropriately (Smith \& Wilhelm, 2002). There may be an especially high return rate for this policy alternative, considering the low cost and ease of implementation. However, Watson, Kehler, and Martino (2010) cautioned that although a boy-friendly approach could raise motivation and achievement amongst boys and young men, it would not address deeper problems around gender, class, or race. In fact, a curriculum focused around boys and young men is often based on gendered stereotypes and can further entrench the status quo by focusing the needs of classroom activities around a gender that already enjoys a large amount of social power (Lingard, Martino, \& Mills, 2009). Rather than creating a curriculum focused on boy-friendly topics and methods predicated on cultural stereotypes, I recommend that teachers simply make space for a wider variety of voices and interests in their classrooms. Creating a safe space where students can safely discuss challenging ideas and participate actively, allowing students to choose topics for writing assignments, and providing literature representing a wide range of subjects, viewpoints, and genres can go a long way in creating a classroom environment where all students, 
especially those who engage in resistance strategies, are more likely to engage

authentically in their learning (Alloway, Freebody, Gilbert \& Muspratt, 2002).

\section{Gender-based Pedagogy and Programs}

An effective policy alternative to the implementation of a boy-friendly curriculum in the classroom would be creating programs designed around the underlying social and emotional factors that heavily impact boys' and young men's academic engagement and achievement. As I stated previously, Kimmel (2010) argued that "what lies beneath boys' problems (apparent or real) is an outdated ideology of masculinity to which boys are struggling desperately to adhere” (p. 95). Lingard, Martino, and Mills (2009) added that "anti-school behaviours of some boys, to which [boy-friendly] pedagogical approaches are a response, is actually a playing out of dominant constructions of masculinity and...such constructions often have a detrimental impact on the learning of both boys and girls" (p. 46). These constructions of masculinity are reinforced by parents, teachers, students, and the media (Watson, Kehler \& Martino, 2010). Therefore, Watson, Kehler, and Martino (2010) argued for a focus on perspectives and solutions to the boy debate that are "purposely promote and support initiatives/strategies/projects that destabilize normative masculinity and femininity" (p. 360). Such a proposal is in line with what critical theorists such as Freire (2000) and hooks (1994) argued: that any change in the status quo must derive first from critical discussions on gender roles and cultural hegemony, from which social change must transpire.

Gender-based pedagogical programs do not simply seek to alter teaching methods to better suit boys' and young men's learning styles, but instead seek to break down 
gender barriers, disrupting the "boy code" and examining how problematic masculinities impact social, academic, and emotional outcomes (Pollack, 1999). For example, lunch or after-school enrichment groups could help boys and young men confront and examine the socially constructed nature of gender and their own masculinities, using critical theory to challenge dominant constructions of gender in schools and in the wider community (Finn, 1999). Such groups could provide opportunities for boys and young men to connect meaningfully with each other and with positive role models in their community. Activities could extend into the wider community, encompassing visits to local businesses; interactions with youth mentors and guest speakers; discussion circles and intellectual activities to explore questions of problematic masculinities; and group activities and challenges to improve contact, cooperation, and communication skills (Finn, 1999; Mortola, Hiton \& Grant, 2008).

Gender-specific programs require trained and supported leaders and facilitators. If the facilitators are teachers, required support includes: paid release time to develop the program, ongoing professional development to continue to improve the program and troubleshoot as the program matures, and quality professional development in the field of gender studies, including access to research and experienced mentors or consultants (Fowler, 2013). To cut costs, gender-specific programs could procure community partnerships to supplement the resources the school system is able and willing to offer. This program would also benefit from the involvement of volunteer mentors from the local community, such as local business people, government officials, parents, coaches, athletes, and college students. Their role would be not only to inspire boys and young 
men to continue their education, but also to demonstrate how multiple versions of masculinity exist in the world.

The potential benefits of this policy are enormous. Such pedagogically-based programs can provide deep growth for boys and young men that transcends curricular engagement and results in lasting change in the ability of boys to understand how to connect with their own emotions, examine their own masculinity, and connect to their peers and their school in more positive ways (Mortola, Hiton \& Grant, 2008). Extracurricular programs that take boys and young men beyond the school environment create a potential for strong relationships with the wider community and could lead to increased opportunities for students to pursue internships or apprenticeships with local businesses, potentially helping them see the link between a formal education and post-secondary life. This emotional growth and enhanced connection with their academic lives could also result in increased engagement in the school and thus higher graduation rates, lower suspension and expulsion rates, and higher grades and test scores.

With careful planning, educators can create a policy that is responsive to the dynamic interplay of gender, race, class, and power and prompts student and teachers to critically examine the role of masculinities in academic environments to create a more powerful human experience for all young people.

\section{Developing Caring Relationships}

Much of the contemporary focus in the field of teaching and learning has been on the standardization of the learning process. Proficiency-based learning has given rise to department- and district-wide common formative and summative assessments, which 
often prompt curriculum teams to develop uniform teaching methods and timelines. Standardized testing, which is now required in some form by most states and for admissions to most colleges, has resulted in a standardization of the curriculum and a focus on test preparation across the U.S. Noddings (2005) condemned this prioritization of curriculum, standards, and assessments (which she called aesthetical caring), claiming that it interferes with a teachers' ability to focus on what really matters: developing authentic caring relationships with the youth in their classroom. If many young people define caring relationships with their teachers using the language of friendship, and if most teachers focus primarily on their professional obligations of teaching academic skills and subject matter, what remains is a chasm between student and teacher expectations that can seem impassable. Noddings (2013) explained that chasm eloquently: "In many of our schools today, we find teachers who are trying to care and students who want to be cared for, and yet many of those students claim, 'Nobody cares!"” (p. XV).

In addition to a focus on testing and curriculum, one of the most substantial barriers to authentic relationships between students and teachers is the imbalance of power that privileges the teacher over the student, allowing the teacher to marginalize and control students based on the student's lower social position (McLaren, 2003; Nakkula \& Ravitch, 1998). In this sense, student-teacher relationships are typically vertical in nature, meaning the contributions of the people in the relationship are not equivalent, nor do both parties exercise the same level of control in the relationship: teachers give and students 
are expected to receive (Laursen \& Hartup, 2002). Teachers teach a lesson and students learn. Teachers supervise and regulate and students are supervised and regulated.

In stark contrast with teachers, adolescents often prefer classroom relationships that are horizontal and equitable, in which the norms governing the relationships call for equality and reciprocity (Laursen \& Hartup, 2002). Such relationships make each party feel like an equal contributor, approximating friendship. Since adolescents may keenly sense their marginalized status, as well as the emotional distance of their teacher, they may respond by expecting and even actively seeking more egalitarian, horizontal relationships with their teachers: If teachers want students to display vulnerability in order to learn and to connect with their peers, then students want teachers to do the same. If teachers want students to be respectful, then students want the same from teachers. If students are working hard, they want to see teachers working hard too. If teachers have strict ethics and standards of production, then students want to know that teachers have upheld those standards with each student's well-being in mind. Such democratic, egalitarian relationships were championed by Freire (2000) and other radical educators and theorists, who argued that differences in social status impede authentic interactions, which must be democratic if they are to be effective (Shuffleton, 2012).

Schools and school districts need to engage in a multi-pronged approach in order to disrupt institutional hegemony, distance students from acts of resistance, and bridge the relationship gap between students and teachers. First, school officials should engage boys and young men in a listening campaign to discern how they feel about their education and their teachers. Second, school officials should use the information culled 
from student interviews to build professional development workshops and structured programs that support teachers in the development of authentic caring relationships.

Listening and outreach. Before implementing any large-scale policy change, it is important for adults to amplify student voices by organizing listening campaigns. This means gathering information through a range of formal and informal conversations, including listening sessions, focus group interviews, individual interviews, and surveys. These conversations must reach a wide range of boys and young men, including those who have been alienated by formal schooling and are less likely to engage in such conversations in the first place. This means that researchers must intentionally seek out a wide range of student populations and engage in conversations in a way that allows participants to speak authentically. Furthermore, interviewers play a key role in the listening process. A wide range of student populations must be comfortable speaking openly with the interviewers, and the interviewers must be trained in the effective implementation of interview protocols and procedures. The goal of these conversations is to gather enough data to understand a range of student perspectives and be able to summarize them succinctly and distribute the findings to teachers and school staff. As was my purpose when I began this study, the goal of any listening campaign is to listen to participants with such empathy and care that the researchers are able to authentically represent their voices, speaking through them, rather than for them.

In addition to listening campaigns, school districts can also employ Professional Learning Communities (PLCs), and district-level or site-specific training opportunities to develop educators' understandings of the underlying social structures associated with 
student resistance. At their most powerful, such professional development opportunities support teachers in the critical interrogation of their own experiences and biases by providing concrete data, powerful readings, personal stories, and compelling simulations and exercises. In fact, there is a wide range of potential approaches in such trainings. For example, facilitators might present local or national statistics, including data procured through listening sessions, to help teachers and staff understand the difficult realities of the boy debate. Facilitators might also introduce theoretical constructs, such as resistance theory, masculinities theory, or caring theory to bolster teacher understanding of resistance practices. Perhaps most importantly, training sessions should include concrete examples of authentic caring relationships and explicit demonstrations of strategies that teachers can use to forge more powerful and productive relationships with students. With a bit of careful organization, schools and school districts can expand this work by implementing structured programs that further support the development of relationships on an institutional level. What follows is a case study of one school that successfully implemented one such program.

Case study: Sherwood High School. Sherwood High School (SHS) focused on building more authentic relationships between students and staff for a number of years and presents a strong case study for completing this work in a methodical and effective way. The approach at SHS was two-pronged. First, the school administration engineered a variety of activities meant to enhance relationships amongst teachers. Second, the school administration engineered a variety of activities meant to enhance relationships between teachers and their students. 
To begin the process of building more authentic relationships with one another, teachers learned each other's stories. Over a period of several years, they participated in many activities ranging from lighthearted team scavenger hunts, to more sobering privilege walks, to small group conversations covering more personal topics. As Gay (2010) stated, "Stories are powerful means for people to establish bridges across other factors that separate them (such as race, culture, gender, and social class), penetrate barriers to understanding, and create feelings of kindredness" (p. 3). The hope was that sharing personal stories and engaging in team building activities would help establish bridges between colleagues, thereby fostering a culture of authentic caring at various levels within the institution.

School administrators also engineered a range of activities meant to enhance relationships between students and teachers. They offered staff development opportunities focusing on building relationships and using culturally responsive teaching practices, including locally administered, half-day professional development sessions; professionally facilitated, month-long workshops; and professional book study groups. In addition to these workshops, students were also asked to complete a survey about their relationships with their teachers. In that survey, students expressed whether they felt any adults in the building cared about them. Using data from the survey, the school administrators then amassed a list of students who felt that no adults at SHS cared about them; teachers were given a list of those students, along with their school photos and teacher comments about them (including personal information about what they enjoyed doing in their free time, about their family life, and about their strengths and challenges 
as a student). Teachers were then asked to focus on building relationships with those students. During the following year, a similar program was implemented using students who had received multiple failing grades during the previous trimester. Of the 40 students who had received multiple failing grades, 28 were male. By the end of that year, SHS administrators reported an increase in the average grade point average (GPA) of the focus group from 2.05 to 2.40 , representing a change of +.35 . The overall change in GPA during the same year within the general population was +.06 ; therefore, the data seems to indicate that the campaign to enhance caring relationships between teachers and students had a positive overall impact on academic achievement. Although this program did not focus on facilitating caring relationships with any particular subpopulation of students, nor did the program administrators disaggregate outcomes by gender, this program remains a good example of how school districts can implement programs that help teachers meaningfully connect with their students at little or no cost to the district.

While we cannot entirely remove barriers to authentic caring relationships between teachers and students, all teachers must view their students and their work through a lens that focuses less intensely on curriculum and standards and more intensely on fostering meaningful and positive relationships with all students. Time and time again, the participants' voices in this study have made the need to nurture authentic relationships vividly clear. But it is important to remember that the mark of a successful classroom relationship is a deepening of engagement with the materials and lessons in the classroom, NOT a deepening of engagement with the teacher; this is not the goal, but the means through which learning happens. Authentic caring teachers seek to deepen 
learning by approximating friendship: building classroom relationships characterized by equality, mutual support, and authentic caring. Dewey (1922) theorized that positive and productive relationships between teachers and students do not simply facilitate learning but are absolutely fundamental to the process of building knowledge. In the spirit of Dewey, I am reminded of Ryan's words, which so eloquently confirm Dewey's theory and remind us why relationships are so very important: "I've done pretty well in your class...and I think it's all because I like the person that's teaching me."

\section{Toward Greater Equity: Implications for Future Research}

If educators, school administrators, and youth advocates aim to strengthen relationships between teachers and students, more work is necessary to understand the emotional distance that exists between teachers and the young men in their classrooms. More work also needs to be done to understand how typical classroom relationships can be altered to make student-teacher connections more authentic. To that point, two major questions for future exploration have emerged from this study and from my role as a teacher-researcher:

1) Can authentic caring be taught effectively enough to change academic outcomes for boys and young men who engage in resistance strategies? That is, can teachers learn to approach students more as friends and equals, or is authentic caring a natural, inherent quality of gifted individual teachers? 
2) Can anything be done to address the gap between teacher expectations and student expectations of classroom relationships? What are the necessary conditions to create more authentically caring relationships within schools?

Both of these questions focus on whether practical solutions exist to address this problem. In fact, extant literature in the field of gender and education tends to do one of two things: provide practical suggestions for addressing gender-based challenges in the classroom without strong theoretical support, or provide strong theoretical commentary without providing practical suggestions for addressing gender-based challenges in the classroom. Therefore, more work needs to be done to bridge the gap between the practical and the theoretical applications of the boy debate. Regardless of where the conversation goes from here, it is vitally important to foreground student voice at every step of the way.

\section{Conclusion}

It was the end of a busy school day at the end of March. We were all tired, all dramatically in need of a few days of rest. Luckily, spring break was creeping around the corner. I shuffled papers, determining what needed to be accomplished that evening and what could wait for the weekend. As I worked, I glanced over at the phone-a red light indicating a new message blinked fervently. The message was from Alex, a student who had been a student in my class over five years ago - he wanted to have coffee and catch up. Over coffee later that week, Alex explained how I was an important part of his life as a student, when he was struggling with depression and questions of identity. With tears in his eyes, he explained the impact I had on him: 
I had a few teachers whom I knew cared about me, but you were the only teacher who really saw me. When I was having a hard day, you seemed to know it. And although you never made me talk about what was bothering me, you always gave me a look that let me know that you knew I was struggling. I always knew I could talk to you if I needed to.

Alex helped me remember that, whether I use the term relationship, friendship, or authentic caring (Noddings, 2013), I am describing a connection embodying a level of care that moves beyond professional respect to genuine affection. And it is precisely this genuine affection that allows students to reach their greatest potential, both inside the classroom and beyond. 


\section{REFERENCES}

American Association of University Women Educational Foundation (1992). How schools shortchange girls (Executive summary). Annapolis Junction, MD: Author.

Addis, M., Reigeluth, C.S., \& Schwab, J.R. (2016). Social norms, social construction, and the psychology of men and masculinity. In Y. J. Wong \& S. R. Wester (Eds.), APA handbook of men and masculinities (pp. 81-104). Washington, DC: American Psychological Association.

Alloway, N., Freebody, P., Gilbert, P., \& Muspratt, S. (2002). Boys, literacy and schooling: Expanding the repertoires of practice. Retrieved from http://www.gu.edu.au/school/cls/clearinghouse/

Anyon, J. (1980). Social class and the hidden curriculum of work. Journal of Education, 162(1), 67-92.

Apple, M. (1993). Ideology and curriculum (2nd ed.). New York: Routledge.

Bandura, A. (1971). Social learning theory. New York, NY: General Learning Press.

Bausch, L. S. (2014). Boys will be boys? Bridging the great gendered literacy divide. Rotterdam: Sense Publishers.

Bentz, V. M., \& Shapiro, J. J. (1998). Mindful inquiry in social research. London: Sage.

Blazina, C., \& Bartone, A. (2016). Moving beyond essentialism in contemporary psychodynamic psychology of men: Implications for theory and research. In Y. J. Wong \& S. R. Wester (Eds.), APA handbook of men and masculinities (pp. 105-122). 
Washington, DC: American Psychological Association.

Bourdieu, P. (1986). The forms of capital. In J. Richardson (Ed.), Handbook of theory and research for the sociology of education (pp. 241-258). Westport, CT: Greenwood.

Brooks, G.R., \& Elder, W.B. (2016). History and future of the psychology of men and masculinities. In Y. J. Wong \& S. R. Wester (Eds.), APA handbook of men and masculinities (pp. 3-21). Washington, DC: American Psychological Association.

Buber, M. (1965). Between man and man. New York: Macmillan.

Carr, W., \& Kemmis, S. (1986). Becoming critical: Education, knowledge and action research. London: Falmer Press.

Chiarella, T. (2006). The problem with boys. Esquire. Retrieved from http://www.esquire.com

Chibucos, T. R., Leite, R. W., \& Weis, D. L. (2004). Social exchange theory. In T.R. Chibucos, R.W. Leite, \& D.L. Weis (Eds.) Readings in family theory, 137-182.

Chu, J. (2014). When boys become boys. New York, NY: NYU Press.

Coleman, J. S. (1988). Social capital in the creation of human capital. American Journal of Sociology, 94, S95-S120.

Cook, K. S., \& Rice, E. (2006). Social exchange theory. In J. Delmater (Ed.). Handbook of social psychology (1st ed., pp 53-76). New York, NY: Springer.

Connell, R.W. (1996). Teaching the boys: New research on masculinity, and gender strategies for schools. Teachers College Record, 98(2), 206-235.

Connell, R. W. (2005). Masculinities (2nd ed.). Berkeley, CA: Univ. of California Press. 
Cortiella, C. (2011). The state of learning disabilities. New York, NY: National Center for Learning Disabilities.

Cox, E. (1995). Boys and girls and the costs of gendered behaviour. Proceedings for Promoting Gender Equity Conference. Canberra, Australia: Ministerial Council for Education, Employment, and Training for Youth Affairs.

Demos, J., \& Demos, V. (1969). Adolescence in historical perspective. Journal of Marriage and Family, 31(4), 632-638.

Denzin, N. K., \& Lincoln, Y. S. (2005). Introduction: The discipline and practice of qualitative research. In N.K. Denzin \& Y.S. Lincoln (Eds.) The SAGE handbook of qualitative research (3rd ed., pp. 1-32). Thousand, Oaks, CA: Sage.

Dewey, J. (1922). Democracy and education: an introduction to the philosophy of education. New York: The Macmillan Company.

Downey, D. B., \& Vogt Yuan, A. S. (2005). Sex differences in school performance during high school: Puzzling patterns and possible explanations. The Sociological Quarterly, 46(2), 299-321.

Emerson, R. M. (1976). Social exchange theory. Annual Review of Sociology, 2, 335362.

Erikson, E. (1988). Youth: Fidelity and diversity. Daedalus, 117(3), 1-24. Retrieved from http://www.jstor.org.proxy.lib.pdx.edu/stable/20025167

Finn, P. J. (1999). Literacy with an attitude. Albany: State University of New York Press.

Fontana, A., \& Frey, J.H. (2005). The interview: From neutral stance to political involvement. In N. K. Denzin \& Y.S. Lincoln (Eds.), The SAGE handbook of 
qualitative research (3rd ed, pp. 695-727.). Thousand Oaks, CA: Sage Publications.

Foucault, M. (1995) Discipline and punish: The birth of the prison (2nd Vintage Books ed.). New York, NY: Vintage Books.

Fox, M., Connolly, B., \& Snyder, T. (2005). Youth indicators, 2005: Trends in the wellbeing of American youth (NCES 2005-050). US Department of Education.

Freiberg, H. \& Brophy, J. (1999). Beyond behaviorism: Changing the classroom management paradigm. Boston, MA: Allyn and Bacon.

Freire, P. (2000). Pedagogy of the oppressed (30th anniv.). New York, NY: Continuum.

Frosh, S., Phoenix, A., Pattman, R. (2002). Young masculinities. New York, NY: Palgrave.

Gallagher, S. (1992). Hermeneutics and education. New York: State University of New York Press.

Garvin, D. A., Edmondson, A.C., \& Gino, F. (2008). Is yours a learning organization? Harvard Business Review, 86(3), 109-116.

Gay, G. (2010). Culturally responsive teaching: Theory, research, and practice. New York: Teachers College Press.

Geertz, C. (2000). Local knowledge: Further essays in interpretive anthropology (3rd ed.). New York, NY: Basic Books.

Gilligan, C. (1993). In a different voice. Cambridge, MA: Harvard University Press. Giroux, H. (1983). Theories of reproduction and resistance in the new sociology of 
education: a critical analysis. Harvard Educational Review 53(3), 257-293.

Giroux, H. (1994). Doing cultural studies: youth and the challenge of pedagogy. Harvard Educational Review 64(3), 278-308.

Goffman, E. (1959). The presentation of self in everyday life. New York: Doubleday.

Grant, J. (2014). The boy problem: Educating boys in urban America, 1870-1970.

Baltimore: Johns Hopkins University Press.

Gray, J. (1992). Men are from Mars, women are from Venus: A practical guide for improving communication and getting what you want in your relationships. New York, NY: HarperCollins.

Guba, E. G., \& Lincoln, Y. A. (2005). Paradigmatic controversies, contradictions, and emerging confluences. In N. K. Denzin \& Y.S. Lincoln (Eds.), The SAGE handbook of qualitative research (3rd ed, pp. 191-215.). Thousand Oaks, CA: Sage Publications.

Gurian, M. (2002). Girls and boys learn differently! San Francisco, CA: Jossey-Bass. Gurian, M. (2005). The minds of boys: Saving our sons from falling behind in school and life. San Francisco, CA: Jossey-Bass.

Hall, G. S. (1882). The moral and religious training of children. Princeton Review, 1(1).

Hammersley, M. \& Atkinson, P. (1995). Ethnography: Principles in practice (2nd ed.). London, England: Routledge.

Hayward, R. (1998). What's love got to do with it? Combining the influences of race and love to create an effective black counselor. In Nakkula, M. \& Ravitch, S. (Eds.), Matters of interpretation: reciprocal transformation in therapeutic and 
developmental relationships with youth. (1st ed). San Francisco: Jossey-Bass.

Hebdige, D. (1988). Hiding in the light. New York: Routledge.

Homans, G. (1958). Social behavior as exchange. American Journal of Sociology, 63(6), 597-606.

Howard, J. A., \& Hollander, J. (1997). Gendered situations, gendered selves. Thousand Oaks, CA: Sage Publications.

Hyde, J. S. (2005). The gender similarities hypothesis. American Psychologist, 60(6), 581-592.

Jones, S., \& Myhill, D. (2004). 'Troublesome boys' and 'compliant girls': Gender identity and perceptions of achievement and underachievement. British Journal of Sociology of Education, 25(5), 547-561.

Keniston, K. (1962). Social change and youth in America. Daedalus, 91(1), 145-171. Retrieved from http://www.jstor.org.proxy.lib.pdx.edu/stable/20026701

Kimmel, M. (2008). Guyland: The perilous world where boys become men. New York, NY: HarperCollins.

Kimmel, M. (2010). Misframing men: The politics of contemporary masculinities. New Brunswick, NY: Rutgers University Press.

Kimmel, M. (2013). The gendered society (5th ed.). New York, NY: Oxford University Press.

Kincheloe, J. (2001). Describing the bricolage: Conceptualizing a new rigor in qualitative research. Qualitative Inquiry, 7(6), 679-692.

Kindlon, D., \& Thompson, M. (1999) Raising Cain: Protecting the emotional life of 
boys. New York, NY: Random House.

Kleinfeld, J. (1975). Effective teachers of Eskimo and native students. The School Review, 83(2), 301-344.

Kleinfeld, J. (2009). The state of American boyhood. Gender Issues, 26(2), 113-129.

Laursen, B., \& Hartup, W. W. (2002). The origins of reciprocity and social exchange in friendships. New Directions for Child and Adolescent Development, 95, 27-40. http://doi.org/10.1002/cd.35

Lingard, B., Martino, M., \& Mills, M. (2009). Boys and schooling: Beyond structural reform.

New York, NY: Palgrave Macmillan.

Lincoln, Y., \& Guba, E. (1985). Naturalistic inquiry. Beverly Hills, CA: Sage.

Lurie, A. (1990). Don't tell the grown-ups: Subversive children's literature. Boston, MA: Little, Brown.

Maccoby, E. E., \& Maccoby, N. (1954). The interview: A tool of social science. In G. Lindzey (Ed.), Handbook of social psychology (1st ed., Vol. 1: Theory and Method). Cambridge, MA: Addison-Wesley.

Malone, L. M., West, J., Denton, K. F., \& Park, J. (2006). The early reading and mathematics achievement of children who repeated kindergarten or who began school a year late (NCES 2006064). National Center for Education Statistics. Retrieved from http://nces.ed.gov/pubs2006/2006064.pdf

Mann, L., Harmoni, R., \& Power, C. (1989). Adolescent decision-making: The development of competence. Journal of Adolescence, 12(3), 265-278. 
Martino, W., \& Ingrey, J. (2016). Education and masculinities. In Y. J. Wong \& S. R. Wester (Eds.), APA handbook of men and masculinities (pp. 637-657). Washington, DC: American Psychological Association.

Martino, W., \& Pallotta-Chiarolli, M. (2003). So what's a boy?: Addressing issues of masculinity and schooling. Maidenhead, UK: Open University Press.

Maxwell, J. (2013). Qualitative research design: An interactive approach. Los Angeles, CA: SAGE.

McLaren, P. (2003). Life in schools: An introduction to critical pedagogy in the foundations of Education (4th ed.). Boston, MA: Pearson.

Mead, S. (2006). The evidence suggests otherwise: The truth about boys and girls. New York: Education Sector.

Merriam, S. (1998). Qualitative research and case study applications in education. San Francisco: Jossey-Bass.

Mickelson, R. (1989). Why does Jane read and write so well? The anomaly of women's achievement. Sociology of Education, 62(1), 47-63.

Mishler, E. (1986). Research interviewing: context and narrative. Cambridge, MA: Harvard University Press.

Morris, E.W. (2012). Learning the hard way: masculinity, place, and the gender gap in education. New Brunswick, NJ: Rutgers University Press.

Mortenson, T. (2011). The state of American manhood. Postsecondary Education Opportunity, 225(3), 1-26.

Mortola, P., Hiton, H., \& Grant, S. (2008). BAM! Boys advocacy and mentoring. New 
York, NY: Routledge.

Nakkula, M. \& Ravitch, S. (1998). Matters of interpretation. San Francisco: Jossey-Bass.

Newkirk, T. (2002). Misreading masculinity: Boys, literacy, and popular culture.

Portsmouth, NH: Heinemann.

Noddings, N. (2013). Caring: A relational approach to ethics and moral education (2nd ed. updated). Berkeley, CA: University of California Press.

Noddings, N. (2005). The challenge to care in schools: An alternative approach to education (2nd ed.). New York, NY: Teachers College Press.

Owens, J. (2016). Habits that make, habits that break: Early childhood behavior problems and the gender gap in education in the United States. Sociology of Education, $89(3), 238-258$.

Pascoe, C.J. (2012). Dude, you're a fag. Berkeley: University of California Press.

Perou, R., Bitsko, R. H., Blumberg, S. J., Pastor, P., Ghandour, R. M., Gfroerer, J. C.,... Huang, L. N. (2013). Mental health surveillance among children-United States, 2005-2011. MMWR Surveillance Summary, 62 (Suppl. 2), 1-35.

Pipher, M. (1994). Reviving Ophelia: Saving the selves of adolescent girls. New York, NY: Grosset Putnam.

Pollack, W. (1999). Real boys: Rescuing our sons from the myths of boyhood. New York, NY: Owl Books.

Popper, K. R. (1959). The logic of scientific discovery. New York: Basic Books.

Raider-Roth, M. (2005). Trusting what you know. San Francisco: Jossey-Bass.

Reichert, M. \& Hawley, R. (2014). I can learn from you: Boys as relational learners. 
Cambridge, MA: Harvard Education Press.

Robinson, K. (2011). Educating the heart and mind. Retrieved from https://www.youtube.com/watch?v=I1A4OGiVK30

Saldaña, J. (2016). The coding manual for qualitative researchers (3rd ed.). Los Angeles: SAGE.

Sax, L. (2009). Boys adrift: The five factors driving the growing epidemic of unmotivated boys and underachieving young men (Reprint ed.). New York, NY: Basic Books.

Shandler, S. (1999). Ophelia speaks: Adolescent girls write about their sense of self. New York, NY: Harper Collins.

Shuffleton, A. (2012). Philia and pedagogy 'side by side': the perils and promise of teacher-student friendships. Ethics and Education, 7(3), 211-223.

Slade, M. (2001). What is a 'good teacher'?: The views of boys. International Education Journal, 2(4), 240-253.

Smiler, A.P., \& Gelman, S.A. (2008). Determinants of gender essentialism in college students. Sex Roles, 58(11-12), 864-874.

Smith, M., \& Wilhelm, J. (2002). "Reading don't fix no Chevys": Literacy in the lives of young men. Portsmouth, NH: Heinemann.

Sommers, C.H. (2013, February 2). The boys at the back. The New York Times. Retrieved from http://www.nytimes.com

Sommers, C. H. (2013). The war against boys: How misguided policies are harming our young men. New York, NY: Simon and Schuster.

Suicide prevention: Youth suicide. (2015). Center for Disease Control and Prevention. 
Retrieved from http://www.cdc.gov/violenceprevention/pub/youth_suicide.html

Toshalis, E. (2012). The rhetoric of care: Preservice teacher discourses that depoliticize, deflect, and deceive. The Urban Review, 44(1), 1-35. doi:10.1007/s11256-011$0177-\mathrm{y}$

Toshalis, E. (2015). Make me!: Understanding and engaging student resistance in school. Cambridge, MA: Harvard Education Press.

Valenzuela, A. (1999). Subtractive Schooling: U.S.-Mexican youth and the politics of caring. Albany, NY: SUNY Press.

Vasudevan, L., \& Campano, G. (2009). The social production of adolescent risk and the promise of adolescent literacies. Review of Research in Education, 33(1), 310253.

Vespa, J. (2017). The changing economics and demographics of young adulthood: 19752016. US Census Bureau. Retrieved from www.census.gov

Visser, S. N., Danielson, M. L., Bitsko, R. H., Holbrook, J. R., Kogan, M. D., Ghandour, R. M., ...Blumberg, S. J. (2014). Trends in the parent-report of health care provider-diagnosed and attention-deficit/hyperactivity disorder: United States, 2003-2011. Journal of the American Academy of Child \& Adolescent Psychiatry, $53(1), 34-46$.

Watson, A., Kehler, M., \& Martino, W. (2010). The problem of boys' literacy underachievement: Raising some questions. Journal of Adolescent and Adult Literacy, 53(5), 356-361.

Way, N. (2011). Deep secrets: boys'friendships and the crisis of connection. Cambridge, 
MA: Harvard University Press.

Weaver-Hightower, M. (2003). The "boy turn" in research on gender and education. Review of Educational Research, 73(4), 471-498.

Whitmire, R. (2010). Why boys fail. New York, NY: AMACOM.

Wibeck, V., Dahlgren, M.A., \& Oberg, G. (2007). Learning in focus groups: An analytical dimension for enhancing focus group research. Qualitative Research, $7(2), 249-267$.

Willis, P. (1977). Learning to labor: How working class kids get working class jobs. Farnborough, England: Saxon House.

$\mathrm{Xu}$, J. (2006). Gender and homework management reported by high school students. Educational Psychology, 26(1), 73-91.

Young, I. (1992). Five faces of oppression. In T. E. Wartenberg (Ed). Rethinking power (pp.174-195). Albany, NY: SUNY Press.

Zafirovski, M (2005). Social exchange theory under scrutiny: A positive critique of its economic-behaviorist formulations. Electronic Journal of Sociology, 2(2), 1-40. 


\title{
Appendix A: Informed Consent
}

\begin{abstract}
Statement of Informed Consent
Research Project: "Exploring the role of student-teacher relationships in secondary schools"
\end{abstract}

Researcher: Cristy Weggelaar, Portland State University

You are invited to participate in a research study conducted by Cristy Weggelaar - a teacher at Sherwood High School, and a doctoral student in the Curriculum and Instruction department in Portland State University. During the study, the researcher expects to learn about students at Sherwood High School, including their engagement in their classes and the quality of their relationships with their teachers.

What will I have to do? If you agree to participate, you will take part in one or two interviews lasting about 60 minutes each. Interviews will be scheduled during the regular school day or after school, depending on your availability.

Are there any risks? There are no major risks associated with participation in this study, although any group interviews in which personal matters are discussed may run the risk of covering sensitive topics and may cause mild psychological distress or social stigmatization. I will work hard to ensure that all participants feel safe participating in this interview, and you will not have to answer any questions you are not comfortable with. I will not schedule any interview that takes you out of a core class and you will not have to answer any questions you are not comfortable with. Participation in this study will not affect your academic standing in any way.

What will I do to protect you? All data from the interviews will be reported anonymously, which means that your real name will not be used. All data will be kept on the researcher's computer, which is password protected; printed and recorded data will be kept secure in the researcher's locked office on campus. Interviews will be audiorecorded for the sole purpose of the researcher to accurately record and analyze data.

Although I will not share your personal information with anyone, it is important to note that as a teacher I am a mandatory reporter. This means that if you share information with 
me that leads me to believe you are being harmed or that you intend to harm someone else, I must report that information to the proper authorities. This includes instances of substance abuse, physical abuse, or thoughts about self-harm. Any such reporting is solely in the interest of keeping you and those around you safe from harm.

\section{What will I get in return?}

- You might enjoy the process of discussing your feelings and experiences about school with me and with your peers.

- If you decide to participate, data from your participation will be analyzed and included in a written report and a presentation to professors at Portland State and shortened version will be shared with teachers and administrators at Sherwood High School.

- Though you will not receive any direct benefit from taking part in the study, your participation will increase what is known about student engagement and student connections to teachers at Sherwood High School.

\section{What if I have more questions about the study?}

If you have questions or concerns about this study, or if you would like to withdraw from the study after signing this form, contact Cristy Weggelaar at: cwegg2@pdx.edu or (503)-825-5500. You may also contact Dr. Anita Bright, Professor at Portland State University, with questions or concerns about this study if you are not comfortable addressing them with Cristy. Her email address is abright@pdx.edu. If you have concerns about your rights as a research subject, please contact the PSU Institutional Review Board Office of Research Integrity at 1600 SW 4th Ave., Market Center Building, Ste. 620 Portland, OR 97201 or (503) 725-2227.

Because you are a student, a parent or guardian must also give permission for you to participate, even if you are 18 or older. Your participation is voluntary and you may withdraw from this study at any time without affecting your relationship with the researcher or your academic standing at Sherwood High School. You will be given a copy of this Informed Consent form for your records. 
Your signature below indicates that you have read and understand the above information and agree to take part in this study.

Signature of student participant Date

Print name of student participant

Signature of parent or guardian Date

Print name of parent or guardian 


\section{Appendix B: Interview Protocol}

This list is meant to be a starting point. The questions here are in no particular order and I do not plan on asking all of them during a single interview. There is a strong and intentional overlap between group interview and individual interview questions.

\section{Group Interview Questions}

1. Do you enjoy high school? What are the elements that make it enjoyable? What's the worst thing about high school?

2. Which teachers do you connect best with?

3. Why do you think you connect so well with those teachers and not other teachers?

4. What are your favorite teachers like?

5. Do you ever feel like you just resist doing things teachers ask you to do because you're mad, frustrated, or annoyed? (Tell me about that a time when that happened.)

6. Some people say that guys just don't care as much about school as girls do. What do you think about that?

7. Do you ever intentionally do something just to make a teacher mad? (Tell me about that.)

8. Do you feel like teachers treat you fairly? Any teachers who are really good at that? Any teachers who seem to be very unfair?

9. How does the work you do in your favorite teachers differ from the work you do in other teachers' classes?

10. Do you skip any classes? (Tell me about why you do that.) 
11. What kinds of teachers do you trust the most? (Why do you trust them?)

12. Tell me about a teacher you trust.

13. What kinds of teachers do you trust the least and why?

14. Without naming them, tell me about a teacher that you don't trust.

\section{Individual Student Interview Questions}

\section{Teacher-student Relationships}

1. Which teachers do you connect best with?

2. Why do you think you connect so well with those teachers and not other teachers?

3. What are your favorite teachers like?

4. How does the work you do in your favorite teachers differ from the work you do in other teachers' classes?

5. Do you ever intentionally do something just to make a teacher mad? (Tell me about that.)

6. Do you feel like teachers treat you fairly? Any teachers who are really good at that? Any teachers who seem to be very unfair?

7. Do you skip any classes? (Tell me about why you do that)

8. What kinds of teachers do you trust the most? (Why do you trust them?)

9. Tell me about a teacher you trust.

10. What kinds of teachers do you trust the least and why?

11. Without naming them, tell me about a teacher that you don't trust.

\section{Academics}

1. In general, what kinds of grades are you getting right now? 
2. What are your favorite subjects right now? Do you perform differently in those subjects than in other subjects?

3. Do you enjoy high school? Have you always felt that way about school?

4. Have you been doing most of your homework this year?

5. Have you ever skipped school? (Why?)

6. Some people say that guys just don't care as much about school as girls do. What do you think about that?

7. Have you ever been called to the principal's office or written up for something? (Tell me about that.)

8. Are you ever late to school? (Tell me about that.)

9. Has the way you feel about school changed over time at all?

\section{Other Questions}

1. Tell me about your parents. What do they do for a living?

2. How old are you and what grade are you in?

3. What race do you identify as?

4. During the group interview, you said... Tell me more about that. 